San Jose State University

SJSU ScholarWorks

Master's Theses

Master's Theses and Graduate Research

Fall 2010

\title{
In Situ Detection Of Tbx5 Expression In Developing Chick Embryonic Heart
}

Vaishali Agarwal

San Jose State University

Follow this and additional works at: https://scholarworks.sjsu.edu/etd_theses

\section{Recommended Citation}

Agarwal, Vaishali, "In Situ Detection Of Tbx5 Expression In Developing Chick Embryonic Heart" (2010).

Master's Theses. 3901.

DOI: https://doi.org/10.31979/etd.84mn-c4vy

https://scholarworks.sjsu.edu/etd_theses/3901

This Thesis is brought to you for free and open access by the Master's Theses and Graduate Research at SJSU ScholarWorks. It has been accepted for inclusion in Master's Theses by an authorized administrator of SJSU ScholarWorks. For more information, please contact scholarworks@sjsu.edu. 
IN SITU DETECTION OF Tbx 5 EXPRESSION IN DEVELOPING EMBRYONIC CHICK HEART

\author{
A Thesis \\ Presented to \\ The Faculty of the Department of Biological Sciences \\ San Jose State University \\ In Partial Fulfillment \\ of the Requirements for the Degree \\ Master of Science \\ by \\ Vaishali Agarwal \\ December 2010
}


(C) 2010

Vaishali Agarwal

ALL RIGHTS RESERVED 
The Designated Thesis Committee Approves the Thesis Titled

IN SITU DETECTION OF Tbx 5 EXPRESSION IN DEVELOPING EMBRYONIC CHICK HEART

by

Vaishali Agarwal

APPROVED FOR THE DEPARTMENT OF BIOLOGICAL SCIENCES

SAN JOSE STATE UNIVERSITY

December 2010

Dr. Steven White

Dr. Michael Sneary

Dr. Bob Fowler
Department of Biological Sciences

Department of Biological Sciences

Department of Biological Sciences 


\section{ABSTRACT \\ IN SITU DETECTION OF Tbx 5 EXPRESSION IN DEVELOPING EMBRYONIC CHICK HEART \\ by Vaishali Agarwal}

The Tbx 5 gene codes for a highly conserved transcription factor containing a DNA-binding motif called the $\mathrm{T}$ box (or T-domain). Tbx 5 is expressed in the posterior sinoatrial segment of the heart along with the developing forelimb buds. Mutations in Tbx 5 gene are associated with Holt Oram Syndrome (HOS), which is characterized by heart septal defects and forelimb abnormalities. Tbx 5 expression was examined during various stages of heart development in chick embryos using both a double stranded digoxygenin-labeled DNA probe and a single stranded digoxygenin-labeled anti-sense RNA probe (riboprobe). Due to the presence of homology in the Tbx family, bioinformatics tools were used to design primers targeting specifically the $T b x 5$ transcript and not other $T b x$ family members. During the course of this project, we conducted eight sets of whole mount in situ hybridization studies. Various experimental parameters, including fixation conditions, hybridization stringency, and wash conditions, were studied thoroughly and optimizations were carried out. We also examined the effects of the type and concentration of the probe upon the signal strength. Our studies indicated intermediate levels of Tbx 5 expression in the inflow tract, with strong expression in the atrio-ventricular regions and left ventricular regions. 


\section{ACKNOWLEDGMENTS}

There are many people that I would like to thank for their support during my graduate studies. Without their support and encouragement I would not have been able to complete this research project.

I can never thank enough Dr. White for accepting me as his graduate student, guiding me and helping me during the difficult phases of research. In spite of his busy schedule he was always there to listen and guide me. I am especially indebted to him for understanding that I have a family and kids to look after thus allowing me to work evenings and weekends to get my research moving. You are a true teacher in every sense of the word; your positive attitude and high energy are truly contagious.

I would like to extend my gratitude towards Dr. Bob Fowler and Dr. Michael Sneary for taking their precious time and being on my thesis committee. I would also like to thank the Department of Biological Sciences for providing me with a Robert Hyde Scholarship, a Rocci and Marianna Pisano Scholarship, and an Albert and Dorothy Ellis Fellowship.

I shall thank Dr. Dritan Agalliu who generously gave our lab his in situ hybridization protocols which helped us tremendously in optimizing our in situ hybridization protocols. 
Thanks to Tim Andriese for his valuable guidance. He was always there to help us with reagents when stocks were low. I would like to thank Jean Geary for her words of encouragement and her smile that made things easy. Thanks to Arthur Valencia for his support.

Thanks to Ricardo Leitao for his selfless support and help. You were always there to help me and guide me even after graduating. Dear Adreina Martinez, it was always wonderful to walk into the lab and see you smiling.

I would like to thank all of the scientific community which published their research. Thanks to all the publications that I read/cited that helped me enhance my knowledge of the subject.

I finally owe a big depth of thanks to my family. I feel short of words in expressing my gratitude to my parents. Dear Mom and Dad thanks for raising me with so much love, affection, and confidence. Without your support and encouragement I wouldn't be here. Thanks to my brother Ashish, for being there for me day or night.

Special thanks to my children Aayush and Shreya for their love, support, and admiration.

Dear Shekhar, thanks for believing in me, your endless love and support motivated me to higher achievements. 
THIS THESIS IS DEDICATED TO MY PARENTS AND SHEKHAR

FOR THEIR LOVE, SUPPORT, AND ENCOURAGEMENT 


\section{TABLE OF CONTENTS}

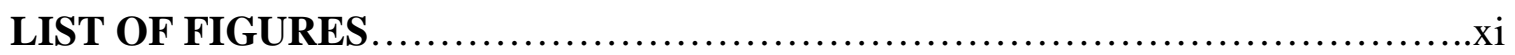

1- LITERATURE REVIEW ............................................

1.1- Heart Formation: An Overview..................................

1.1.1- Heart Tube Formation......................................2

1.1.2- Cardiac Looping.........................................6

1.1.3- Heart Septation............................................8

1.2- The Chick as an Experimental Model in the Study of Heart

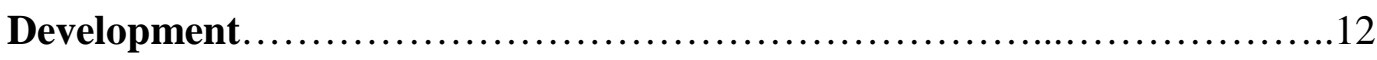

1.3- A Brief Overview of the $\boldsymbol{T b x}$ Family and Structural Characteristics....14

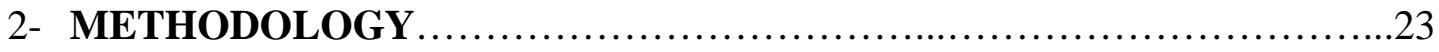

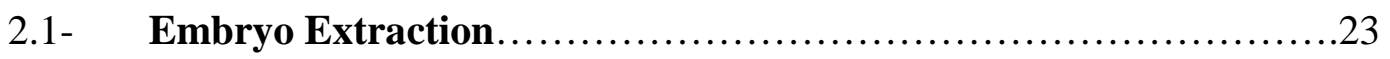

2.1.1- Incubation of Fertile Eggs................................23

2.1.2- Embryo Harvest...........................................24

2.2- Whole Mount In Situ Hybridization...........................27

2.2.1- Fixation.................................................. 27

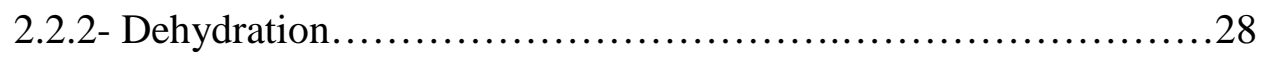

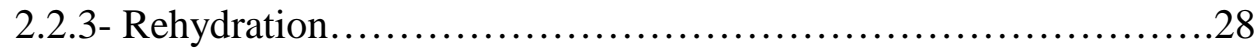

2.2.4- Proteinase K Digestion..................................28

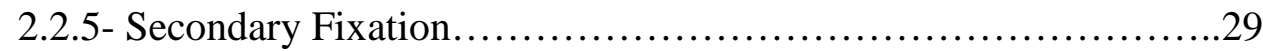

2.2.6- Prehybridization.......................................29 


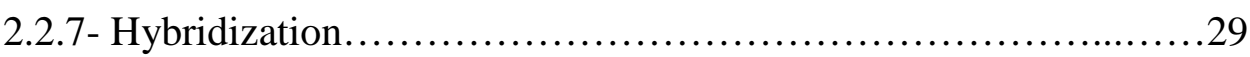

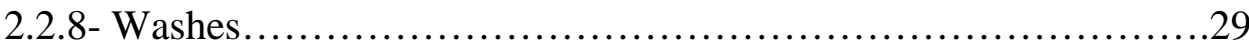

2.2.9- Preblocking .....................................................

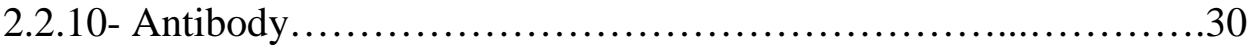

2.2.11- Washes....................................................... 30

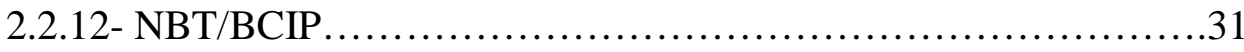

2.2.13- Washes...................................................... 31

2.3- Construction of Probe ............................................. 31

2.3.1- 199 Base Pair Probe................................................

2.3.1.1 - 199 Base Pair DNA Probe................................34

2.3.1.2- 199 Base Pair RNA Probe................................34

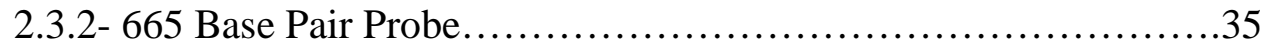

2.3.2.1 - 665 Base Pair DNA Probe................................37

2.3.2.2- 665 Base Pair RNA Probe...............................37

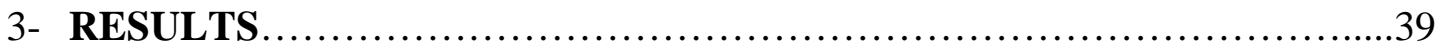

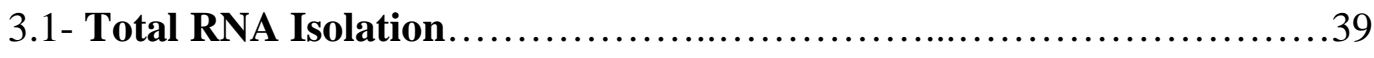

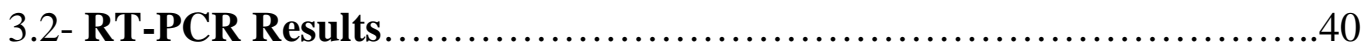

3.3- Probe Construction................................................... 41

3.4- Sequencing Results....................................................

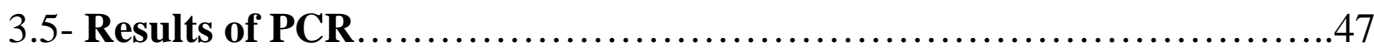

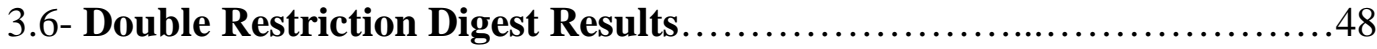

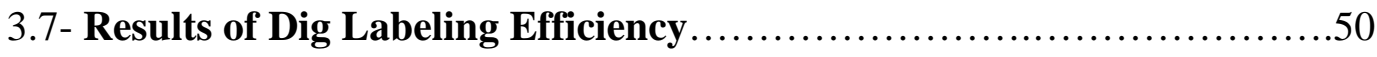


3.8- In Vitro Transcription Results

3.9- Whole Mount In Situ Hybridization Results....................................52

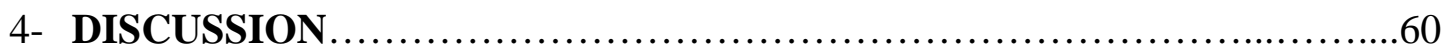

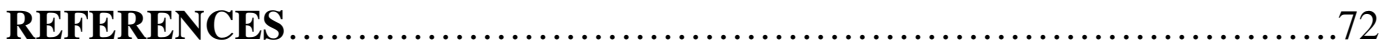

APPENDIX

Appendix A - Protocol for Step Down RT-PCR ........................ 78

Appendix B - Protocol for Promega's pGEM- Easy Vector System ..........79

Appendix C - Protocol for Zyppy MiniPrep Kit..........................81

Appendix D - Protocol for Double Restriction Digest.....................82

Appendix E - Protocol for Qiagen's Taq DNA Polymerase PCR............83

Appendix F - Protocol for Promega's Wizard SV gel and and PCR Clean-

Up System....................................................... 84

Appendix G - Protocol for Roche's In Vitro Transcription ...... ...........85

Appendix H- Protocol for using Novagen's Red Pellet Paint ...............86

Appendix I - Protocol for Mirus's Label IT Nucleic Acid Labeling Kit ... 87

Appendix J - Protocol for Dot Blot Assay to check for the labeling

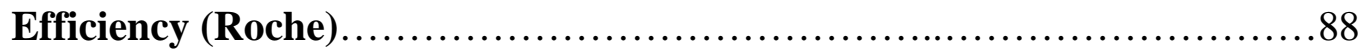




\section{LIST OF FIGURES}

Fig.1: Anatomical representation of the heart tube............................5

Fig. 2: Mouse embryos with 4, 6 and 8 somites............................6

Fig. 3: Overview of stages of cardiac looping in chick heart development...........8

Fig. 4: Photograph of fertile eggs in the lab incubator........................ 24

Fig. 5: Demonstration of embryo harvest being done by Dr. White................25

Fig. 6: Picture of embryo in the egg after removal of the overlying membranes and just prior to isolation, still connected by the vascularized vitelline membrane.....................................................26

Fig. 7: Picture of the embryo after all the membranes are removed, prior to

fixation

Fig. 8: Nanodrop results of total RNA isolated diluted $1: 2 \ldots \ldots \ldots \ldots \ldots \ldots \ldots \ldots \ldots$

Fig. 9: 1\% agarose E gel to confirm the 199 base pair amplified region by RT-

PCR.

Fig.10: Results of Multiple Sequence Alignment of $T b x 2, T b x 3, T b x 4, T b x 5$, and $T b x 20$ showing sequence similarity among the $T b x$ family members.

Fig. 11: Depiction of unconserved region of $T b x 5$ used to create the probe. 
Fig. 12: Sequencing results of pGEM- T easy vector containing 199 base pair

.$T b x 5$ region..........................................................44

Fig. 13: BLAST results confirming the identity of 199 base pair long probe.

Fig. 14: Sequencing results of pGEM- T Easy vector containing 665 bp Tbx 5 region.

Fig.15: BLAST results confirming the 665 bp probe identity to be identical to $\operatorname{Tbx} 5$

Fig. 16 Results of PCR product for 199 bp and 665 bp probe respectively.... 48

Fig.17: Results of double restriction digest of plasmid pBLUE Script containing Tbx 5 insert

Fig. 18: Results of Dot Blot Assay to check for the labeling efficiency....

Fig. 19: Results of $2 \%$ agarose gel to confirm the size of Dig labeled DNA and RNA probes.

Fig. 20 (A) \& (B): Negative experimental control for whole mount in situ hybridization for $T b x 5$

Fig. 21 (A) \& (B): Negative control (sense probe at $200 \mathrm{ng} / \mathrm{ml}$ ) for whole mount in situ hybridization

Fig. 22: Whole mount in situ hybridization of chick embryo using 199 bp RNA probe at $200 \mathrm{ng} / \mathrm{ml}$ for $T b x 5$. .53

Fig. 23: Whole mount in situ hybridization of chick embryo using 199 bp RNA probe at $750 \mathrm{ng} / \mathrm{ml}$ for $T b x 5$ .54

Fig. 24: Whole mount in situ hybridization of chick embryo using 199 bp RNA 
for $T b x 5$ probe at $1000 \mathrm{ng} / \mathrm{ml}$

Fig. 25: Whole mount in situ hybridization of chick embryos with Tbx 5665 bp RNA probe at $200 \mathrm{ng} / \mathrm{ml}$.

Fig. 26: Whole mount in situ hybridization of chick embryos with Tbx 5665 bp RNA probe at $750 \mathrm{ng} / \mathrm{ml}$. .55

Fig. 27: Whole mount in situ hybridization of chick embryos with Tbx 5665 bp RNA probe at $1000 \mathrm{ng} / \mathrm{ml}$. .56

Fig. 28: Whole mount in situ hybridization of chick embryos probed with $199 \mathrm{bp}$ DNA probe at $200 \mathrm{ng} / \mathrm{ml}$. .56

Fig. 29: Chick embryos probed with 199 bp DNA probe at $750 \mathrm{ng} / \mathrm{ml}$ for whole mount in situ hybridization of Tbx 5

Fig. 30: Whole mount in situ hybridization of chick embryos using 665 bp DNA probe for $T b x 5$ at $200 \mathrm{ng} / \mathrm{ml}$..

Fig. 31: Whole mount in situ hybridization of chick embryos probed with Tbx 5 $665 \mathrm{bp}$ DNA probe at $750 \mathrm{ng} / \mathrm{ml}$.

Fig. 32: Chick embryos probed with Tbx 5665 bp DNA probe at $1000 \mathrm{ng} / \mathrm{ml}$ for whole mount in situ hybridization .58

Fig. 33: Image of embryo stored in methanol for a month and probed with $199 \mathrm{bp}$ DNA at $750 \mathrm{ng} / \mathrm{ml}$.

Fig. 34: In situ hybridization to Tbx 5 transcripts in mouse embryos, exhibiting strong staining in the heart and developing upper limb but low expression of $T b x 5$ in the eye. 
Fig. 35: Whole mount in situ hybridization to Tbx 5 transcripts in chick embryo indicating significant expression in the eye, heart and developing upper

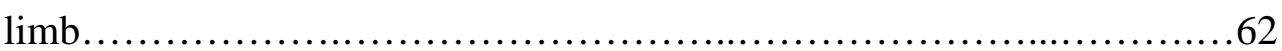

Fig. 36: Results of immunohistochemical studies conducted to study the expression of $T b x 5$ in chick embryo heart.............................63

Fig. 37: Depiction of primer design having T7 at the end of the amplified region, for the successful creation of antisense and sense probe In Vitro Transcription. 


\section{1-LITERATURE REVIEW}

\subsection{Heart Formation: An Overview}

Heart formation is a highly complicated process in which a number of regulatory processes convert a group of cardiac progenitor cells into a complex network of specialized cells that make the adult four chambered heart (Drenckhahan, 2009). During the various stages of heart development, there may be any number of signaling and/or gene regulation errors, the sum of which can lead to a broad constellation of congenital heart defects (CHD). Approximately 1\% of newborns are affected by some abnormality in heart formation (Hoffman and Kaplan, 2002), making heart abnormalities the most common forms of human birth defect. This high frequency of heart abnormalities suggest to us that the various signaling and gene regulatory systems controlling cardiogenesis must maintain a sensitive balance if perturbations in morphogenesis are to be avoided. The heart is, in fact, the first organ to function in the developing embryo, and it is physiologically critical that the heart start to functioning even before its morphogenesis is complete. A diffusion based mechanism for tissue perfusion and waste/metabolite removal would, for example, prove rapidly inadequate by Hamburger and Hamilton (HH) stage 10-11 of embryonic development. The changing functional demands on the heart force rapid morphological changes during development. The system, by definition, is extremely sensitive, and sensitive systems tend to be error-prone. 
Despite its obvious importance, we know little about the mechanisms underlying cardiogenesis. While the anatomical process of embryonic heart development has been studied for nearly a century, the molecular processes driving that morphogenesis still remain largely unknown. To address this disparity, various studies involving both vertebrates and invertebrates have been conducted over the past 25 years, providing at least some insight into the nature and functionality of the signaling pathways involved and elucidating to some degree the dynamic expression patterns of key regulatory genes involved in those pathways. To provide a context for our work on $\operatorname{Tb} \times 5$, a brief overview of heart development will be presented here.

\subsubsection{Heart Tube Formation}

In the chick embryo heart development is initiated at the gastrula stage, around Hamburger and Hamilton stage 3 (Harris et al., 2002). At this time cells from the primitive streak (the anatomical midline of the chick and the anterior/posterior embryonic axis marker) invaginate and migrate out under the definitive embryonic ectoderm layer. The migrating definitive endodermal cells displace the hypoblast (originally underlying the ectoderm), while the mesoderm cells invest between these two other layers. This process thus forms the three primary germ layers of the embryo: the ectoderm, the endoderm, and the mesoderm. Just prior to gastrulation, those cells that will ultimately give rise to the primary heart field appear to be localized initially to the cranial third of the primitive streak, immediately caudal to Hensen's node. During gastrulation they invaginate at the primitive streak and migrate out as part of the lateral plate mesoderm 
(Fishman et al., 1997, Moorman et al., 2003). Soon thereafter (or possibly simultaneous with migration), the mesodermal layer splits into an upper somatic mesodermal layer (adjacent to and overlying the ectoderm) and a lower splanchnic mesodermal layer (adjacent to and underlying the endoderm), with a thin cavity, or intraembryonic coelom, separating the two mesodermal layers. At this time the underlying endoderm is thought to secrete a number of different signaling factors (especially Bone Mophogenetic Proteins [BMP], Fibroblast Growth Factors and Sonic Hedgehog), with BMPs (members of the Transforming Growth Factor beta family) thought to play a key role in initially specifying the adjacent overlying splanchnic mesoderm as "cardiogenic" mesoderm (Drenckhahan, 2009, Schoenwolf et al., 2009, Alsan and Schultheiss, 2002, Gilbert, 2006). Simultaneously, the notochord and developing neuroectoderm (midline structures in the embryo) secrete BMP antagonists like Chordin and Noggin (which sequester BMPs and prevent their action) and Wnts (which exhibit a signal transduction system that antagonizes that of the BMPs). Under the influence of these spatially restricted and opposing signaling factors, an "inverted U-shaped" domain of cardiogenic splanchnic mesoderm develops (the primary heart field or "cardiac crescent"), with the two thick arms of the inverted $\mathrm{U}$ in the upper and middle lateral plate, linked by a thin region cranial to the developing neural plate (Harvey, 2002, Ramsdell et al., 2005). The unopposed BMPs in the cardiac crescent region then stimulate expression of a number of transcription factors, with $N k x 2.5$ and Gata 4 being prominent and thought important in the continuing cardiac specification of the mesoderm (Berg et al., 2009, Searcy et al., 1998). In addition, the production of retinoic acid (RA), secreted as a gradient by the 
developing posterior mesoderm, is thought to help "regionalize" the caudal portion of the developing heart field, driving the posterior cardiac precursors to a more "inflow" or "venous" specification (Gilbert, 2006).

Up to this point the embryonic plate could be essentially described as a flat, ovoid disc. After this time, however, the overall structure of the embryo starts to change dramatically. Forward growth of the developing neural plate causes a flexion or bending at the oropharyngeal region (a domain just cranial to the neural plate that possesses no mesoderm and is thus quite thin) and starts to swing the cranial-most portion of the embryonic disc (that region anterior to the neural plate) down toward the future chest. Simultaneously, the lateral portions of the embryonic disc flex sharply inward ventrally towards the midline. As a result of these embryonic folding events, the two lateral domains of the cardiac crescent are also swung in ventrally towards the midline. As the two lateral domains are swung together, however, vasculogenesis occurs in each domain, giving rise to two endocardial tubes. These tubes then ultimately meet and fuse in the midline (occurring abound stage $\mathrm{HH} 10$ in the chick), producing the definitive heart tube (Harris et al, 2002).

The definitive heart tube soon develops a number of layers: (i) an inner endocardial tube (an endothelial layer bounding the lumen of the heart tube), (ii) an outer layer of cadiomyogenic progenitors that form the myocardium (muscular portion of the heart), and (iii) an intervening layer of extracellular matrix termed cardiac jelly separating the two cellular layers (Figure 1). Only later will the epicardial layer of the heart develop to cover the myocardium, as will be discussed below. 


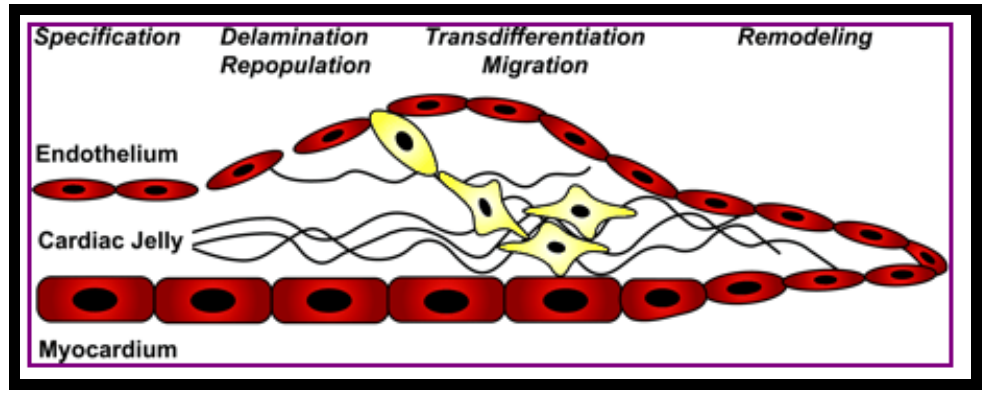

Fig. 1. Anatomical representation of the heart tube. Figure adapted from Armstrong and Bischoff, 2004 with permission from Wolters Kluwer Health.

Throughout this time the continued expression of $N k x 2.5$ and Gata 4 drive the expression of a number of other transcription factors important in cardiogenesis, including Mef2, dHand, eHand, and a number of Tbx family members (including the continued expression of Tbx 5) (Berg et al, 2009, Plageman and Yutzey, 2005).

Not all of the cardiac cells found in the mature heart, however, are derived from the primary heart field. The cells giving rise, for example, to the epicardium (the third, outermost cellular layer of the heart), the coronary endothelium (or at least the majority of it), and the associated smooth muscle cells supporting the coronary vasculature appear to arise from a special domain called the proepicardial organ (Munoz-Chapuli et al, 2002). Furthermore, additional cardiogenic precursors are recruited from the mesoderm immediately adjacent and medial to the initial cardiac crescent, a domain now referred to as the secondary heart field (Schoenwolf et al, 2009, Buckingham et al, 2005). It is currently thought that the primary heart field gives rise to the right and left atria and the left ventricle, with only light cellular investment in the right ventricle and outflow tract structures. The secondary heart field, in contrast, is thought to form the majority of right 
ventricle, outflow tract and the posterior-most portions of the venous pole (Schoenwolf et al., 2009). It is currently unclear whether the proepicardial organ is a portion of the secondary heart field or an independent third field.

\subsubsection{Cardiac Looping}

As has been mentioned previously the heart starts pumping blood even before its morphogenesis is complete, actually around the time of definitive heart tube formation (Gilbert, 2006). Looking at an embryonic heart beating at an early stage gives an impression of the presence of two separate blood streams in the heart tube. This is because of the asymmetric contractions (Moorman, 2003). As shown in Figure 2, the symmetric arms of the heart tube form the primary atrial component, a subdomain of which ultimately participates in the formation of the atrioventricular canal (Moorman, 2003).

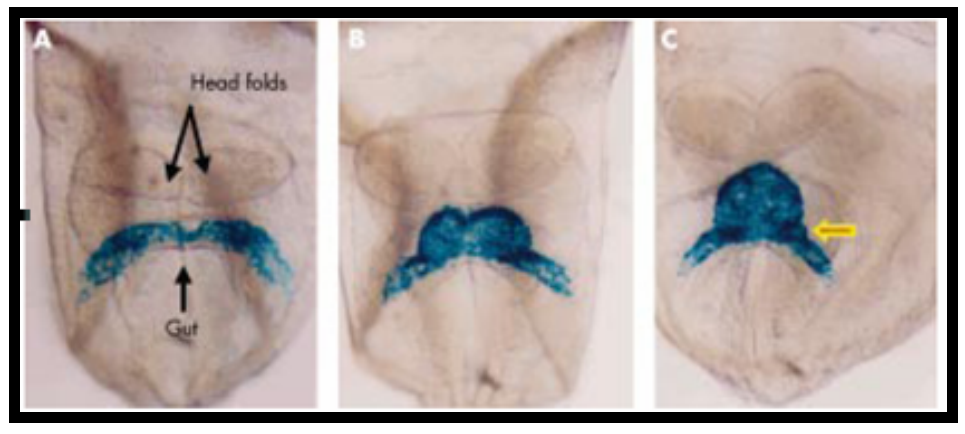

Fig. 2. Mouse embryos with 4, 6 and 8 somites. Blue color indicates myocardium. The yellow arrow indicates the cells fated to be atrio ventricular canal. Figure adapted from Moorman et al., 2003 and reprinted with permission from BMJ Publishing Group Ltd.

The tubular heart ultimately develops into a complex four chambered heart via the combined processes of cardiac looping and septation, with the former process taking 
place around HH stage 10 through to stage 18 (Manner, 2000). As shown in Figure 3, during the initial steps (spanning stage HH10 to late HH12) the heart tube bends rightward into a "C- shaped" loop, clearly defining the sinus horns and sinus venosus region (at the posterior pole of the heart), a common atrial domain, a large ventricle (which give rise to the definitive left ventricle), a much smaller and tapering bulbus cordis (which will ultimately form most of the right ventricle), and (at the anterior pole) an outflow track with a prominent conus arteriosus (Moorman, 2003; Saber et al., 2008). During this stage the ventricular regions develops a bulging towards the right, and is the first anatomical manifestation of left/ right symmetry in the vertebrate embryo (Voronov, 2004). As the heart tube continues to elongate at both the venous and arterial poles, it later bends and twists into a "S- shape" (Manner, 2009), which serves to swing the common atrial region up and the ventricular region down, placing the ventricular region below the atria as in the basic plan of the adult heart (a process spanning about stage HH13 to 18). The genes involved in specifying the 4 chambers are still under intense investigation, but probably involve $N k x$, Gata and $T B X$ family members, Hand genes, Xin, flexin and Pitx2, among others (Schoenwolf et al., 2009; Gilbert, 2006). The end result of cardiac looping is to bring the four presumptive chamber domains of the future heart into their correct spatial relationship relative to each other. 


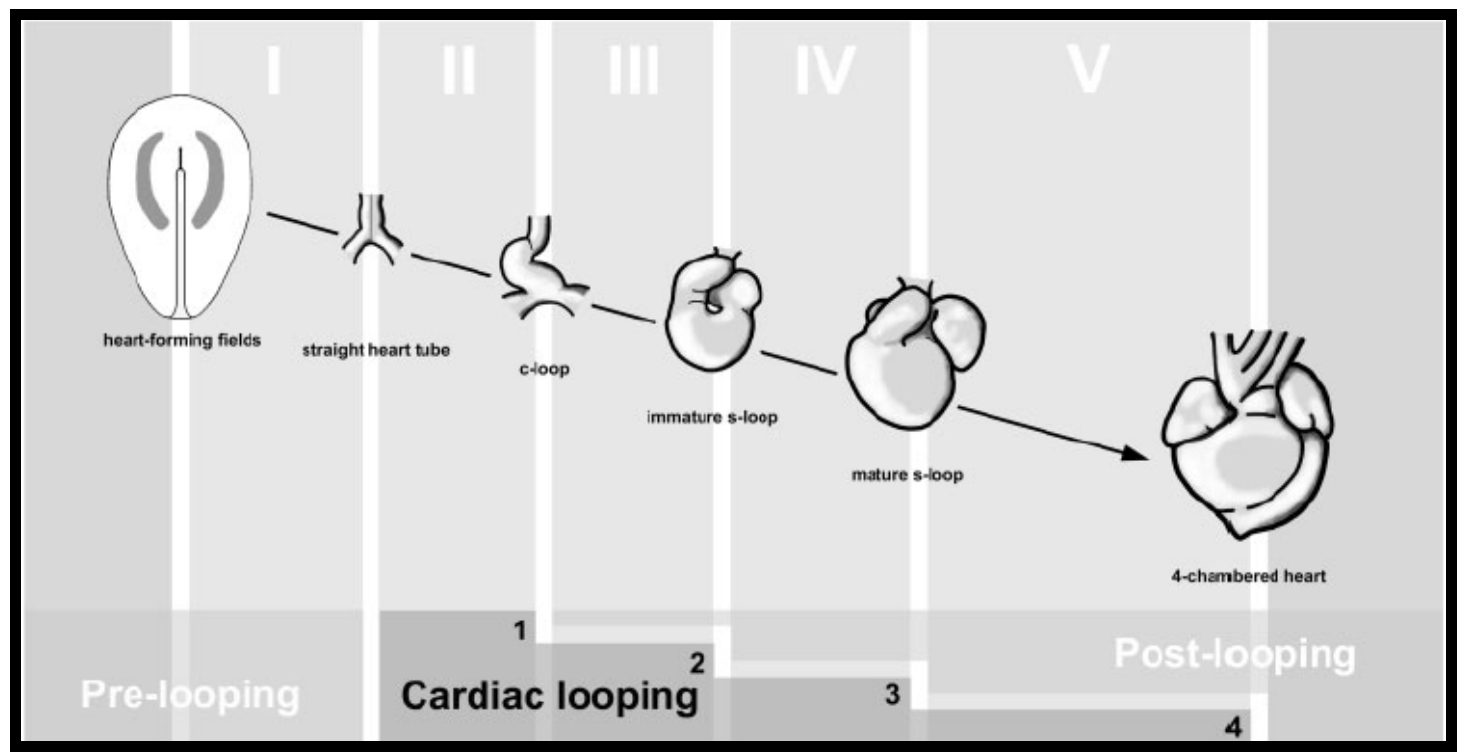

Fig. 3. Overview of stages of cardiac looping in chick heart development. Figure adapted from Manner 2009 and reprinted with permission from John Wiley and Sons Inc.

Following looping, the remainder of heart development consists basically of expansion and remodeling of the chambers, developing the appropriate septa (walls) and valves between them, creation of the epicardium and coronary vasculature, forming the cardiac conduction pathways and establishing connections with the peripheral nervous system. While we consider it beyond the scope of this brief review to discuss all those subsequent processes, at least some description of septation and valve development is in order, given the possible involvement of Tbx 5 in their formation (Bruneau et al., 1999).

\subsubsection{Heart Septation}

The division of the heart into 4 distinct and separate chambers is a highly complex developmental process. Localized ("differential") growth and tissue remodeling are thought to be mainly responsible for creating the muscular interventricular and 
interatrial walls (septa) of the heart, while endocardial-derived and neural crest-derived cushion tissue formation and remodeling appear to be the principle mechanisms for creation of the valves and for septation of the outflow tracts (Schoenwolf et al., 2009).

The process of atrial septation begins with the highly localized growth of a thin plate-like ridge of tissue in the cranial-dorsal roof of the atrium, extending downward into the common atrium as a crescent shaped wedge referred to as the septum primum (Larsen, 2001). As development proceeds, the septum primum grows further, extending towards the common atrioventricular canal, separating the common atrium into right and left atrial chambers and creating a progressively diminishing opening termed the foramen primum or ostium primum (Larsen, 2001). During the growth of the septum primum, four endocardial-derived thickenings (termed endocardial cushion tissues) develop around the periphery of the common atrioventricular canal: large dorsal (or superior) and ventral (or inferior) cushions, and smaller right and left cushions. The large dorsal and ventral endocardial cushions eventually meet and fuse to form the atrioventricular septum (or septum intermedium) which divides the common atrioventricular canal, thereby creating a left and right atrioventricular canal. With the eventual fusion of atrioventricular septum and growing septum primum, the ostium primum is finally obliterated (closes) but not before programmed cell death in a cranial-dorsal region of the septum primum creates another foramen (opening) referred to as the foramen secundum (or ostium secundum). This foramen secundum thus continues to allow for the "right to left" shunting of blood between the two atria needed for proper chamber development (Larsen, 2001). 
Intra-atrial sepation, however, is still incomplete. While the septum primum is still growing towards the atrioventricular septum a second ridge of tissue forms on the ceiling of the right atrium and extends downward, just adjacent and to the right of the septum primum. In contrast to the septum primum, this septum secundum is a thick and muscular plate. It too grows to create a wall separating the two atria, but before it reaches the atrioventricular septum it stops, leaving a hole called the foramen ovale near the floor of the right atrium. Even at this point the "right to left" shunting of blood between the two atria can thus continue, as contraction of the right atrium can send at least some blood through the foramen ovale of the septum secondum, through the foramen secondum of the septum primum, and finally into the left atrium. This shunt will in fact continue to operate throughout the remainder of fetal development, normally closing only at birth (Larsen, 2001).

Simultaneous with the process described above, other regions of the heart are also undergoing massive remodeling. The common atrioventricular canal, for example, must be repositioned by a rightward shift, allowing the alignment of the future left and right atrioventricular canals with their respective atria and ventricles (Larsen, 2001). No less importantly, the primitive ventricle and bulbus cordis must be remodeled into left and right ventricular primordial (respectively) as the intraventicular septum begins to form.

Formation of the thick muscular wall giving rise to separate right and left ventricles begins with a slowly elongating ridge known as the muscular interventricular septum (Waldo, 1998; Larsen, 2001). This wall, even initially quite thick at its base, grows upward to eventually create and separate the two ventricular chambers. 
Simultaneously, the ventricular myocardium begins to thicken and form trabecule (myocardial ridges) on the inner walls of both ventricles. Growth of the muscular interventricular septum up to the central atrioventricular septum is not continuous however, but is arrested when it has only grown about half-way up. This temporary cessation (or at least profound slowing) of growth is necessary, since fusion with septum intermedium too soon would render the left ventricle totally shut off from the ventricular outflow tract (Larsen, 2001).

With growth of the interventricular septum arrested, development of the atrioventricular valves begins. The valves are thought to arise from proliferation and differentiation of endocardial cushion tissue surrounding the lumen of each atrioventricular canal. The valve leaflets are thought to be freed from the wall by remodeling, while adjacent regions of the myocardial wall are freed (also via remodeling) to create thin, strand-like chordae tendineae and small cones of myocardium called papillary muscles.

Around this time the cardiac outflow tract becomes divided via the formation of a pair of endocardial and neural crest cell-derived conotruncal ridges that grow inward in a roughly spiral pathway along the length of the conotruncal segment. These ridges eventually grow together and fuse, creating two separate outflow tract tubes (the proximal portions of the aorta and pulmonary artery). Simultaneously, those conotruncal ridge segments also expand as a downward growing plate to eventually fuse with the muscular ventricular septum, finishing the wall separating the right and left ventricles and giving rise to separate right and left ventricular outflow pathways. Also at this time, two 
smaller additional masses of cushion tissue (the intercalated cushion tissues) form at the base of the outflow tract and, via remodeling, give rise to the semilunar valves.

While no intent was made here to make this an exhaustive review, hopefully enough background has been provided to give our work on $T b x 5$ some context. Prior to discussing $T b x 5$ and the $T b x$ gene family, however, it seems appropriate to present at least a brief rationale regarding the of use of the chick as an experimental model.

\subsection{The Chick as an Experimental Model in the Study of Heart Development}

Use of the chick (gallus gallus) embryo as an experimental model for developmental studies dates back to 300 B.C. where the Egyptians performed the first scientific study of embryo development, work which was continued by researchers like Aristotle who studied the morphology of the chick embryo (before the invention of magnifying devices) (Stern, 2004). Leonardo Da Vinci (who lived from 1452-1519) and Ulisse Aldrovandi (who lived from 1522-1605) studied the anatomy of the embryonic chick within the developing egg (Stern, 2004). William Harvey studied the early developmental stages of the chick embryo and concluded that heart was the first functioning organ in the developing embryo (Stern, 2004).

Organisms like the fruit fly (Drosophila), Zebrafish, the toad Xenopus, chick and mice are all currently used to study cardiogenesis, in large part because the molecular pathways involved in heart development demonstrate an often remarkable degree of conservation, making the findings broadly applicable. That said, the mouse is probably 
generally considered the premier model system, with the principle advantage being sophisticated genetics... inbred strains, the capacity to isolate and manipulate embryonic stem cells with the powerful ability to create animals with specific gene knockout constructs. Chick embryos, however, present a number of advantages over most other "model organisms" used to study cardiogenesis, especially when the interest is specifically directed to development of the four chambered heart. In brief, fertile chick eggs (and thus chick embryos) are very inexpensive and available throughout the year, are cheaply and easily reared (requiring a minimum of equipment, facilities, per diem charges and animal husbandry on the part of the investigator), are translucent enough early in cardiogenesis to allow direct observation of blood flow in the beating heart, are large in size (making stereomicroscopic observations, harvesting and any surgical manipulation much easier), and are genetically very complex (carrying about as many genes as the mouse or human, and exhibiting most of the same genetic regulatory systems, signaling and metabolic pathways). Unlike insects, nematodes, fish, amphibians, and reptiles, avians possess a true 4 chambered heart, essentially identical to that found in mice and humans. This advantage alone is often sufficient to justify its use. When compared to placental animals, chick embryos are infinitely more convenient for surgical resection, ablation, transplantation, and microinjection (or most other forms of microsurgical manipulation), as well as electroporation, lipofection, or infection with recombinant virus for protein or RNA expression, in vivo cell movement or cell lineage studies. The chicken embryo can be removed from the shell and cultured for a short time span in a dish (usually 2 days at most) to facilitate manipulation, or can be incubated in 
the egg (in ovo) to any desired stage of development. The egg shell may be left intact throughout development or it may be "windowed" (in which a small hole is cut in the egg shell, a sterile glass cover slip placed over the hole and the cover slip sealed to the shell) to allow continuous visual monitoring of the developmental process. The pre- and postgastrulation stages of the chick are well studied and characterized (greatly facilitating estimation of the developmental stage and the presence of developmental defects), and there is a vast store of developmental literature involving the chick (spanning nearly 100 years) upon which to draw. For these reasons the chick remains a heavily used experimental model for the study of cardiovascular system development (especially heart development) in higher vertebrates.

\subsection{A Brief Overview of the Tbx Family and Structural Characteristics}

On a historical note, the T-box gene family's name is derived from work originally initiated in the 1920 s at the Pasteur Institute by the Russian scientist Nadine Dobrovolskaia-Zavadskaia, carrying out a radiation-induced genetic screen for mutant developmental phenotypes in the mouse. She identified one phenotype associated with a stunted tail, and mapped the gene to what she termed the "T locus." She named the gene Brachyury (Greek for "short tail"), but the "T" designation remained (DobrozolskiaZavadskia, 1927, reviewed in Korz and Grunwald, 2001). About 60-65 years later the

Brachyury gene was cloned and found to possess a DNA sequence stretch that came to be called the "T-box." Within the next decade a number of genes were identified that carried a similar "T-box" sequence, and the T-box gene family was realized. 
All the $T b x$ gene family members identified to date encode transcription factors, all related and defined by the presence of a highly conserved protein motif called the "Tdomain" (encoded by the T-box), involved in DNA binding and protein dimerization (Minguillon and Logan, 2003). The genes in this family appear to be broadly conserved evolutionarily (Wilson and Conlon, 2002), with expression found in organisms ranging from insects, through nematodes, to fish, birds and mammals. Most of the T-box gene loci appear to be dispersed randomly throughout chordate genomes (human T-box genes are found, for example, on chromosomes 1, 2, 3, 6, 7, 12, 16, 17, 22, and X), probably arising by gene duplication and subsequent cluster dispersion (Wilson and Conlon, 2002, King et al., 2006). While the function of the various $T b x$ family members is currently being intensely investigated in many different organisms by a great number of laboratories world-wide, in broad sweep we now recognize that they play important roles in embryonic development across a number of organs and tissues, with individual family members often operating on many different target tissues.

The general structure of a T-box protein appears to be: (i) a N-terminal domain (possibly exhibiting cofactor-binding function), followed by (ii) the T-domain (exhibiting DNA binding and dimerization functions), followed by (iii) a region containing a nuclear localization domain, and (iv) a C-terminal region containing a transcriptional activator or repressor domain (Minguillon and Logan, 2003, Wilson and Conlon, 2002). T-box genes all contain multiple exons, with the T-domain itself being generally encoded by at least five exons (Wilson and Conlon, 2002). The exon structure for the various T-box gene family members can, however, vary considerably. Entrez analysis of the human $T b x$ 
5 gene, for example, reveals it to contain eight exons distributed over about 53 kilobases (kb) along chromosome 12. Despite this variability in gene structure, however, homology within the T-domain between the various T-box proteins still averages approximately $70 \%$. It can be significantly higher though, as the T-domains of $T b x 4$ and Tbx 5, for example, share 93\% identity (Tada and Smith, 2001). Proteins encoded by the 20 different T-box genes currently known to exist in the vertebrate genome range from around 50 kiloDaltons $(\mathrm{kDa})$ to $78 \mathrm{kDa}$ in size, of which no small part (an average of approximately 180 amino acids, ranging about 17-26 kDa) comprises the T-domain itself (Ghosh et al., 2009, Bollag et al., 1994, Wilson and Conlon, 2002, Tada and Smith, 2001). While the original experiments with the Brachyury (T) protein revealed that it bound preferentially to the consensus sequence T(G/C)ACACCT-AGGTGTGAAATT (note the palindromic region underlined) as a monomer, it was hypothesized that it might bind as a dimer in vivo (Kispert and Herrmann, 1993). Subsequent work has shown Brachyury can also bind as a monomer to the T-half site AGGTGTGAAATT (King et al., 2006) or the half-palindromic sequence (T/C)TTCACACCT (Casey et al., 1998). Further studies have since revealed that all T-box proteins can bind to T-half sites as monomers (King et al., 2006), raising the possibility that target specificity might be generated, at least in part, by: (i) variations in half-site DNA sequence, allowing for differential binding by monomeric and/or homodimeric T-box proteins due to affinity differences for the site, and/or (ii) the formation of heterodimeric T-box proteins binding to different but adjacent half-sites. A third, and independent, mechanism for generating T-box specificity could also involve protein-specific interaction with coactivators or corepressors, a 
possibility bolstered by the observation that T-box proteins demonstrate synergistic activation of target genes when coexpressed with specific homeodomain, GATA zinc finger or LIM domain-type transcriptional regulators (Hiroi et al., 2001, Garg et al, 2003, Krause et al., 2001, topic also reviewed in Naiche et al., 2005).

As has been mentioned previously, the T-box proteins are involved in a variety of developmental processes. Of the $20 \mathrm{Tbx}$ genes currently identified in the human, at least 6 are now associated with well known developmental disorders (Ghosh et al., 2009). Mutations in Brachyury (T), for example, are associated with spinal cord defects, mutations in Tbx 1 associated with velo-cardiofacial (DiGeorge) syndrome (a disorder characterized by absence or hypoplasia of the thymus, cleft palate, facial dysmorphism and such cardiovascular abnormalities as hypoplasia of the $4^{\text {th }}$ pharyngeal arch artery, outflow tract defects and ventricular septal defects) (Baldini, 2004), mutations in Tbx 3 associated with Ulnar mammary syndrome (a disorder characterized by hypoplastic mammary glands, abnormal external genitalia and limb abnormalities), mutations in $T b x$ 4 associated with Small Patella syndrome (characterized by hip, knee and foot defects), and mutations in Tbx 5 associated with Holt-Oram syndrome, characterized by upper limb defects, atrial and ventricular septal defects and conduction system defects including AV block (reviewed in Naiche et al., 2005, Stennard and Harvey, 2005). As suggested by the brief description above, many (but not all) of the disorders associated with mutations in T-box genes give rise to defects in skeletal (especially limb) formation and/or heart development. Tbx 2, 3, 4, 5, 15 and 18, for example, are expressed in specific (though often overlapping) regions of the limb buds, while Tbx 1, 2, 3, 5, 18 and 
20 are currently thought to be similarly expressed in unique but overlapping regions of the developing heart (reviewed in Naiche et al., 2005; Stennard and Harvey, 2005). Important also is the fact that any given $T b x$ gene might be expressed in a wide variety of tissues during development. $T b x 5$, for example, is expressed (and known to play a crucial role) in the development of heart and forelimb, but is also at least transiently expressed in the dorsal side of the retina (Koshiba et al., 2000), the optic vesicle, the otic vesicle (Takeuchi et al., 2003), the genital papilla and the lung buds (Brown et al., 1998), and presumably plays developmental roles in those tissues as well. Nor is $T b x 5$ unique is this regard. In situ hybridization studies on $T b x 2$ have also indicated at least transient expression in both limb buds, various regions of the heart and aortic sac, the optic and otic vesicles, the dorsal root ganglia and duodeum (Brown et al., 1998). Similar studies of Tbx 18 have revealed at least transient expression in the epicardium of the heart, the proepicardial serosa, the somites, the emerging forelimb and the developing urogenital system (Haenig and Kispert, 2004), while $T b x 20$ has been reported in the primitive streak, the posterior lateral mesoderm and cardiac crescent, the endocardium and myocardium of the linear and looped heart tube, the ventricle and atrioventricular canal of the multichambered heart, the optic vesicle, the allantois, ventral neural tube and the hindbrain (Iio et al., 2001). In fact, it appears that essentially all the $T b x$ family members are expressed in a variety of tissues at various times during development. In the face of this almost unfathomable extent of developmental involvement across the entire $T b x$ family, it seems reasonable to select one key gene with a well known, clinically definable 
role in cardiogenesis and examine in detail its expression pattern and, ultimately, its interaction partners, downstream targets and regulation. We have selected $T b x 5$.

As stated above, Tbx 5 is known to be absolutely required for normal

development of the forelimbs and heart (Takeuchi et al, 1999). Forelimb buds will not, in fact, even form in the absence of Tbx 5 (King et al, 2006), and the associated cardiac malformations can be profound. Holt-Oram syndrome (HOS), like many human diseases, is actually a spectrum of phenotypes due to allelic variation at the $T b x 5$ locus (Fan et al., 2003). HOS is caused by a variety of mutations in the C-terminal half of the Tbx 5 gene, encompassing translocations, frame shifts, nonsense and missense mutations, and mutations giving rise to altered splice sites (Zaragoza et al, 2004), and the resultant effects of those different mutations can give rise to a spectrum of clinical presentations. The more severe forms of Holt-Oram syndrome (involving incapacitating atrial and/or ventricular septal defects, sinus node dysfunction and variable degrees of AV block, up to complete AV block) certainly attest to the requirement for $T b x 5$ in cardiogenesis (Newbury-Ecob et al, 1996; Basson et al., 1997; Hatcher and Basson, 2009). Indeed, typically Tbx 5 null mouse embryos do not survive past embryonic day 10.5 (Bruneau et al., 2001). Yet, while the importance of Tbx 5 in cardiogenesis seems beyond question, its functional interaction partners, transcriptional regulation, target genes and even expression domains remain either controversial or only vaguely understood. Work by Ghosh et al (2001), for example, succeeded in deriving a minimal DNA octomer consensus sequence $[(\mathrm{A} / \mathrm{G}) \mathrm{GGTGT}(\mathrm{C} / \mathrm{G} / \mathrm{T})(\mathrm{A} / \mathrm{G})]$ for which $T b x 5$ demonstrates reasonably stable binding. The presence of 3 variable base positions in this short 
oligonucleotide stretch, however, makes it difficult to identify bona fide $T b x 5$ binding sites in promotors (or more distal upstream regions) of putative target genes. Work in identifying Tbx 5 interaction partners has gone better. Hiroi et al (2001), for example, presented convincing evidence that $T b x 5$ can associate with $N k x 2-5$ and that the association could drive cardiomyocyte differentiation in a synergistic fashion. Soon thereafter, Garg et al (2003) presented evidence for a Tbx 5: GATA 4 interaction. These interactions appear quite important, given that both $N k x 2-5$ and GATA 4 are expressed throughout cardiogenesis and that mutations in these genes are well known to produce heart defects during development. These interaction studies were then followed by the work of Krause et al (2004), who presented evidence for a physical association between TBX 5 and a PDZ-LIM protein (LMP-4) in the heart, by Brown et al (2005), who found evidence for an association between $T b x 5$ and $T b x 20$, and by Koshiba-Takeuchi et al (2006), who demonstrated interactions between Tbx 5 and Sall4 in the heart. The interaction between $T B X 5$ and $T B X 20$ (at the very least) appears significant in light of the fact that: (i) $T b \times 20$ is expressed in the developing heart, and (ii) mutations in mouse Tbx 20 have produced documented heart defects (Stennard et al, 2005). Most recently Ghosh et al (2009) provided evidence for a physical interaction between Tbx 5 and $M E F 2 C$. This is potentially very important given the ability of $M E F 2$ family members to associate with myogenic bHLH protein like MyoD, myogenin, Myf5 and MRF4 to regulate muscle differentiation (Bour et al, 1995; Black and Olson, 1998). Despite this progress in identifying Tbx 5 interaction partners, however, we are only now gaining an understanding of the target genes these transcription factors (or combinations of factors) 
actually regulate. Tbx 5 upregulation followed by measurement of changes in gene expression can identify potential $T b x 5$ target genes, and work of this type (Plageman and Yutzey, 2006; Lu et al, 2008) suggests the following as Tbx 5 targets: (i) Nappa (natriuretic peptide precursor A), (ii) $f g f 10$ (fibroblast growth factor 10), (iii) $C x 40$ (connexin 40), (iv) pla2g2e (phospholipase A2, group II E), (v) hey2 (hairy/enhancer of split-related 2), (vi) amhc (atrial myosin heavry chain), (vii) gelsolin and (viii) CKB (creatine kinase, brain) being the more prominent. Detecting an increase in transcript abundance of a gene following $T b x 5$ expression, however, does not actually prove that Tbx 5 directly binds to the promoter/regulatory region of that gene to induce its transcription. For proof of the ability of $T b x 5$ to directly bind to a promoter and induce that specific target gene, reporter construct experiments and electromobility shift assays are usually required and, to date, these confirmatory experiments have been carried out for only a few of the genes cited above. Finally, there is still controversy regarding the pattern of Tbx 5 expression in the developing heart as a function of developmental stage. According to researchers like Bruneau et al. (1999) and Takeuchi et al. (2003), Tbx 5 is expressed only in the left ventricle and not in the right ventricle. Bimber et al. (2007), however, report the expression of $T b x 5$ in the right ventricle along with the left ventricles (Fig. 36). They performed immunohistochemical studies on embryonic chick heart and report strong expression of $T b x 5$ in the left ventricle and atria, but also low to moderate expression in the right ventricle. This conflict is further compounded by the fact that the vast majority of papers reporting in situ results fail to present their hybridization methodology (especially with regards to probe characteristics, probe concentration, 
hybridization/wash stringency conditions, etc.) or their probe sequences. Given the high degree of sequence similarity between the various $T b x$ family members, it is quite possible that at least some of the reportedly "specific" signal might in fact be due to cross-hybridization of the probe with transcripts encoding other $T b x$ family members... either as a result of inappropriately chosen hybridization conditions or inappropriate probe design. To address these problems, we embarked on a project that involved rational, $T b x 5$-specific probe design and a detailed optimization of our in situ hybridization methodology. 


\section{2- METHODOLOGY}

\subsection{Embryo Extraction}

\subsubsection{Incubation of Fertile Eggs}

Fertile eggs were obtained from Cal Cruz Hatcheries Inc, Santa Cruz, CA. Since the eggs were "cool stored" by the hatchery operators very soon after fertilization, for practical purposes such eggs were considered to be at "day 0" of incubation. The eggs were then transported rapidly back to our laboratory at SJSU for immediate placement in a humidified, $37.5^{\circ} \mathrm{C}$ incubator fitted with an automatic egg turner. The incubator's internal reservoir was filled with water and the electric heater/fan assembly switched on at least 2 hrs prior to use, the eggs placed in the trays in the "air sac up" position (Fig. 4) and eggs then allowed to incubate. The incubator humidity was maintained by filing up

the internal water reservoir as needed (typically every other day), and the egg turner (run by a small electric motor) slowly rotated the eggs across an arc of about $90^{\circ}$ every hour (to minimize adhesion of embryos to the egg shell inner membranes). Our experience suggests that, with our incubation system, there is some initial "lag period" in the resumption of development. To obtain “3 day old embryos," for example, eggs were often incubated for 3 days and 4 nights. 


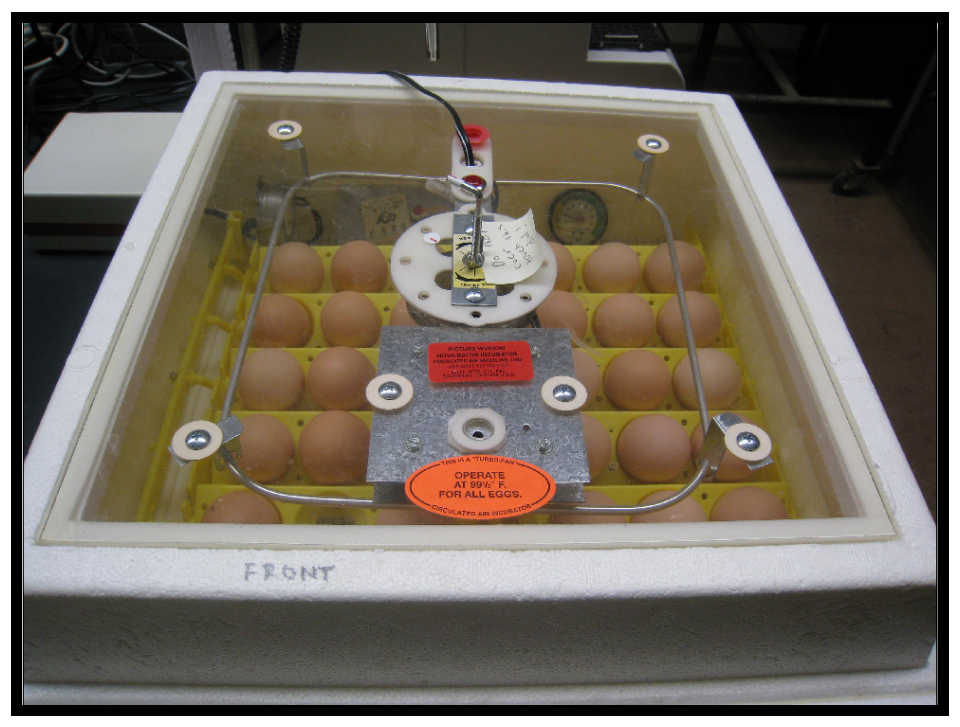

Fig. 4. Photograph of fertile eggs in the lab incubator. The clear Lucite observation window and thermometer and humidity gauges (visible at the back wall of the incubation chamber) allowed easy monitoring of the incubation conditions.

\subsubsection{Embryo Harvest}

Embryo harvest was performed in an aseptically prepared (cleaned and 70\% ethanol rinsed) surgical area (Fig. 5). The surgical instruments (forceps, scissors, and spatulas) were sterilized repeatedly as needed by immersion in $70 \%$ ethanol and flaming over an alcohol lamp. Liquid reagents used in the harvest (typically just deionized [DI] water and $1 \mathrm{X}$ phosphate buffered saline $[\mathrm{PBS}])$ were sterilized by autoclaving. The eggs were placed in a holder (a bottle cap often worked well), oriented "air sac end" up, and the egg shell wiped clean with a 70\% ethanol-soaked Kimwipe. 


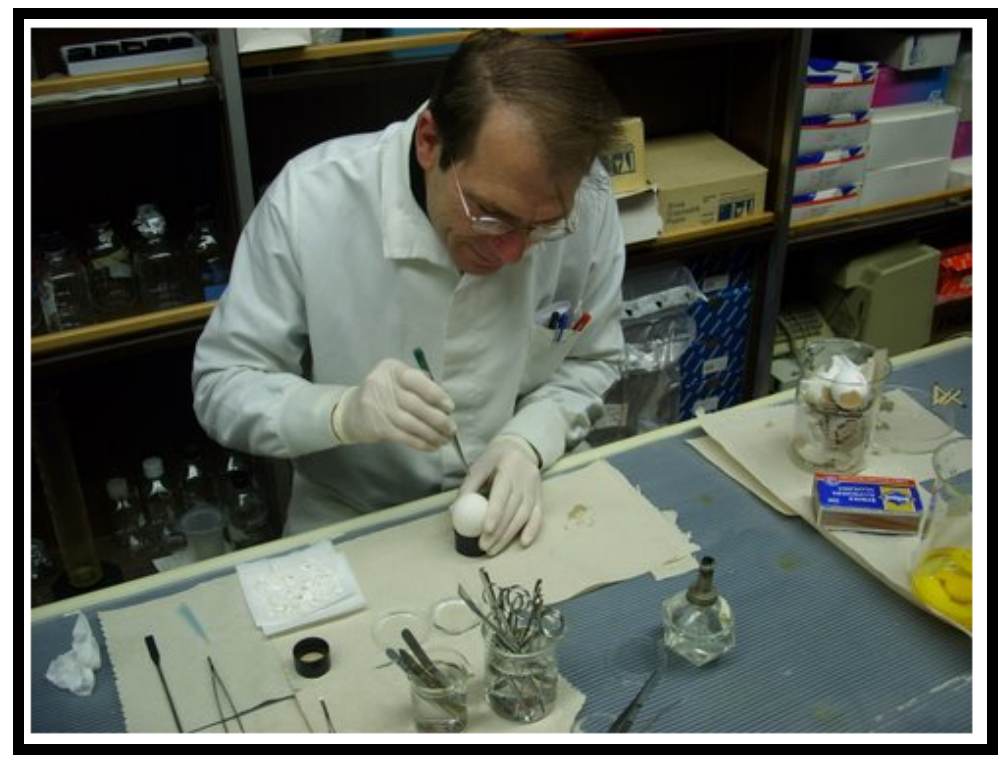

Fig. 5. Demonstration of embryo harvest being done by Dr. Steven White, photographed by Sureetha Ashokan.

Blunt-ended forceps were then used to punch a small hole in the egg shell, and that portion of the shell overlying the air sac was removed. The white shell membrane and associated chorioallantoic membrane were then carefully removed to expose the embryo for stereomicroscopic observation, assessment of the developmental stage, and further processing (Fig. 6). 


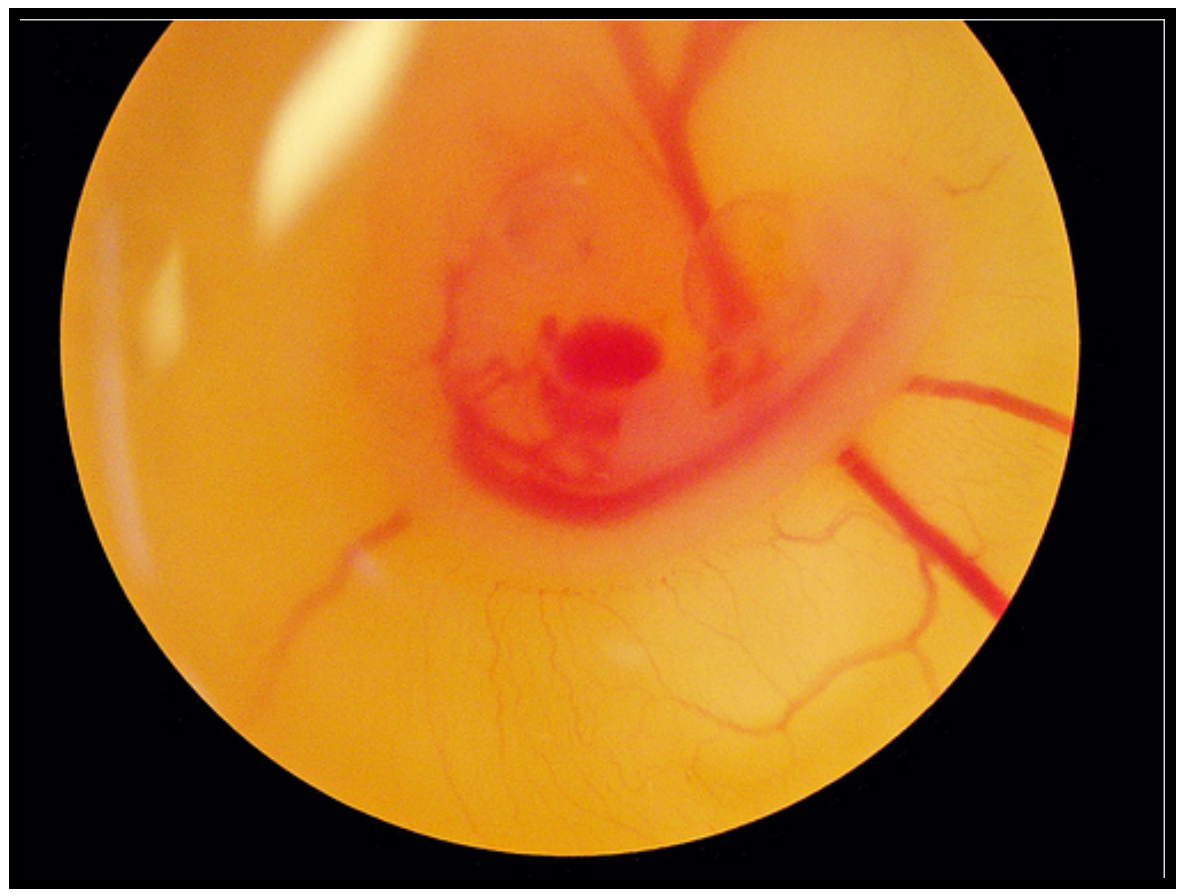

Fig. 6. Photograph of embryo in the egg after removal of the overlying membranes and just prior to isolation, still connected by the vascularized Vitelline membrane.

A scissors was used to cut the embryo carefully away from most of the underlying highly vascularized (Vitelline) membrane, and a spoon-shaped spatula was used to transfer the embryo into a sterilized plastic Petri dish containing autoclaved $1 \mathrm{X}$ PBS. If needed, any adhering yolk particles were rinsed off the embryo and the embryo transferred to a new dish containing sterile PBS. Using a dissecting microscope, small surgical scissors, and a narrow-bladed scalpel, the more tightly associated membranes were then removed from around the embryo. For most embryos the brain cavity was opened (typically either by cutting or poking through one or both telencephalic hemispheres or by poking a hole in the neural tube at the level of the diencephalon) to minimize background signal due to probe and/or antibody trapping. If needed, embryos 
were then transferred to yet another Petri dish containing 1X PBS to wash away any residual yolk or membrane/tissue fragments (Fig. 7).

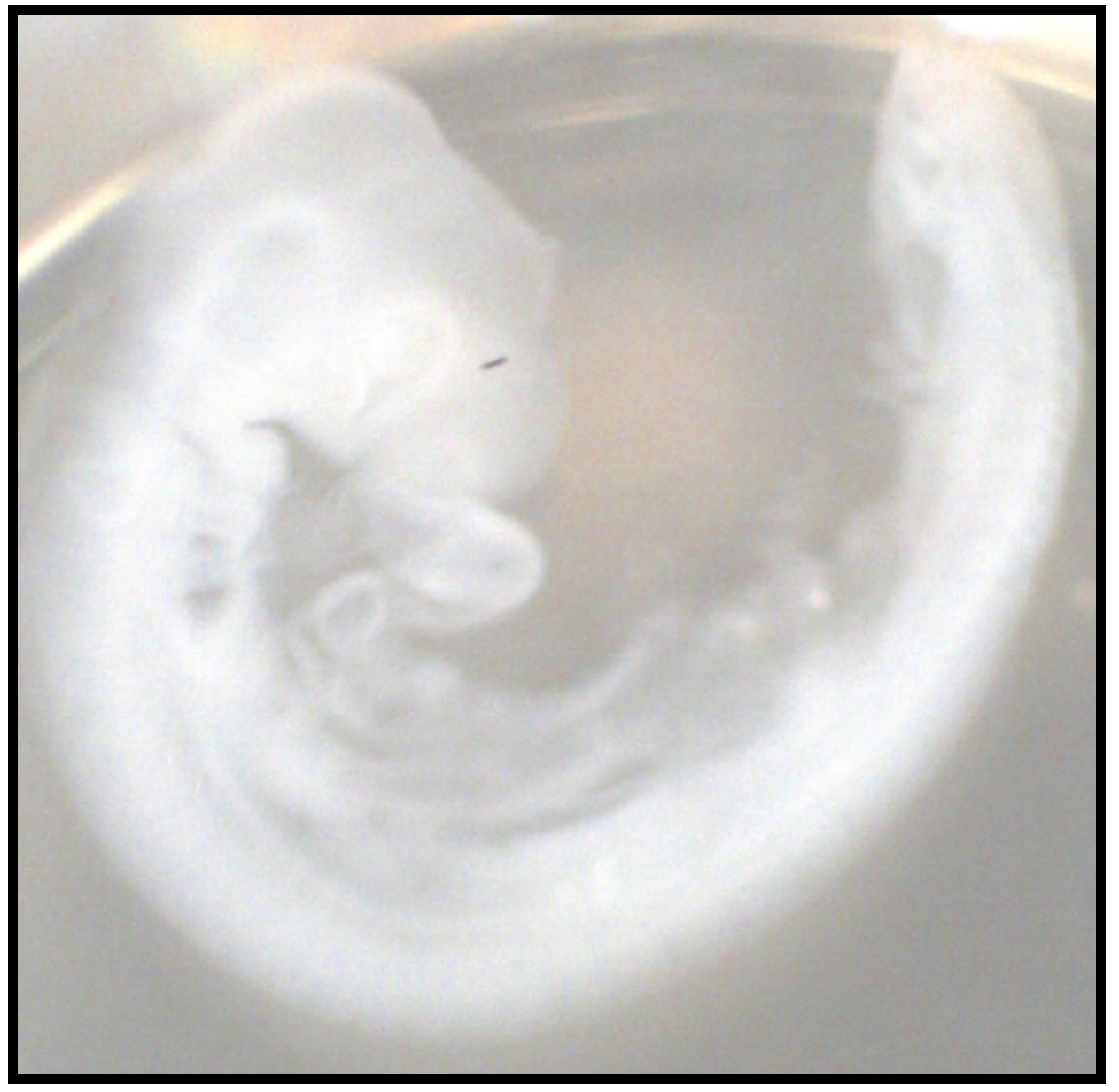

Fig. 7. Photograph of the embryo after all the membranes are removed, prior to fixation.

\subsection{Whole Mount In Situ Hybridization}

\subsubsection{Fixation}

Each embryo was transferred to a $20 \mathrm{ml}$ glass liquid scintillation counter vial containing $10 \mathrm{ml}$ freshly prepared cold $4 \%$ paraformaldehyde in $1 \mathrm{X}$ PBS (PFA). It is 
extremely important that PFA should be fresh, prepared typically 1.5 hours prior to initiating harvest of the embryos. Fixation was done overnight at $4^{\circ} \mathrm{C}$.

\subsubsection{Dehydration}

Each embryo was dehydrated in a series of freshly prepared $5 \mathrm{ml}$ methanol/PBS solutions $(25 \%, 50 \%, 75 \%, 90 \%$ and $100 \%)$ for 15 minutes each. Following this series, the embryos were dehydrated twice in $100 \%$ methanol. For rehydration, a methanol gradient was prepared using 100\% methanol, PBS and 0.1\% Tween 20 (PBT). A P1000 $(1000 \mu \mathrm{l})$ pipettor was used to add and remove the methanol/PBT solution. Extreme care was taken while removing the solution as the embryos were very fragile and could be aspirated into the pipet and be destroyed. Any remaining solution was removed using a Pasteur pipet.

\subsubsection{Rehydration}

Each embryo was rehydrated in a downward methanol: PBT gradient (90\% methanol twice, $75 \%, 50 \%, 25 \%, 10 \%$ methanol + PBT and thrice in $100 \%$ PBT) using the above described methodology for 15 minutes on ice at each step. Embryos were very carefully transferred from the scintillation vial to a 48 well plate using a soft sable brush

\subsubsection{Proteinase K Digestion}

Each embryo was placed in $1 \mathrm{ml}$ of PBT containing Proteinase K $(4.5 \mu \mathrm{g} / \mathrm{ml})$ for 30 minutes. The digestion was stopped by washing the embryos in freshly prepared 2 $\mathrm{mg} / \mathrm{ml}$ glycine in PBT. Embryos were further washed twice in PBT for 5 minutes each. 


\subsubsection{Secondary Fixation}

Embryos were refixed in $5 \mathrm{ml}$ of $4 \%$ PFA and $0.2 \%$ Glutaraldehyde in PBT for 15 minutes. Embryos were washed thrice in PBT for 5 minutes each.

\subsubsection{Prehybridization}

Embryos were placed in $900 \mu 1$ prehybridization solution at $65^{\circ} \mathrm{C}$ for 3 hours. The 48 well plates was sealed using parafilm.

Fifty $\mathrm{ml}$ of prehybridization solution was prepared as follows by first mixing 0.5 g Boehringer blocking powder, $25 \mathrm{ml}$ of deionized formamide and $12.5 \mathrm{ml}$ of 20X SSC $(3 \mathrm{M} \mathrm{NaCl}, 0.3 \mathrm{M} \mathrm{NaCitrate}, \mathrm{pH} 7.0)$ at a $\mathrm{pH} 7$ together, then heated at $65^{\circ} \mathrm{C}$ for 1 hour, after blocking powder dissolves, $6 \mathrm{ml}$ DEPC treated deionized water, $5 \mathrm{ml}$ of yeast tRNA (10 mg/ml) from SIGMA, $100 \mu 150 \mathrm{mg} / \mathrm{ml}$ heparin (SIGMA), $250 \mu \mathrm{l} 20 \%$ Tween-20, $500 \mu 1$ 10\% CHAPS and $500 \mu 10.5$ M EDTA were added. The above solution was filtered using 0.45 micron.

\subsubsection{Hybridization}

Immediately prior to hybridization $200 \mathrm{ng}$ (or as per mentioned) of probe was added to $100 \mu \mathrm{l}$ of prehybridization solution and heated at $95^{\circ} \mathrm{C}$ for 5 minutes. This solution was then added to the embryos sitting in prehybridization solution. The reaction was placed at $65^{\circ} \mathrm{C}$ for overnight.

\subsubsection{Washes}

Hybridization solution was removed and the embryos were washed with $800 \mu \mathrm{l}$ of prehybridization solution at $65^{\circ} \mathrm{C}$ for 5 minutes. $400 \mu \mathrm{l}$ of $2 \mathrm{X} \mathrm{SSC}$ solution was added 
thrice to the existing solution at an interval of 10 minutes. Solution was removed and embryos were washed twice for 30 minutes in $2 \mathrm{X} \mathrm{SSC}(\mathrm{pH} 7)$ at $65^{\circ} \mathrm{C}$.

Embryos were washed twice at room temperature for 10 minutes each in Maleic Acid Buffer (100 mM maleic acid, $150 \mathrm{mM} \mathrm{NaCl}, \mathrm{pH} 7.5)$. Next embryos were washed in Maleic Acid Buffer twice at $65^{\circ} \mathrm{C}$ for 30 minutes each. Two washes were done in PBS at room temperature for 10 minutes each and then in PBT at room temperature for 5 minutes. All washes were carried out in a 24 well plate and agitated on a rocker.

\subsubsection{Pre blocking}

Embryos were placed in $1 \mathrm{ml}$ of antibody buffer (10\% goat serum heat inactivated, $1 \%$ Boehringer blocking reagent in PBT) at $4^{\circ} \mathrm{C}$ for overnight with rocking.

\subsubsection{Antibody}

Each embryo was placed in $1.5 \mathrm{ml}$ of antibody buffer with 1:10,000 dilution of Anti digoxygenin antibody $(1.5 \mu \mathrm{l})$ from Roche. The reaction was incubated overnight at $4^{\circ} \mathrm{C}$ with rocking.

\subsubsection{Washes}

Embryos were washed in $5 \mathrm{ml}$ of PBT $+0.1 \% \mathrm{BSA}$, five times for 45 minutes each. Next embryos were washed twice in PBT for 30 minutes each at room temperature. Embryos were further washed at room temperature twice in AP1 Buffer ( $\mathrm{pH}$ 9.5) (100 mMTris 9.5, $100 \mathrm{mM} \mathrm{NaCl}, 50 \mathrm{mM}$ Magnesium chloride) for 10 minutes each with rocking. 


\subsubsection{NBT/BCIP}

For the process of color development to $20 \mathrm{ml}$ NTMT (100 mM NaCl, $100 \mathrm{mM}$ Tris at $\mathrm{pH}$ 9.5, $50 \mathrm{mM}$ MgChloride, $1 \mathrm{mM}$ levasmisol [0.48 $\mathrm{g}]$ and distilled water [84.5 ml]) $90 \mu \mathrm{l}$ NBT (Nitro-Blue Tetrazolium Chloride) and $70 \mu 1$ BCIP (5-Bromo-4-Chloro3'-Indolyphosphate p-Toluidine Salt) was added. $5 \mathrm{ml}$ of the above solution was added to each embryo including the experimental and negative controls. Reaction was placed in dark and incubation time was very carefully monitored.

\subsubsection{Washes}

Reaction was stopped by washing the embryos thrice in $5 \mathrm{ml}$ of PBS solution for 5 minutes each.

\subsection{Construction of Probe}

For the purpose of whole mount in situ hybridization four different types of probes were constructed: (i) 199 base pair DNA probe, (ii) 199 base pair RNA probe, (iii) 665 base pair DNA probe and (iv) 665 base pair RNA probe.

\subsubsection{Base Pair Probe}

Total RNA was extracted from 3- 5 day old chick embryos using Ambion Totally RNA and was a generous gift from a fellow graduate student (Ricardo Leitao). Harvested embryos were weighed, flash frozen in liquid nitrogen and stored at $-80^{\circ} \mathrm{C}$ until needed. On the morning of RNA isolation twelve frozen embryos were rapidly transferred to a pool of liquid nitrogen in a pre chilled mortar and dry ice, and were ground to a fine powder using a mortar and pestle. The powder was then placed in polypropylene tubes containing denaturing solution (a proprietary solution of guanidine 
thiocyanate and EDTA) added in the ratio of $10 \mu$ solution per milligram of tissue. RNA extraction was done as per the manufacturer's instructions.

Step down RT PCR was performed using Qiagen's one step RT PCR kit (Appendix B), using the following primers:

Forward Primer 3' GCG AAG GAA GCT CGT AAC AT 5'

Reverse Primer 3'GCT CGT GCA AAA ACA CAT TTG 5'

Step down / Touch down RT-PCR reaction was used as it increases the specificity and sensitivity of the RTPCR reaction. Initial annealing temperature used was $65^{\circ} \mathrm{C}$, with each cycle temperature was dropped by $0.5^{\circ} \mathrm{C}$, making the final temperature to be $50^{\circ} \mathrm{C}$. A total of 40 cycles were employed.

$\begin{array}{ll}\text { Reverse Transcription } & 50^{\circ} \mathrm{C} \text { for } 30 \text { minutes } \\ \text { Initial PCR activation } & 95^{\circ} \mathrm{C} \text { for } 15 \text { minutes } \\ 3 \text { step cycle: } & \\ \text { Denaturation } & 94^{\circ} \mathrm{C} \text { for } 1 \text { minute } \\ \text { Annealing } & 65^{\circ} \mathrm{C} \text { for } 1 \text { minute } \\ \text { Extension } & 72^{\circ} \mathrm{C} \text { for } 1 \text { minute } \\ & ------------------ \\ 3 \text { step cycle: } & 30 \text { cycles } \\ \text { Denaturation } & \\ \text { Annealing } & 94^{\circ} \mathrm{C} \text { for } 1 \text { minute } \\ \text { Extension } & 50^{\circ} \mathrm{C} \text { for } 1 \text { minute } \\ & 72^{\circ} \mathrm{C} \text { for } 1 \text { minute } \\ \text { Final extension } & -------------------- \\ & 10 \text { cycles } \\ & 72^{\circ} \mathrm{C} \text { for } 10 \text { minutes }\end{array}$

A $1 \mathrm{X}$ TAE $1 \%$ agarose gel was run to confirm the size of the amplified region. Band extraction was performed using Qiagen's MinElute Gel Extraction Kit as directed in the manufacturer's protocol. 
The amplified DNA was cloned in Promega's pre-linearized pGEM- T Easy vector using T4 DNA ligase and reaction buffer as per the protocol (Appendix B). The ligation product was transformed into JM 109 competent cells using Promega's heat shock protocol. Following the subsequent 90 minutes growth period, $100 \mu \mathrm{l}$ of bacterial suspension was then spread onto pre-warmed LB agar plates containing ampicillin (100 $\mathrm{ug} / \mathrm{ml})$, IPTG $(80 \mu \mathrm{M})$ and XGAL $(50 \mu \mathrm{g} / \mathrm{ml})$ and the plates incubated overnight at $37^{\circ} \mathrm{C}$. Five white colonies were selected and used to inoculate separate $5 \mathrm{ml}$ cultures of LB media containing $100 \mu \mathrm{g} / \mathrm{ml}$ of ampicillin.

A Zyppy Mini Prep Kit (Zymo Research) was next used to isolate plasmid from each culture (Appendix C), and the DNA was then quantified using a NanoDrop spectrophotometer and examined by agarose gel electrophoresis. Plasmid DNA was sent out for sequencing to Sequetech Corporation (Mountain View) using M13 reverse and forward primers.

BLAST analysis was performed using Tbx 5 sequence obtained from NCBI website w.r.t to the sequencing results in order to confirm the Tbx 5 insert identity.

Multiple sequence alignment and local sequence alignment was then performed in order to find a region within the Tbx 5 gene of gallus gallus unique to this family member (since, as has been mentioned in the Introduction, significant sequence similarity is observed across the $T b x$ family). Once a region unique to $T b x 5$ was identified, primers targeting this region were designed using both Primer 3 (http://frodo.wi.mit.edu/primer3/) and software made available at the IDT Inc website.

(http://www.idtdna.com/Home/Home.aspx 


\subsubsection{199 Base Pair DNA Probe}

For development of a DNA probe targeting the unique region of the $T b x 5$ transcript, secondary PCR was first performed using the Tbx 5 specific primers described above. The PCR product was verified to be a single band using agarose gel electrophoresis, and the resulting DNA purified using Promega's Wizard PCR clean up kit as per the manufacturer's instructions (Appendix F). The resulting DNA was DIG labeled using a Mirus's Label IT kit as directed in the manufacturer's instructions (Appendix I).

\subsubsection{199 Base Pair RNA Probe}

For the creation of an anti-sense RNA probe, a secondary PCR reaction was first performed to create a transcription template using a pair of $T b x 5$ gene specific primers, one of which was modified to bear an appended $\mathrm{T} 7$ promoter. A similar approach was used to create a DNA template for production of a sense RNA probe. The design of these primer pairs is shown below with the T7 promoter region underlined.

For creation of a template able to support synthesis of sense RNA probe:

Forward Primer: 5' TAA TAC GAC TCA CTA TAG GGA GAT ACA ATG

CAA GGA AGC G 3'

Reverse Primer: 5' GTA AAA CGA CGG CCA GT 3'

Anti sense probe:

Forward Primer: 5'GCT CGT GCA AAA ACA CAT TTG 3' 
Reverse Primer: 5' TAA TAC GAC TCA CTA TAG GGA GAG TTT ACA CAA AAA CGT GCT CG 3'

PCR product was analyzed using agarose gel electrophoresis and the product clean up carried out using Promega's Wizard PCR Clean Up Kit (Appendix F). For creation of the single stranded RNA probe in vitro transcription was performed using the Roche DIG labeling In Vitro Transcription kit containing Digoxygenin-11-UTP (Roche Inc) as per manufacturer's instruction (Appendix G). Resulting RNA was confirmed for size and yield by agarose gel electrophoresis.

RNA was pelleted using Novagen's Red Pellet Paint reagent according to the manufacturer's instructions (Appendix H). RNA was assayed for labeling efficiency by dot blotting followed by development with anti -DIG fragments conjugated to Alkaline Phosphatase and NBT/BCIP per the manufacturer's instructions (Appendix J).

\subsubsection{Base Pair Probe}

665 base pair DNA probe was prepared in collaboration with Dr. S. White and a fellow undergraduate student (Adreina Martinez). Dr. White provided us with a pBluescript plasmid containing an insert of approximately $1400 \mathrm{bp}$, with about $800 \mathrm{bp}$ of that being Tbx 5 cDNA. Liquid culture of LB/AMP $(100 \mu \mathrm{g} / \mathrm{ml})$ was prepared by inoculating the culture with the plasmid and incubating it overnight at $37^{\circ} \mathrm{C}$ with shaking. Plasmid prep was performed using Zyppy Plasmid Miniprep Kit (Appendix C). DNA was quantified using a NanoDrop spectrophotometer. In order to confirm for the presence of the Tbx 5 insert a double restriction digest was performed using EcoRI and NotI enzymes (Appendix D) and results were analyzed on a 1\% agarose gel. 
The insert was cloned into Promega's pre-linearized pGEM- T Easy vector and ligation was performed as per the manufacturer's instructions (Appendix B). The resulting ligation reaction mixture was then transformed into $E$. coli by a standard heat shock protocol, grown for 90 minutes and then plated onto LA/AMP/IPTG /XGAL plates and incubated overnight at $37^{\circ} \mathrm{C}$. Liquid culture was prepared by inoculating $5 \mathrm{ml}$ of LA/AMP media with the bacterial suspension incubating overnight at $37^{\circ} \mathrm{C}$ with shaking. Plasmid Prep was performed using Zyppy Plasmid Mini Prep Kit (Appendix A).

The mini plasmid prep was sent out for sequencing using M13 reverse and forward primers. The sequencing results were confirmed by performing a sequence alignment of Tbx 5 sequence obtained from NCBI web site.

Primer 3 was used to design the primers for $T b x 5$ gene, GC\% forward primer ((20 base pair) was $55 \%$ and for reverse primer (20 base pair) was 55\% and melting temperatures were 59.48 and 59.69 respectively. The following primers were used

Forward Primer: 3' GCGAAGGAAGCTCGTAACAT 5'

Reverse Primer: 3' GGAGgTAACAGCGATGAAGG 5'

PCR reaction was set up using Qiagen Taq DNA polymerase and Core Buffer components (Appendix E). PCR results were analyzed by running on a $2 \%$ agarose gel. The PCR product was cleaned up for the removal of any existing dNTP's and salts by using Promega's Wizard SV gel and PCR Clean-Up System (Appendix F). PCR clean up results were quantified using spectrophotometer and confirmed by running an agarose gel. 


\subsubsection{665 Base Pair DNA Probe}

DNA was Digoxygenin labeled by using Label It Kit (Mirus Inc) as per the manufacturer's instructions (Appendix H). The kit covalently attaches Digoxin molecule to the nucleic acid. Resulting Dig labeled DNA was analyzed by gel electrophoresis to confirm size and yield.

An assay was performed to check for the labeling efficiency using Dot Blot. Dot blot was developed using anti-DIG Fab fragments conjugated to Alkaline Phosphatase and NBT/BCIP according to manufactures instructions (Appendix J).

\subsubsection{665 Base Pair RNA Probe}

For RNA probes secondary PCR was performed using T7 ending Tbx 5 gene specific primers. The following primer sequence was used to attach the T7 promoter (underlined region).

Anti sense probe

Forward Primer: 5' GCG AAG GAA GCT CGT AAC AT 3'

Reverse Primer: 5' TAA TAC GAC TCA CTA TAG GGA GAG GAG GTA ACA GCG ATG AAG C 3'

Sense probe

Forward Primer: 5' TAA TAC GAC TCA CTA TAG GGA GAG CGAAGGAAG CTC GTAACA T 3'

Reverse Primer: 5' GGA GGT AAC AGC GAT GAA GG 3'

PCR product was verified using agarose gel electrophoresis. PCR product clean up was done by using Promega's Wizard PCR clean up kit (Appendix G). 
For single stranded RNA probe in vitro transcription was performed using DIG labeling In Vitro Transcription kit containing Digoxygenin-11-UTP (Roche Inc) as per manufacturer's instruction (Appendix H). The resulting RNA was confirmed for size and yield by agarose gel electrophoresis.

RNA was pelleted using Novagen's red pellet paint as per manufacturer's instructions (Appendix I). Pellet paint co-precipitant is a visible dye used in alcohol precipitation of the nucleic acid. DNA/RNA is efficiently precipitated and easily located by the pink color of the dye. 


\section{3- RESULTS}

\subsection{Total RNA Isolation}

Total chick embryo's RNA isolated using Ambion's totally RNA was diluted 1:2 and analyzed on nanodrop for concentration (Fig. 8).

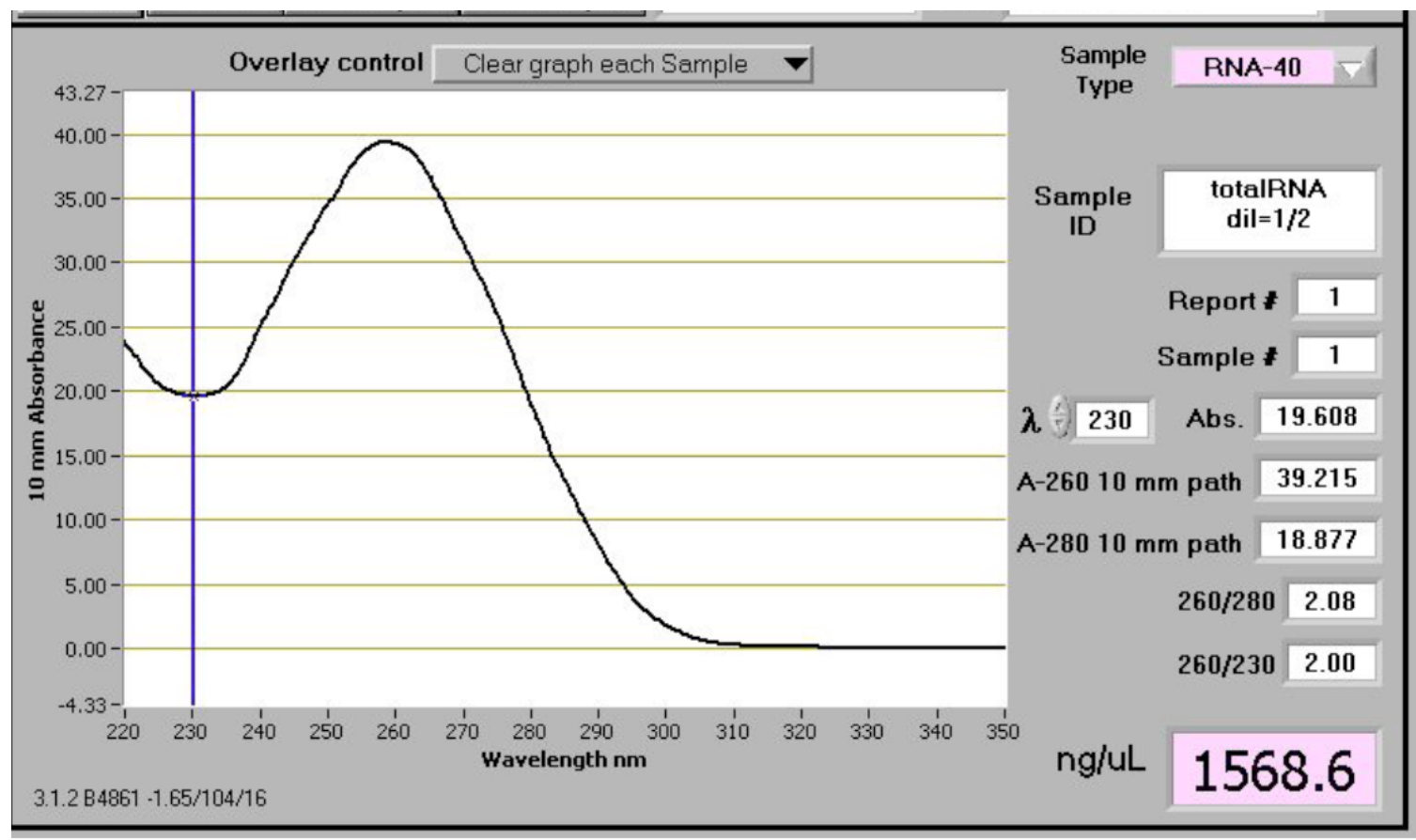

Fig. 8. Nanodrop results of total RNA isolated diluted 1:2.

Agarose gel electrophoresis of the sample confirmed the RNA was intact (gel results not shown), and the total RNA was then used for RT-PCR as described below. 


\subsection{RT-PCR RESULTS}

In order to create 199 bp DNA and RNA probe, RT-PCR was performed on total RNA extracted from chick embryos. A $1 \%$ agarose gel was run to check for the RT-PCR product (Fig. 9). The agarose gel results confirm the presence of about $200 \mathrm{bp}$ long desired amplified DNA.

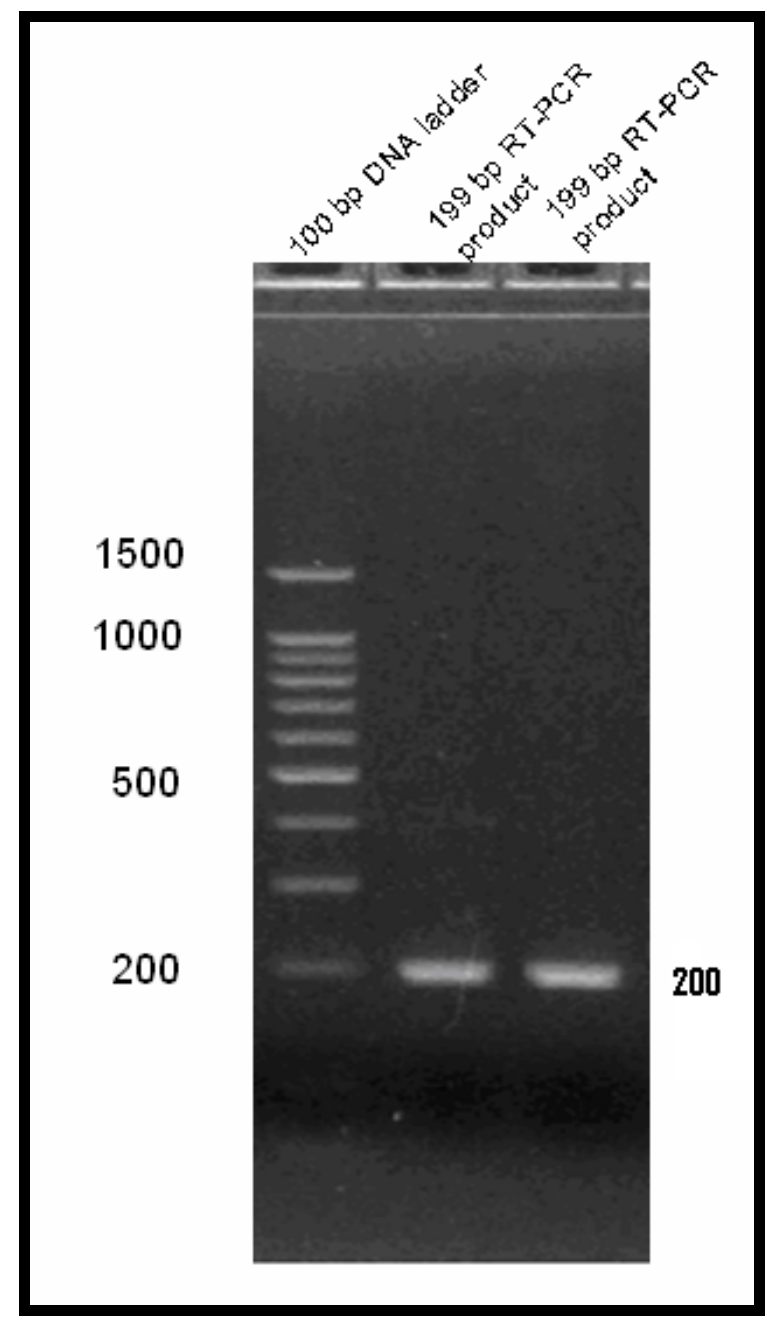

Fig. 9. 1\% agarose E gel to confirm the 199 base pair amplified region by RT-PCR. Lane 1: 100 bp DNA ladder, Lane 2, 3: RT-PCR product. 


\subsection{Probe Construction}

During the construction of our probe we performed Multiple Sequence Alignment for some members of $T b x$ family and found them to be very similar suggesting homology (Fig. 10). The asterisk sign represents the identical bases among $T b x$ 2, 3, 4, 5, and 20. Multiple sequence alignment results below show significant sequence similarity among the Tbx family members. It is also interesting to note that at many base positions 3 or 4 bases are identical. Thus it is essential to identify region of Tbx 5 which doesn't share significant sequence similarity with other family members in order for the probe to be Tbx 5 specific rather than $T b x$ family specific. 


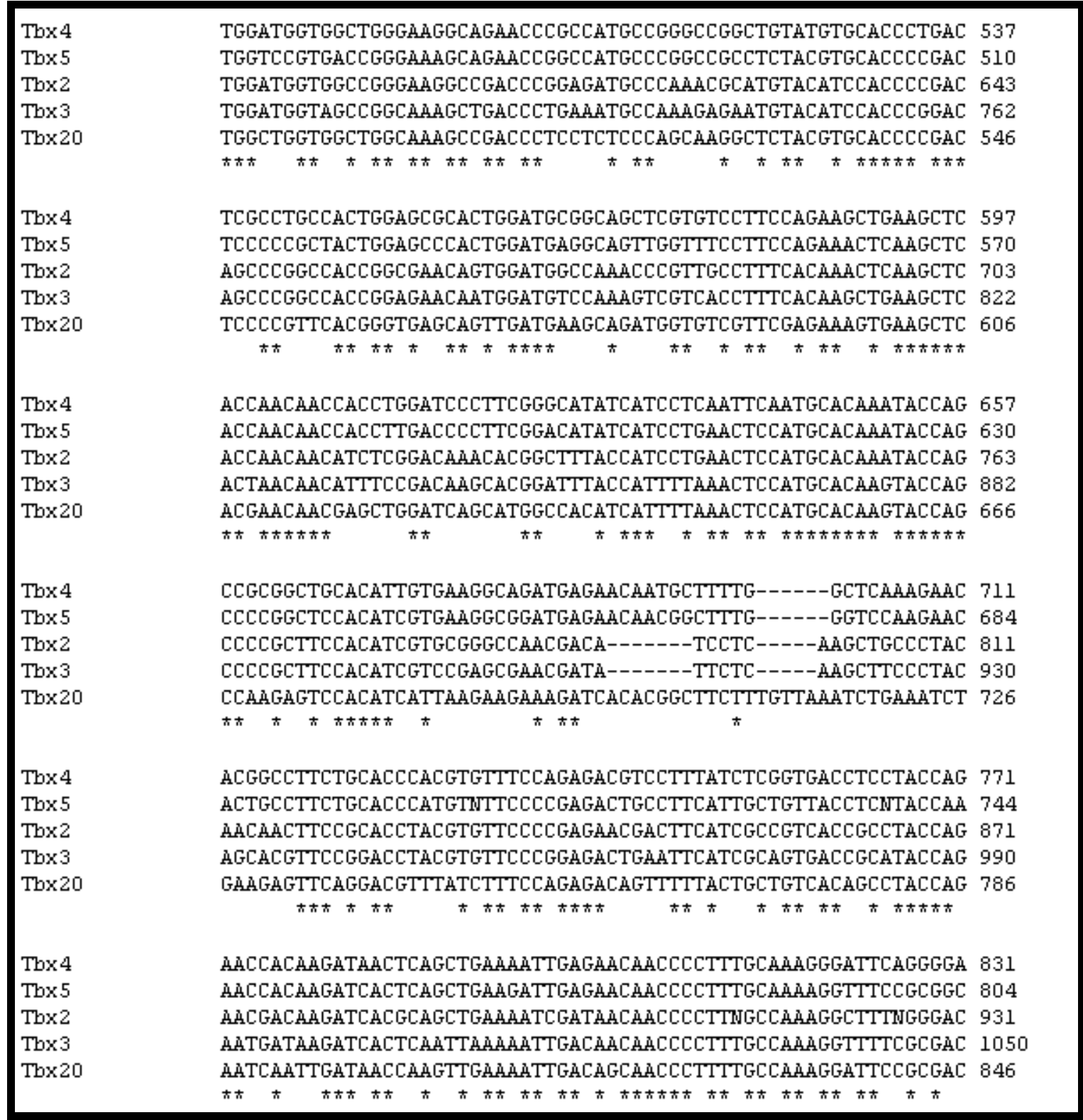

Fig. 10. Results of Multiple Sequence Alignment of $T b x 2, T b x 3, T b x 4$, $T b x 5$ and $T b x$ 20 showing sequence similarity among the $T b x$ family members. 
Since we wanted our probe to be specific to Tbx 5 and not target other members of the $T b x$ family, we designed our probe by identifying regions of $T b x 5$ sequence which depicted least similarity to other members of the $T b x$ family. That area of least similarity (Fig. 11) is highly unlikely to cross hybridize with other Tbx family members and give false signal for $T b x$ 5. This region was used to design the probe using Primer 3 and free software available at IDT website.

Tbx2
Tbx3
Tbx20
Tbx4
Tbx5
Tbx2
Tbx3
Tbx 20
Tbx4
Tbx5

Tbx 2
Tbx 3
Tbx20
Tbx 4
Tbx 5

Tbx 2
Tbx 3
Tbx 20
Tbx 4
Tbx 5
Tbx 2
Tbx 3
Tbx 20
Tbx 5

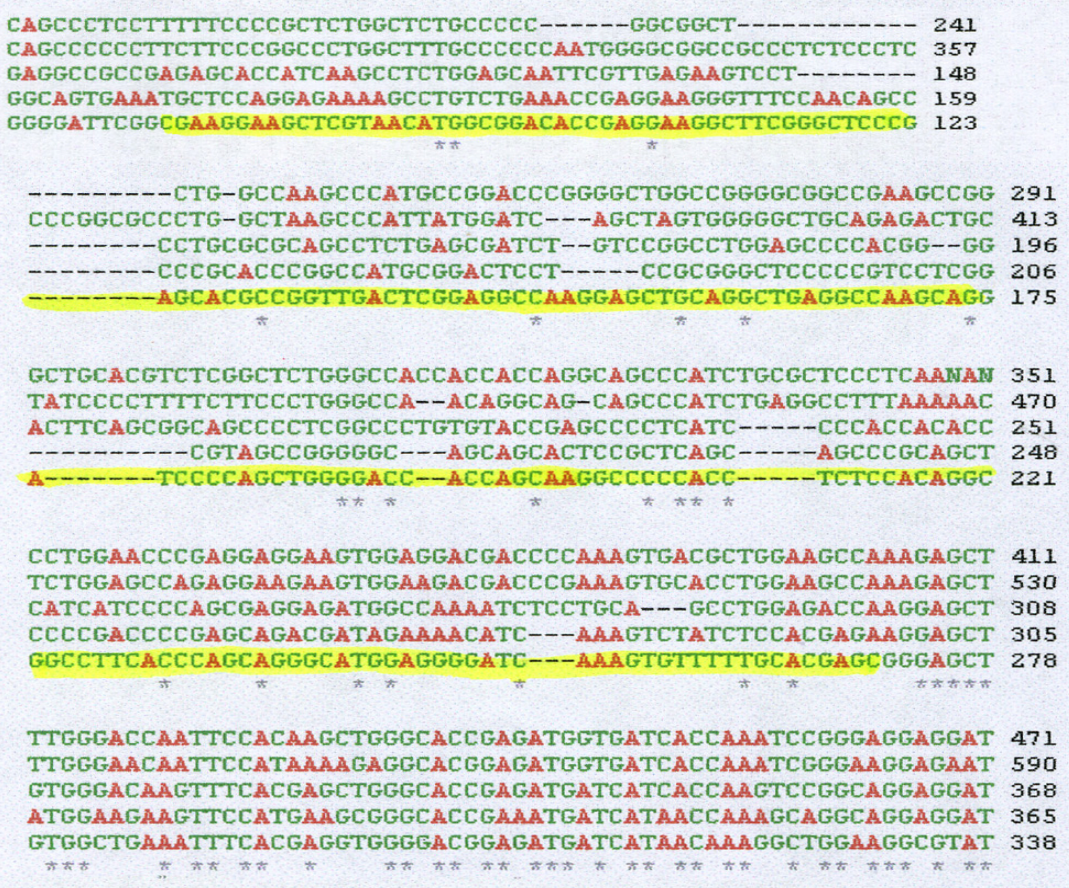

Fig.11. Depiction of unconserved region of $T b x 5$ used to create the probe. Yellow highlighted region of $T b x 5$ depicts poorly conserved region amongst the $T b x$ family members and was used for designing probe specific to $T b x 5$.

\subsection{Sequencing Results}

A $1 \%$ agarose gel electrophoresis confirmed the RT-PCR product was of the expected length of about $200 \mathrm{bp}$. After the RT-PCR product was purified, it was ligated 
in pGEM -T Easy vector. The following are the sequencing results (Fig. 12). The blue colored area indicates the 3' readable part of the $\mathrm{T} 7$ Promoter. Red colored area indicates the target 199 base pair region. Underlined red area indicates forward and reverse primers used to amplify the region.

NNNNTNNTAGGGCGATTGGGCCCGACGTCGCATGCTCCCGGCCGCCATGGC
GGCCGCGGGAATCGATTGGAAGGAGCTCGTAACATGGCGGACACCGAG
GAAGGCTTGGGCTCCCGAGCACGCCGGTTGACTCGGAGGCCAAGGAGCTGC
AGGCTGAGGCCAAGCAGGATCCCCAGCTGGGGACCACCAGCAAGGCCCCCA
CCTCTCCACAGGCGGCCTTCACCCAGCAGGGCATGGAGGGGATCAAAGTGTT
TTTGCACGAGCGGGAGCTGTGGCTGAAATTCACGAGGTGGGGACGGAGATG
ATCATAACAAAGGCTGGAAGGCGTATGTTCCCAGTTACAAAGTGAAGGTCA
CTGGACTCAATCCAAAAACGAAGTACATACTGTTGATGGATATTGTACCAGC
GGATGACCACAGATACAAATTGCAGATAATAAATGGTCCGTGACCGGGAAG
GCAGAACCGGCCATGCCCGGCCGCCTCTACGTGCACCCCGACTCCCCCGCTA
CTGGAGCCCACTGGATGAGGCAGTTGGTTCCTTCCAGAAGCTCAAGCTCAC
CAACAACCACCTTACCCCTTCGACATATCATCCTGAACTCCATGCACAAAT
ACCAGCCCCGGCTCCACATCGTGAAGGCGGATGAGAACAACGGCTTTGGCTC
CAAGAACACTGCCTTCTGCACCCATGTCTTCCCCGAGACTGCCTCATCGCTG
TTACCTCCAATCACTAGTGAATTCGGGCCGCCTGCANGTCGACCATATGGG
AGAGCTCCCAACGCGTTGGATGCATAGCTTGAGTATTCTATAGTGTCACCTAA
ATAGCTTGCGTANCATGGNCATAGCTGTTCCTGTGTGAATTGTATCCGCTCA
CATTCCACACACATACGAGCCGGAGCATAAGTGTANNCTNNNNCCTANGAGT
GAGCTACTCACATTNNNCNTGCGCTCACTNNCNGCTTTCNNNCNGNNNAANN
GTCCNNCNNN

Fig.12. Sequencing results of pGEM T Easy vector containing 199 base pair Tbx 5 region.

In order to double check if the 199 base pair amplified region belonged to $T b x 5$ of chicken, a BLAST search was performed against the NCBI database. The results (Fig. 13) shown below depict $100 \%$ sequence identity, thus suitable as a probe for in situ hybridization. 


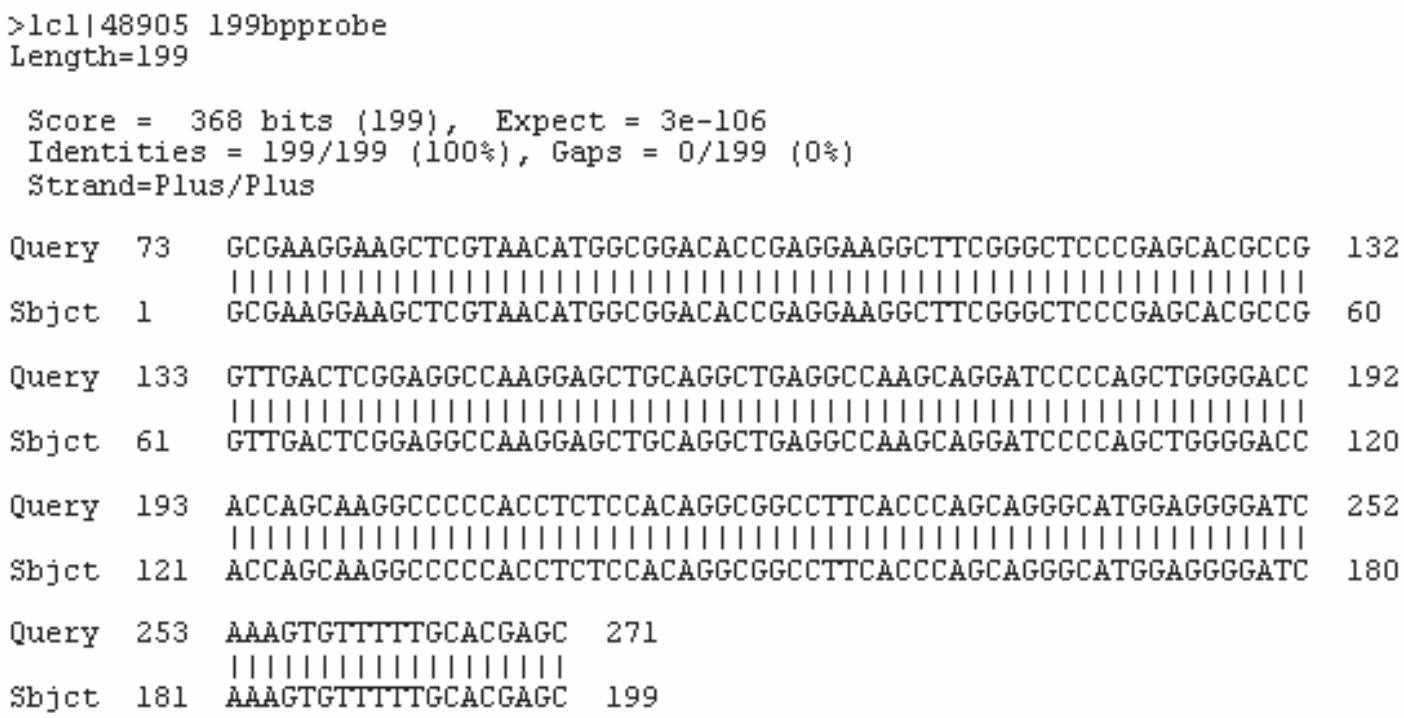

Fig.13. BLAST results confirming the identity of 199 base pair long probe.

Below are the sequencing results of pGEM -T Easy vector containing the $665 \mathrm{bp}$ Tbx 5 probe (Fig. 14), the blue colored area indicates the 3'readable part of the T7 promoter. The red colored area indicates the desired 665 bp Tbx 5 region. The red underline region denotes the forward and the reverse primers used to amplify the region. 


NGNNNNANTNNATAGGGCGATGGGCCCGACGTCGCATGCTCCCGGCCG
CCATGGCGGCCGCGGGAATCGATTGCGAAGAAGCTCGTAACATGGGGAC
ACCGAGGAAGGCTTCGGGCTCCCGAGCACGCCGGTTGACTCGGAGGCCAAG
GAGCTGCAGGCTGAGGCCAAGCAGGATCCCCAGCTGGGGACCACCAGCAAG
GCCCCCACCTCTCCACAGGCGGCCTTCACCCAGCAGGGCATGGAGGGGATCA
AAGTGTTTTGCACGAGCGGGAGCTGTGGCTGAAATTCACGAGGTGGGGAC
GGAGATGATCATAACAAAGGCTGGAAGGCGTATGTTTCCAGTTACAAAGTG
AAGGTCACTGGACTCAATCCAAAAACGAAGTACATACTGTTGATGGATATTG
TACCAGCGGATGACCACAGATACAAATTGCAGATAATAAATGGTCGTGAC
CGGGAAGGCAGAACCGGCCATGCCCGGCCGCCTCTACGTGCACCCCGACTCC
CCCGCTACTGGAGCCCACTGGATGAGGCAGTTGGTTTCCTTCAGAAGCTCA
AGCTCACCAACAACCACCTTGACCCCTCGGACATATCATCCTGAACTCCATG
CACAAATACCAGCCCCGGCTCCACATCGTGAAGGCGGATGAGAACAACGGCT
TTGGCTCCAAGAACACTGCCTTCTGCACCCATGTCTTCCCCGAGACTGCCTTC
ATCGCTGTTACCTCCAATCACTAGTGAATTCGCGGCCGCCTGCAGGTCGACCA
TATGGGAGAGCTCCCAACGCGTTGGATGCATAGCTTGAGTATTCTATAGTGTC
ACCTAAATAGCTTGNGTAATCATGGTCATAGCTGTTCCTGTGGAAATTTT
ATCCGCTCACAATTCCACACAACATACGAGCCGGAAGCATAAAGTGTAAAN
NNGGGGNGCCTAATGAGTGANCTACTCACANNNGCNNGCGCTCANTNNNGC
TTTNNNNGGGNN

Fig.14. Sequencing results of pGEM- T Easy vector containing 665 bp $T b x 5$ region. Blue region indicates T7 Promoter, green region indicates the beginning of pGEM-T Easy vector, red area indicates the desired probe region and the underlined red colored area indicates the primers used to amplify the probe.

The pGEM- T Easy plasmid sequence containing 665 bp Tbx 5 region was compared with chicken Tbx 5 mRNA retrieved from NCBI website using a BLAST search (Fig. 15). The results show that the two sequences are identical in overlapping regions i.e., $100 \%$ similarity indicating it to be suitable as a probe for in situ hybridization. 


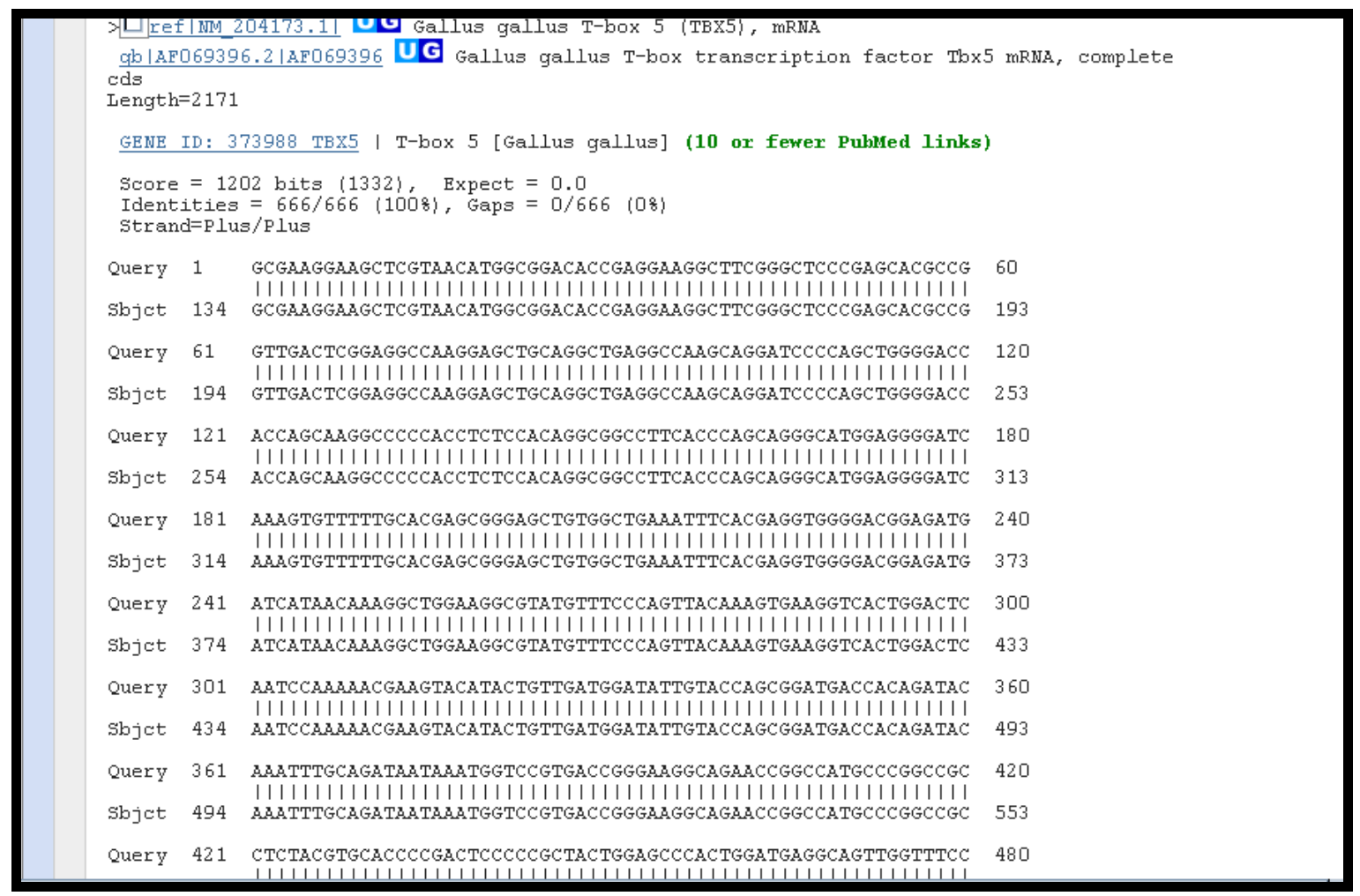

Fig.15. BLAST results confirming the 665 bp probe identity to be identical to Tbx 5 .

\subsection{Results of PCR}

After the confirmation of the sequence identity, PCR amplification was done with

Tbx 5 specific primers (Fig.16). In order to trouble shoot for our low yield during in vitro transcription we designed PCR primers with 5' overhang of T7 promoter. 


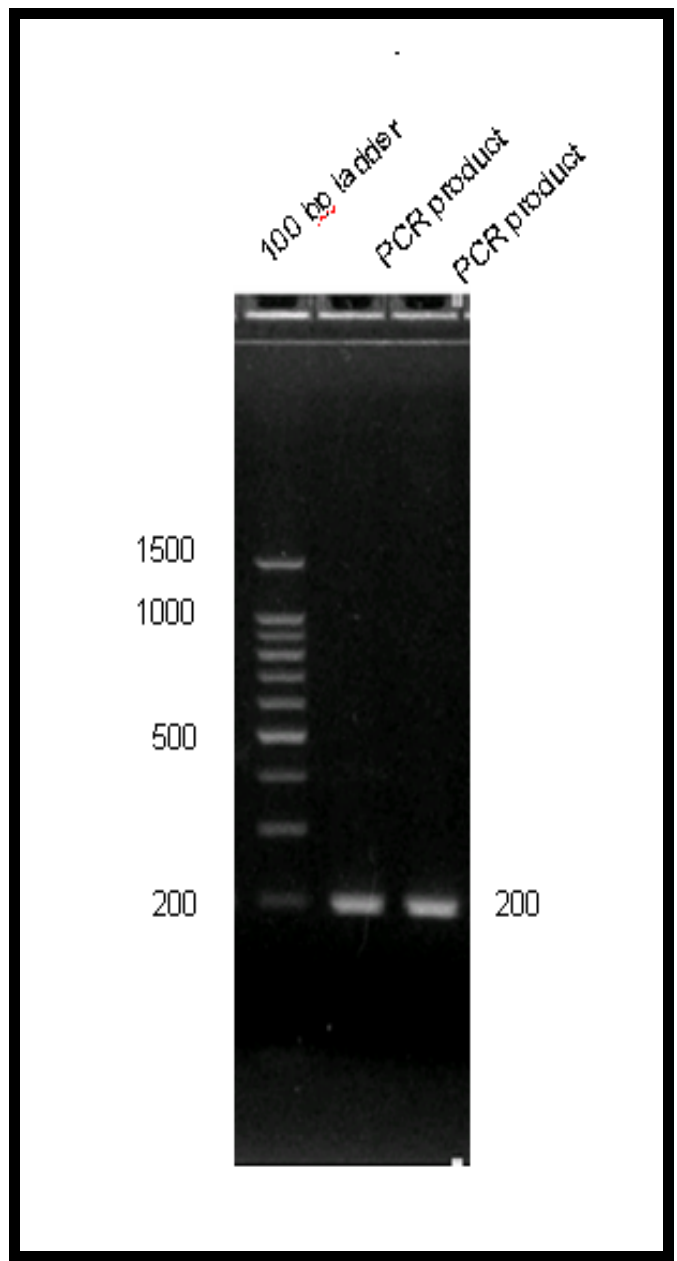

Fig. $16(\mathrm{~A})$

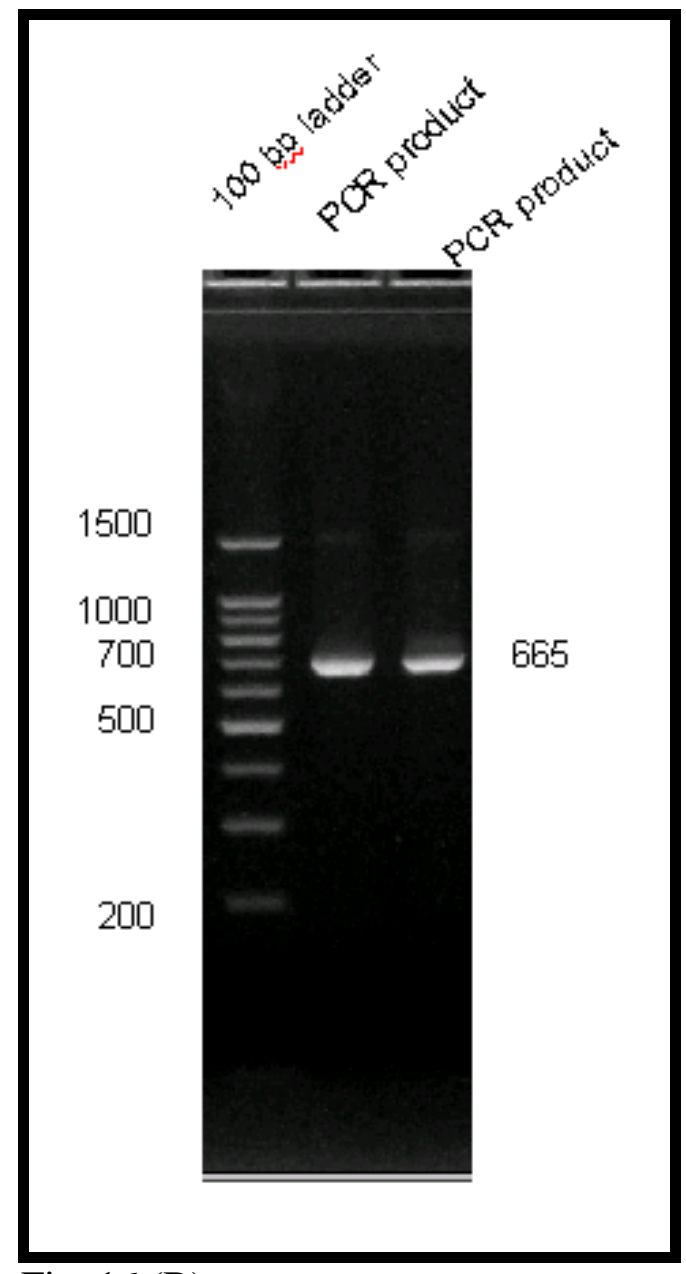

Fig. 16 (B)

Fig. 16 (A). Results of PCR product for 199 bp probe. Fig. 16 (B).Results of PCR amplification for $665 \mathrm{bp}$ probe.

\subsection{Double Restriction Digest Results}

A pBluescript vector containing 1400 bp long Tbx 5 insert was supplied by Dr.

White. We performed a double digest on the vector using Not1 and EcoR1 enzymes.

Results of the double enzyme digest were analyzed on a 1\% agarose gel (Fig.17). 


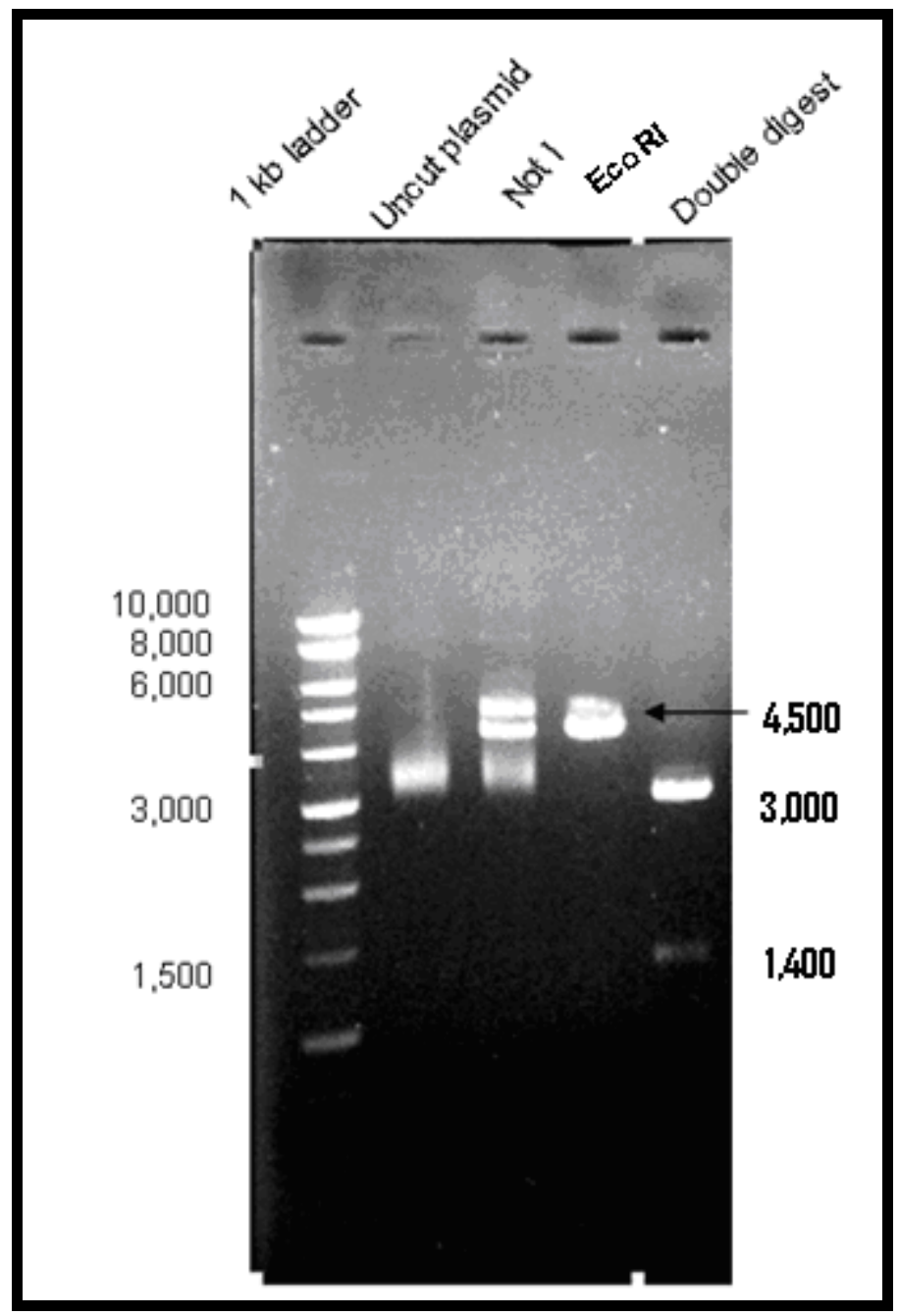

Fig.17. Results of double restriction digest of plasmid pBluescript containing Tbx 5 insert. Lane 1: Promega's1 Kb DNA ladder, Lane 2: uncut pBluescript vector containing Tbx 5 insert. Lane 3: a mixture of uncut, linearized and nicked pBluescript vector containing Tbx 5 insert following incubation with Not1. Lane 4: a mixture of nicked and linearized pBluescript vector containing Tbx 5 insert following incubation with EcoRl. Lane 5: Not 1 and EcoRl double digest showing empty, linearized pBluescript vector and free $T b x 5$ insert.

For our purpose lane 3 and 4 are irrelevant (Lane 3 shows three bands indicating incomplete digestion by enzyme NotI which might be due to the shelf life of the enzyme. 
The upper band represents uncut DNA, second band indicates potentially linearized DNA and the third band is the nicked DNA). The Not1/EcoRI double digest in lane 5 shows two bands, one around the size of $3000 \mathrm{bp}$ and other around the size of $1400 \mathrm{bp}$. The upper band indicates the empty pBluescript vector and the lower band indicates the 1400 bp Tbx 5 insert.

\subsection{Results of Dig Labeling Efficiency}

We performed a Dig Labeling efficiency dot blot assay to confirm the digoxygenin labeling on a nylon membrane. 1:10 dilution series was plotted on the nylon membrane starting with $6.95 \mathrm{ng}$ of DNA. We found out that we were able to detect down to a concentration of $6.95 \mathrm{pg}$ of probe DNA (Fig. 18).

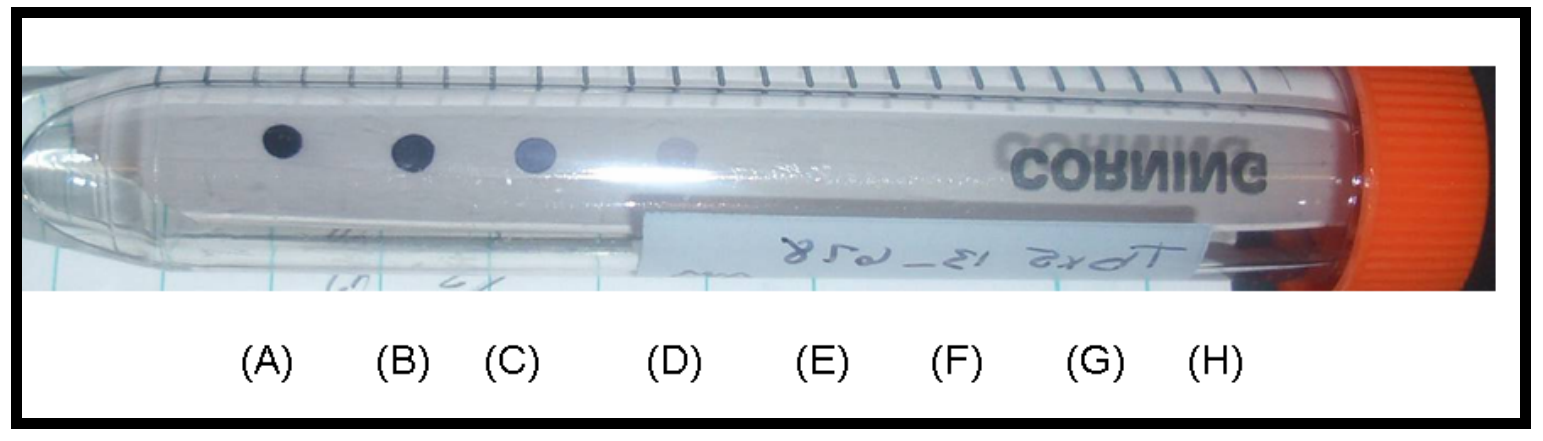

Fig.18. Results of Dot Blot Assay to check for the labeling efficiency. (A): $6.95 \mathrm{ng}$ of DNA, (B): $0.695 \mathrm{ng}$ of DNA, (C): $0.695 \mathrm{pg}$ of DNA, (D): $6.95 \mathrm{pg}$ of DNA, (E) : > $6.95 \mathrm{pg}$ of DNA, $(\mathrm{F}):>6.95 \mathrm{pg}$ of DNA, $(\mathrm{G})>6.95 \mathrm{pg}$ of DNA and $(\mathrm{H}) \mathrm{TE}$. 


\subsection{In Vitro Transcription Results}

To generate anti-sense riboprobes, we first created T7-ended 665 and 199 base pair Tbx 5 templates by appending a T7 promoter to the reverse primers. Following PCR amplification with these modified primers we were able to isolate templates suitable for the generation of 199 and 665 base long anti- sense RNAs. Each template was then used in an in vitro transcription reaction employing DIG-labeled UTP, allowing the production of DIG- labeled antisense RNA for use in the in situ hybridization experiments.

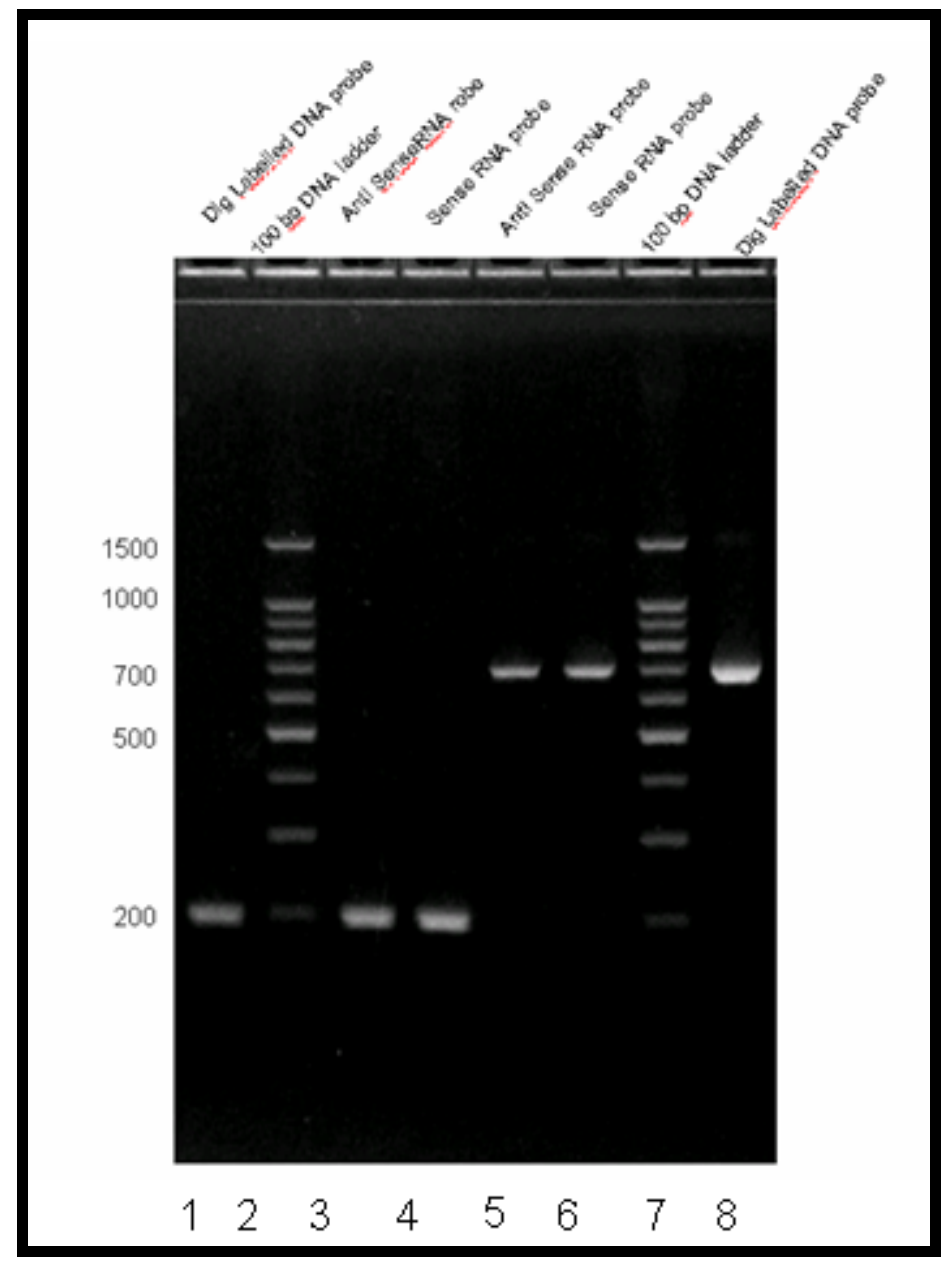


Fig. 19. Results of $2 \%$ agarose gel electrophoresis to confirm the size of Dig labeled DNA and RNA probes. Lane 1: Dig labeled $199 \mathrm{bp}$ DNA probe. Lane 2: $100 \mathrm{bp}$ Invitrogen DNA ladder. Lane 3: 199 bp Dig labeled RNA sense probe and Lane 4: 199 bp Dig labeled RNA anti sense probe. Lane 5: 665 bp Dig labeled RNA sense probe. Lane 6: 665 bp Dig labeled RNA anti sense probe, Lane 7: 100 bp Invitrogen DNA ladder and Lane 8: 665 bp Dig labeled DNA probe.

\subsection{Whole Mount In Situ Hybridization Results}

Whole mount in situ hybridization using Tbx 5 specific probes was performed using the techniques described in the Methods sections. No hybridization was observed in the control tissue with no probe (Fig. 20) and the control tissue probed with sense RNA (Fig. 21). Distinct and definitive signal was observed in the experimental tissues probed with Tbx 5 specific probes (Fig. 22 - Fig. 33).
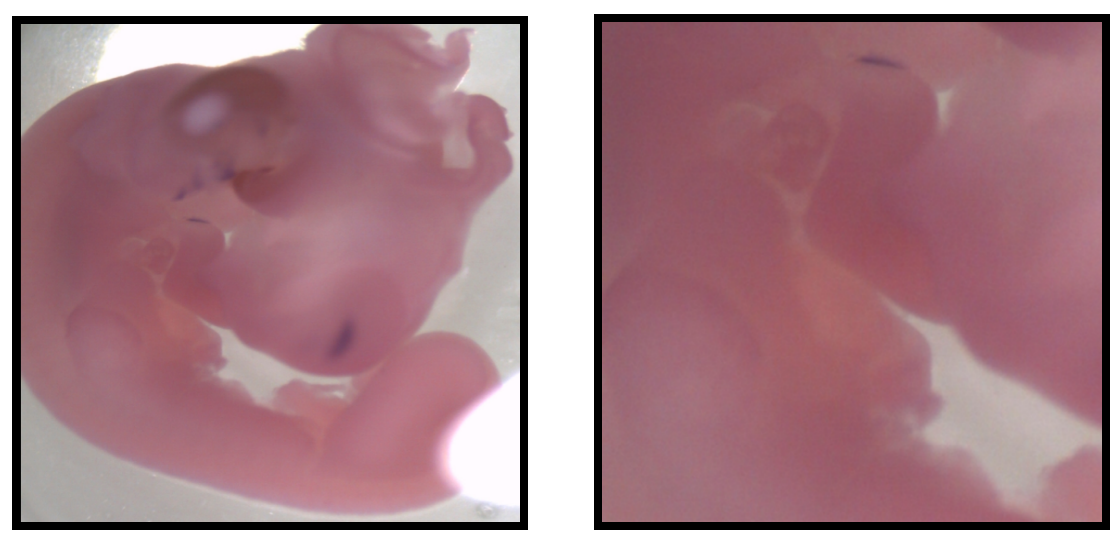

Fig. 20 (A) \& (B). Negative experimental control with no probe for whole mount in situ hybrdization for Tbx 5. (A). Experimental Control (No probe). (B). Magnified portion of Fig. 20 (A) Control (No probe).

As shown in Fig. 20, the chick embryo is at developmental stage $\mathrm{HH} 22-23$ and is experimental control with no probe. Lack of any signal denotes no hybridization. 

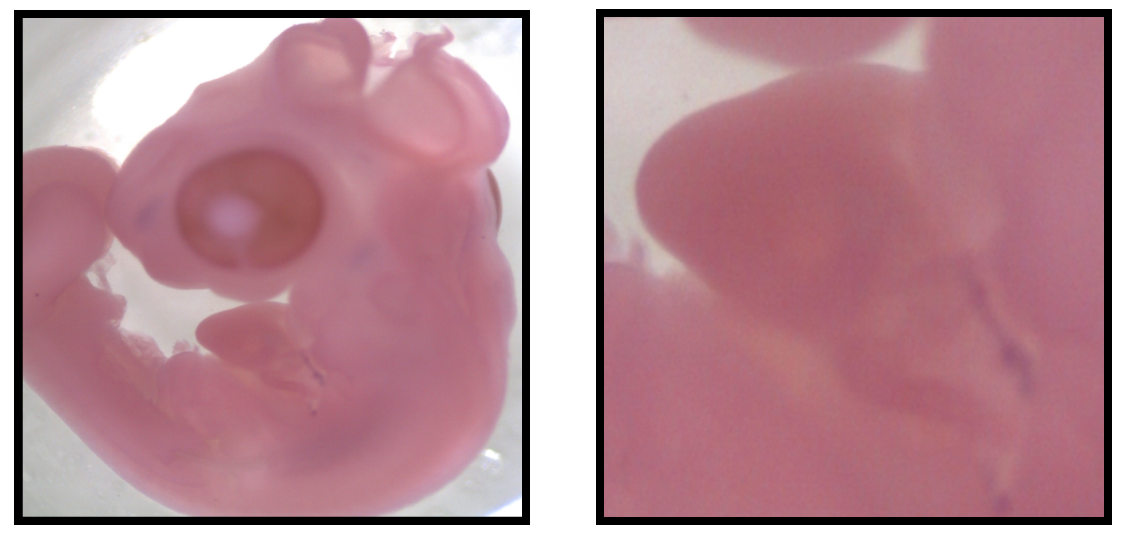

Fig. 21 (A). Negative control (Sense probe at $200 \mathrm{ng} / \mathrm{ml}$ ) for whole mount in situ hybridization. Fig.21 (B) is a magnified version of negative control, sense probe.

Fig. 21 exhibits chick embryo at developmental stage $\mathrm{HH} 22-23$. It is negative experimental control, probed with $T b x 5$ sense probe. It shows no signal depicting lack of non specific binding and background. Lack of signal in the control tissue also denotes the specificity of the anti-DIG antibody.
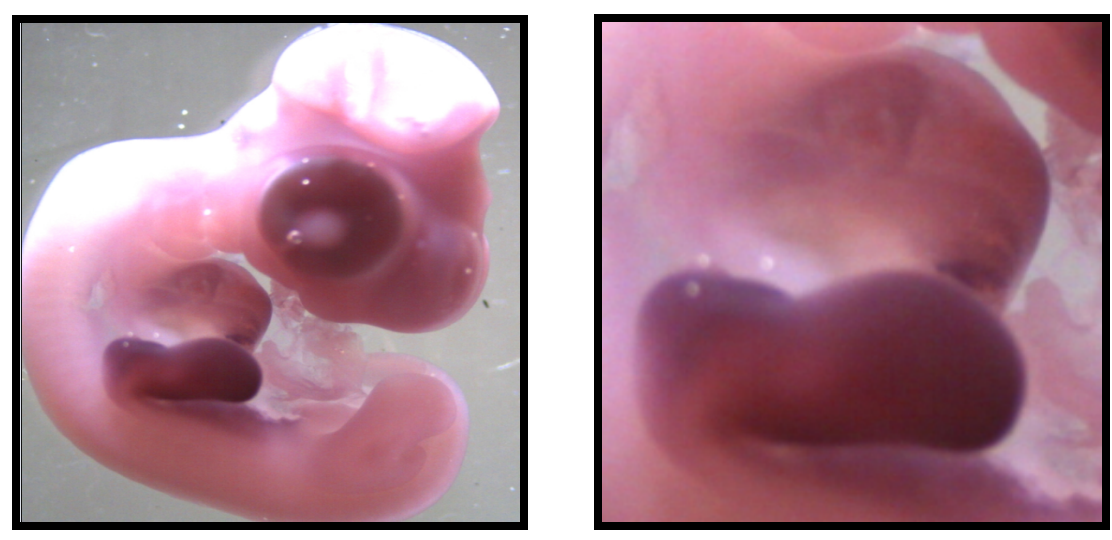

Fig. 22. Whole mount in situ hybridization of chick embryo using 199 bp RNA probe for Tbx 5 at $200 \mathrm{ng} / \mathrm{ml}$. (A). RNA $199 \mathrm{bp}$ probe (antisense probe at $200 \mathrm{ng} / \mathrm{ml}$ ). (B). Magnified portion of Fig. 22 (A). 
Fig. 22 (A) is stage HH 23-25 embryo probed with Tbx 5 at $200 \mathrm{ng} / \mathrm{ml}$, signal can be seen in atrioventricular canal and left ventricle. Fig. 22 (B) is a magnified version of Fig. 22 (A).
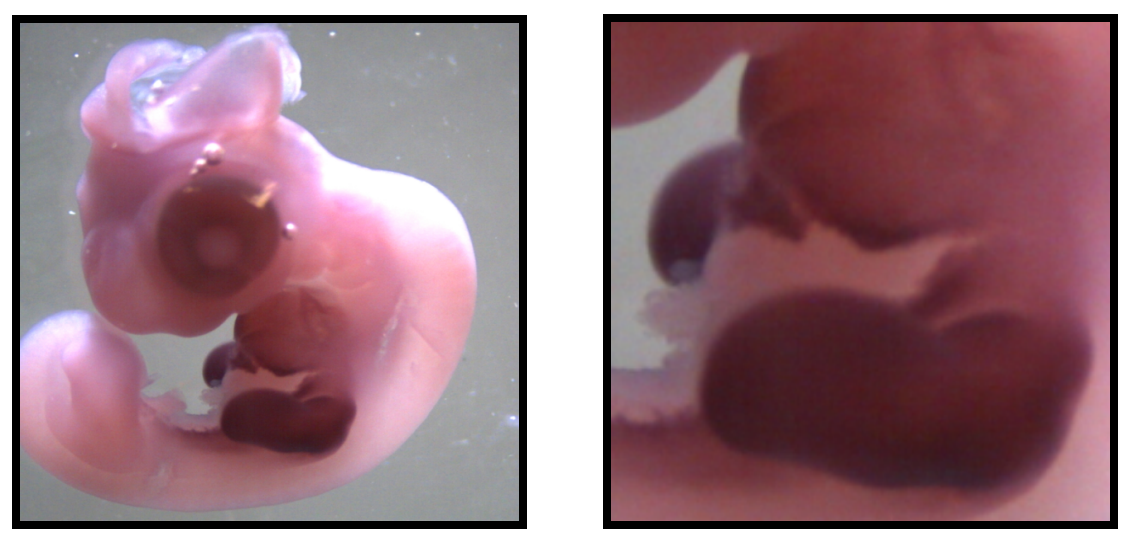

Fig. 23. Whole mount in situ hybridization of chick embryo using 199 bp RNA probe for Tbx 5 at $750 \mathrm{ng} / \mathrm{ml}$. (A). RNA 199 bp probe (antisense probe at $750 \mathrm{ng} / \mathrm{ml}$. (B). Magnified portion of Fig. 23 (A).

As shown in Fig. 23 (A), chick embryo is at developmental stage HH 24 and is probed at $750 \mathrm{ng} / \mathrm{ml}$. In the chick embryo strong signal can be seen in the atria, atrioventricular canal, the left ventricle, the retinal region, and the forelimb buds.
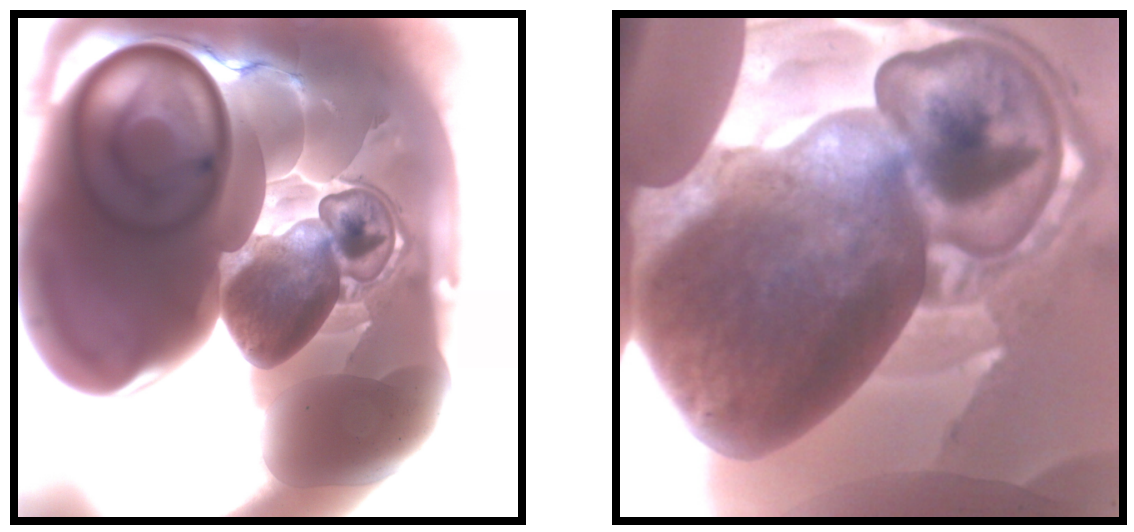

Fig. 24. Whole mount in situ hybridization of chick embryo using 199 bp RNA probe for Tbx 5 at $1000 \mathrm{ng} / \mathrm{ml}$. Fig. 24 (A). RNA 199 bp probe (antisense probe at $1000 \mathrm{ng} / \mathrm{ml}$ ) (B). Magnified portion of Fig. 24 (A) (antisense probe at $1000 \mathrm{ng} / \mathrm{ml}$ ). 
Fig. 24 (A) is HH 24-25 staged chick embryo probed with $T b x 5$ at $1000 \mathrm{ng} / \mathrm{ml}$. Definitive signal can be seen in the atria, the ventricle, retinal regions of the eye, and the developing forelimb buds. Note the outflow tract of the embryo is ripped. Fig. 24 (B) is a magnified version of Fig. 24 (A).
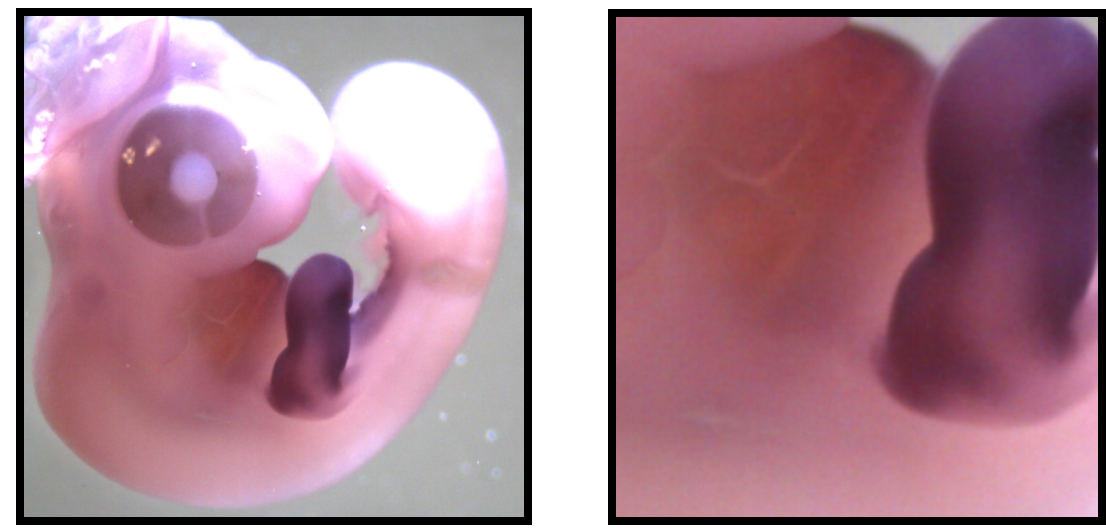

Fig. 25. Whole mount in situ hybridization of chick embryos with Tbx 5665 bp RNA probe at $200 \mathrm{ng} / \mathrm{ml}$. RNA $665 \mathrm{bp}$ probe (antisense probe at $200 \mathrm{ng} / \mathrm{ml}$. (B). Magnified portion of Fig. 25 (A).

As shown in Fig. 25, chick embryo is at developmental stage HH 19-20 exhibiting signal in atria, atrioventricular canal, the left ventricle, forelimb buds, and the retina.
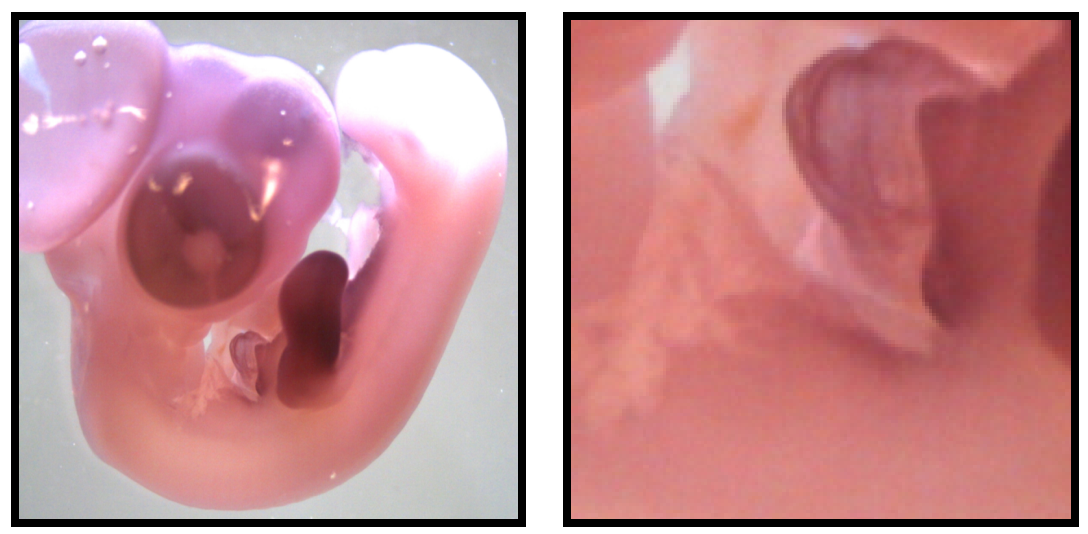

Fig. 26. Whole mount in situ hybridization of chick embryos with $T b x 5665 \mathrm{bp}$ RNAprobe at $750 \mathrm{ng} / \mathrm{ml}$. (A). RNA $665 \mathrm{bp}$ probe (antisense probe at $750 \mathrm{ng} / \mathrm{ml}$ ). (B). Magnified portion of Fig. 26 (A). 
Fig. 26 depicts a chick embryo at developmental stage HH 25-26, where signal can be seen in the atria and the apex of the left ventricle along with strong $T b x 5$ expression in the forelimb buds and the retina.
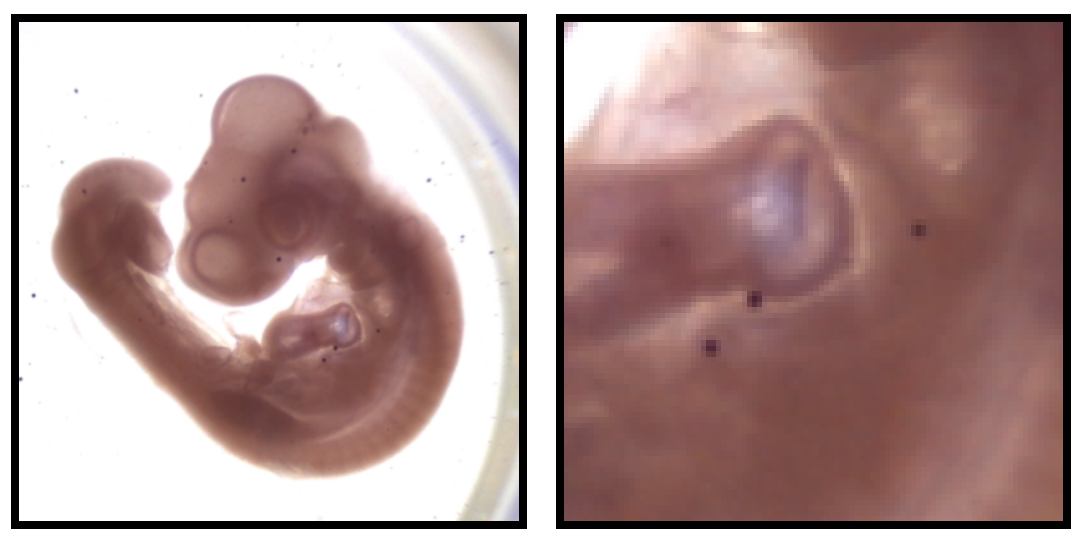

Fig. 27. Whole mount in situ hybridization of chick embryos with Tbx 5665 bp RNA probe at $1000 \mathrm{ng} / \mathrm{ml}$. Fig. 27 (A). RNA 665 bp probe (antisense probe at $1000 \mathrm{ng} / \mathrm{ml}$ ) (B). Magnified portion of Fig. 27 (A) (antisense probe at $1000 \mathrm{ng} / \mathrm{ml}$ ).

In Fig. 27, embryo is at the developmental stage HH 18-19. Clear signal can be seen in the atrial region of the heart along with the retinal region and the developing forelimb buds.
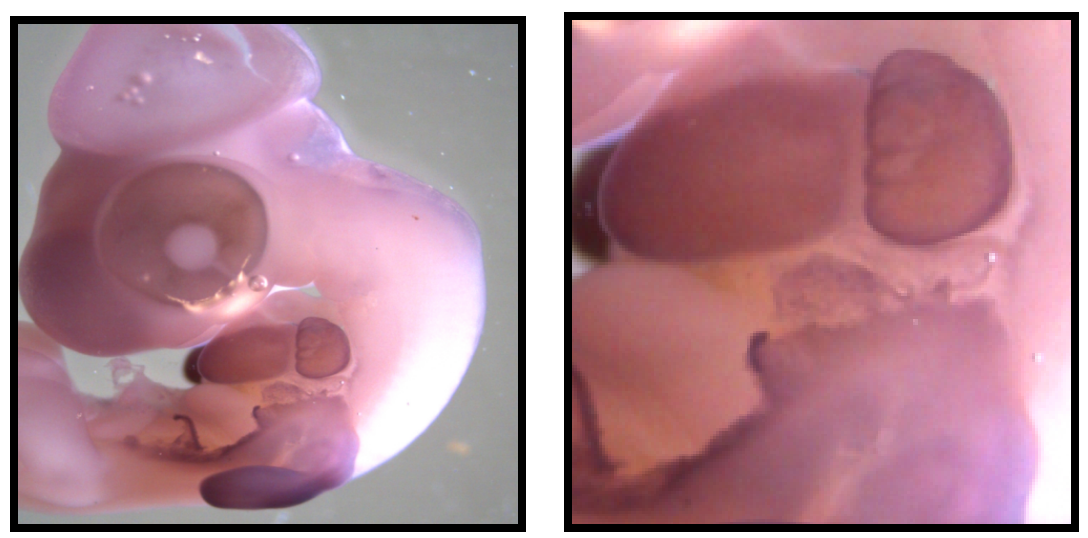

Fig. 28. Whole mount in situ hybridization of chick embryos probed with 199 bp DNA probe at $200 \mathrm{ng} / \mathrm{ml}$. Fig. 28 (A). DNA $199 \mathrm{bp}$ probe (Probe at $200 \mathrm{ng} / \mathrm{ml}$ ). (Probe at 200 $\mathrm{ng} / \mathrm{ml}$ ) (Probe at $200 \mathrm{ng} / \mathrm{ml}$ ). 

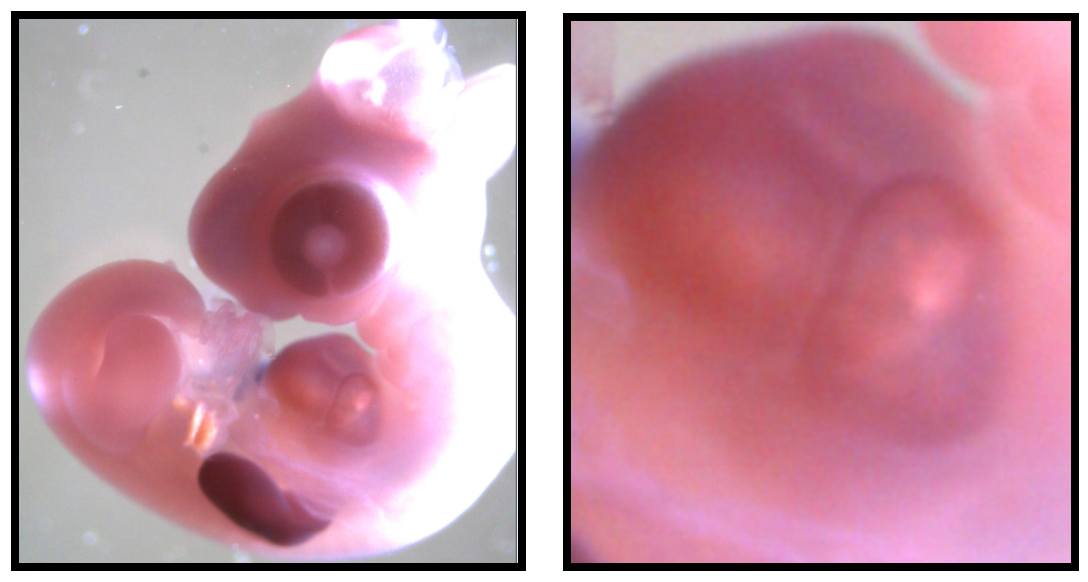

Fig. 29. Chick embryos probed with $199 \mathrm{bp}$ DNA probe at $750 \mathrm{ng} / \mathrm{ml}$ for whole mount in situ hybridization of Tbx 5. Fig. 29 (A). DNA 199 bp probe (Probe at $750 \mathrm{ng} / \mathrm{ml}$ ). (B). Magnified portion of Fig. 29 (A) (Probe at $750 \mathrm{ng} / \mathrm{ml}$ ).
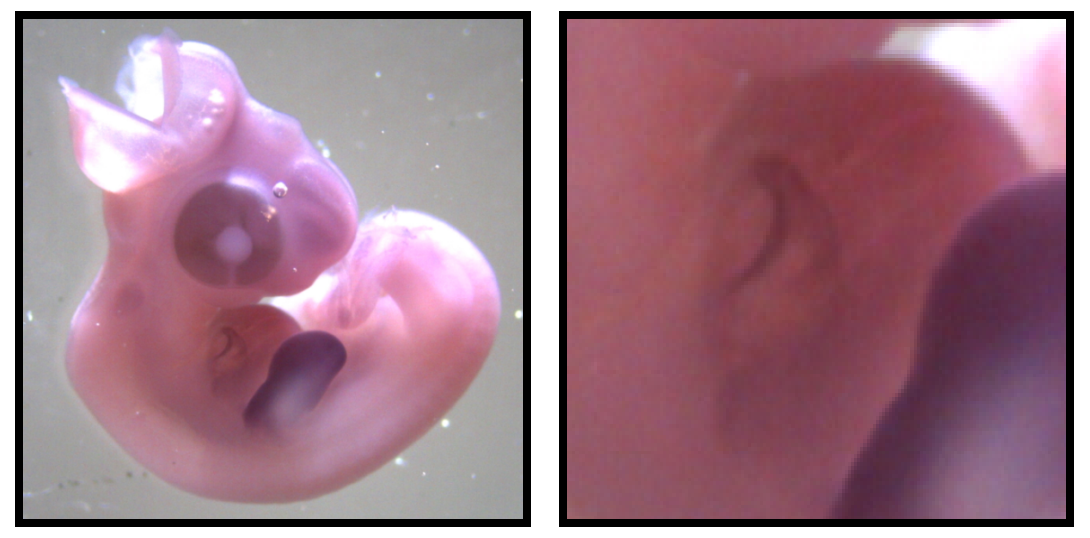

Fig. 30. Whole mount in situ hybridization of chick embryos using 665 bp DNA probe for $T b x 5$ at $200 \mathrm{ng} / \mathrm{ml}$. Fig. 30 (A). DNA 665 bp probe (antisense probe at $200 \mathrm{ng} / \mathrm{ml}$ ) (B). Magnified portion of Fig. 30 (A) (antisense probe at $200 \mathrm{ng} / \mathrm{ml}$ ).

As shown in Fig. 30, chick embryos at stage HH 21-22 exhibit staining in the ventricular region of the heart, along with strong staining in the forelimbs and relatively weaker staining in the retina. It is to be noted that the outflow tract is broken. 

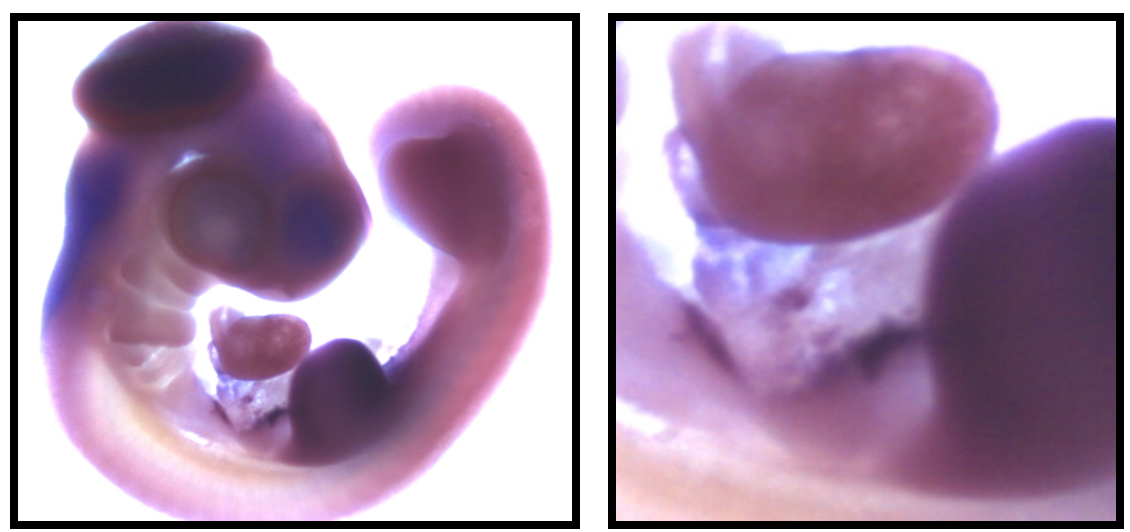

Fig. 31: Whole mount in situ hybridization of chick embryos probed with Tbx 5665 bp DNA probe at $750 \mathrm{ng} / \mathrm{ml}$. Fig. 31 (A). DNA 665 bp probe (antisense probe at 750 $\mathrm{ng} / \mathrm{ml}$ ). (B). Magnified portion of Fig. 31 (A) (antisense probe at $750 \mathrm{ng} / \mathrm{ml}$ ).

As shown in Fig. 31, chick embryo is at stage HH 20-21. Chick embryo exhibits no staining in the outflow tract, but signal can be seen in the left atria, left ventricle and the atrioventricular region. Also strong signal is seen in the forelimb buds and the retina of the eye.
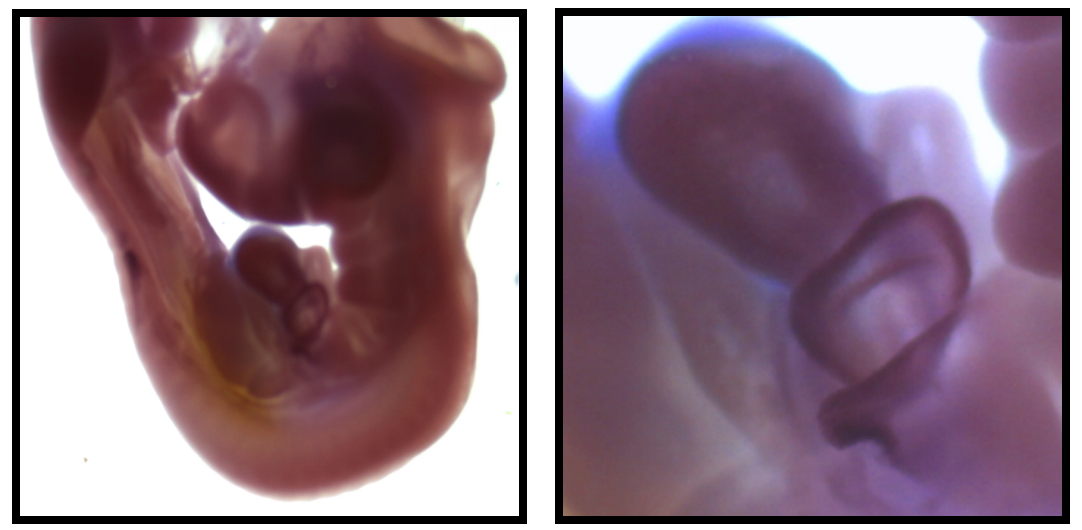

Fig. 32. Chick embryos probed with Tbx 5665 bp DNA probe at 1000 $\mathrm{ng} / \mathrm{ml}$ whole mount in situ hybridization. Fig.32 (A). DNA 665 bp probe (antisense probe at $1000 \mathrm{ng} / \mathrm{ml}$ ). (B). Magnified portion of Fig. 32 (A) (antisense probe at $1000 \mathrm{ng} / \mathrm{ml}$ ). 

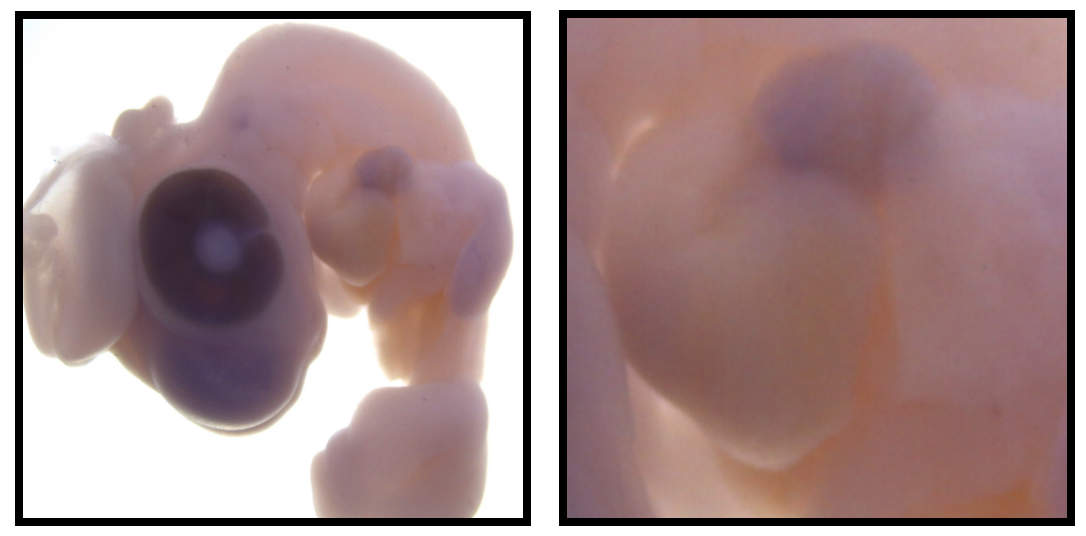

Fig. 33. Images of embryo stored in methanol for a month and probed with $199 \mathrm{bp}$ DNA at $750 \mathrm{ng} / \mathrm{ml}$. Fig. 33 (A). Embryo stored in methanol for a month (DNA $199 \mathrm{bp}$ probe at $750 \mathrm{ng} / \mathrm{ml}$ ). (B). Magnified portion of Fig. 33(A) (DNA $199 \mathrm{bp}$ probe at $750 \mathrm{ng} / \mathrm{ml})$.

As shown in Fig. 33, the chick embryo is at the developmental stage $\mathrm{HH}$ 23-24. The embryo has been stored in methanol for a month. Hardening of the tissue has been observed in embryos stored in methanol for a month. Signal can be seen in the atrial region of the heart, retinal region of the eye, and the developing forelimb buds. 


\section{4- DISCUSSION}

Tbx family members are transcription factors defined by the presence of a highly conserved sequence called the T-domain, involved in DNA binding and protein dimerization (Minguillon et al., 2003). While a number of Tbx gene family members are known to play some role in cardiogenesis, $T b x 5$ has captured the greatest interest. This is probably due in large part to the discovery that mutations in $T b x 5$ are associated with the congenital heart defect known as HOS (Holt Oram Syndrome, OMIM 142900), characterized by upper limb and heart defects, the latter specifically associated with conduction and septal defects in the heart (Basson et al., 1999).

$T b x 5$ is essential for heart and forelimb formation in all vertebrates, but its regulation and functional interactions with other transcription factors and structural proteins are still not completely understood.

Careful analysis of our results indicates that $T b x 5$ is expressed in the eye, forelimb, atria, atrioventricular canal, and left ventricle. Our results are in agreement with the findings of Takeuchi et al. (2003), who also report Tbx 5 expression in the dorsal side of the chick's developing eye. According to those investigators, expression of $T b x$, in the chick eye is first seen around stage $\mathrm{HH} 11$ in the retina and then found later in the dorsal eye cup, retinal pigment epithelium, and neural retina. Bruneau et al. (1999) conducted whole mount in situ hybridizations on mouse embryos to study the role of $T b x$ 5 in early heart development. While their results are in agreement with ours with respect to $T b x 5$ expression in the heart, our findings differ regarding the extent of retinal staining. To better illustrate this point we present the two results below for direct 
comparison. Fig. 34 (taken, with permission, directly from the Bruneau paper) displays only very light staining in the eye compared to that seen in our study (Fig. 35). A number of possible interpretations might follow from these results. One is that the chick eye merely has more pigmentation, and all the "signal" was really due to this endogenous pigment. Unstained chick embryos or those stained with "sense" riboprobes as a negative control do not show this degree of signal, so differences in endogenous eye pigmentation do not appear to offer a sufficient explanation. An alternative interpretation is that the differences in retinal staining intensity in one study or the other are simply artifactual. Perhaps, for example, if Bruneau and co-workers had repeated their study, they might have indeed observed greater retinal expression of $T b x 5$. Conversely, we might see less upon repeated re-examination of our own. We have reproduced these results a number of times, however, so we are inclined to believe our results are true. A more provocative interpretation is that there might indeed be real expression differences between the two species used in these studies (mouse vs. chick). The two embryos shown in Figures 34 and 35 are approximately of the same developmental stage, so a simple explanation based on stage differences does not seem reasonable. It may instead be that there exist real differences in the pattern and extent of $T b x 5$ retinal expression in avians compared to mammals. The keen visual acuity (resolution) of avians (especially well studied in hawks, owls, eagles, and other birds of prey) is one obvious physical manifestion of a difference in the eyes of these two species. It seems entirely possible that the difference in $T b x 5$ expression we observe is genuine, reflecting a subtle but real alteration in the genetic and developmental program utilized in the embryonic construction of the retina. 


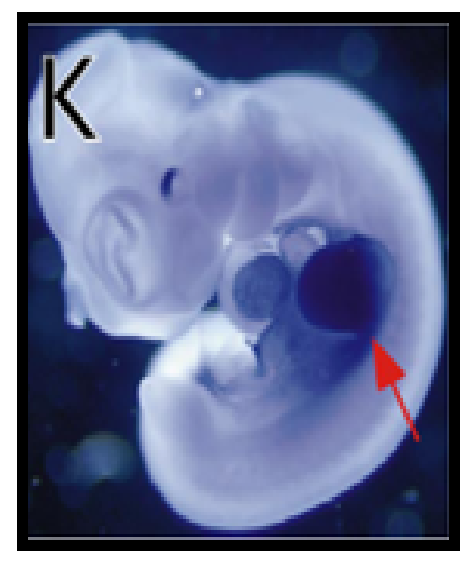

Fig. 34. In situ hybridization to Tbx 5 transcripts in mouse embryos, exhibiting strong staining in the heart and developing upper limb but low expression of Tbx 5 in the eye. Figure reprinted from Bruneau et al. with permission from Elsevier.

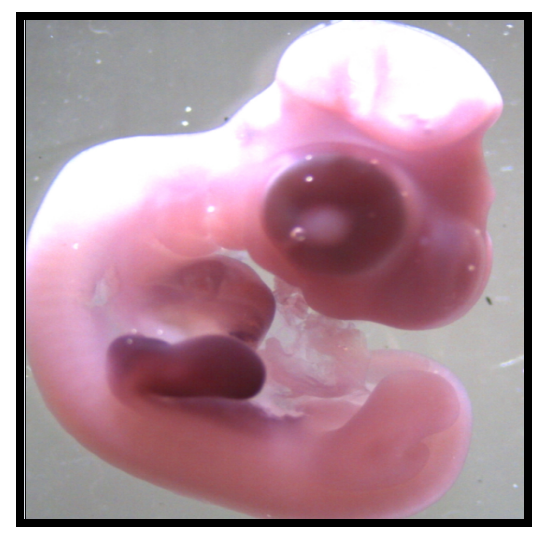

Fig. 35. Whole mount in situ hybridization to Tbx 5 transcripts in chick embryos, indicating significant expression in the eye, heart and developing upper limb.

Interestingly, conflicting data have been published regarding the ventricular expression domains of Tbx 5. According to Bruneau et al. (1999) and Takeuchi et al. (2003), Tbx 5 is expressed only in the left ventricle and not in the right ventricle. Bimber et al. (2007), however, report the expression of $T b x 5$ in both the right and left ventricles (Fig. 36). They performed immunohistochemical studies on embryonic chick heart, finding strong expression of $T b x 5$ in the left ventricle and atria and low expression in the 
right ventricle. Results of our studies are in agreement with Bruneau et al. (1999) and Takeuchi et al. (2003) and apparently at odds with those of Bimber et al (2007), as we report expression of $T b x 5$ in the atria and the left ventricle with no detectable signal in the right ventricle.
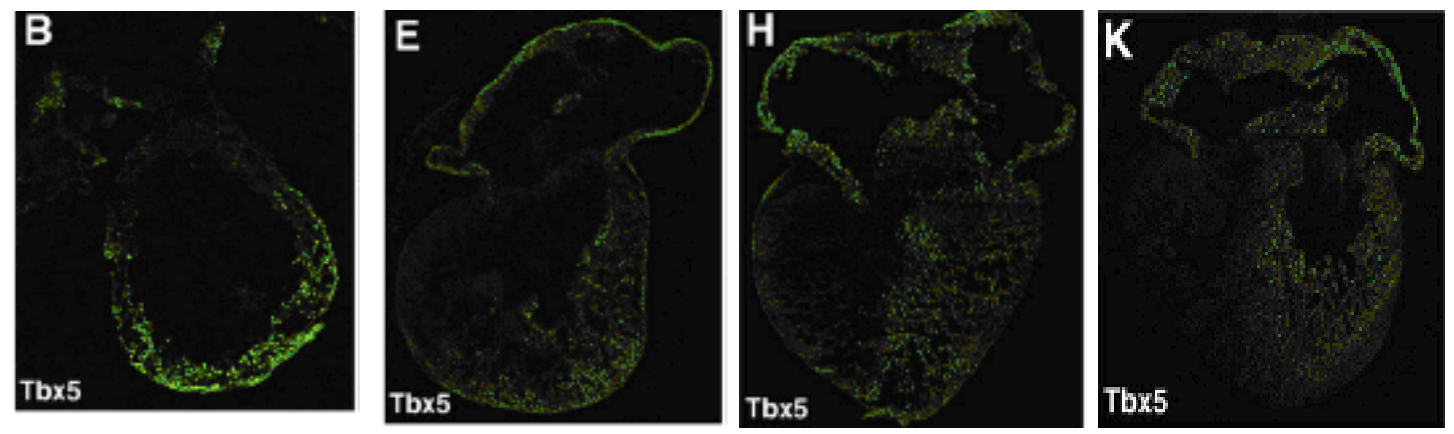

Fig. 36. Results of immunohistochemical studies conducted to study the expression of Tbx 5 in chick embryo heart. Figure has been modified to show the results of only $T b x 5$ from Bimber et al. with permission from Elsevier.

While not commented upon in the papers cited above, however, these discrepancies may actually reflect differences in what is being detected. The right ventricular expression of Tbx 5 reported by Bimber et al. (2007) might be explained by the fact that Bimber et al. (2007) performed immunohistochemical studies which target the $T B X 5$ protein rather than $T b x 5$ mRNA. Since a number of labs have reported the expression of $T b x 5$ mRNA throughout the entire heart tube at very early stages of cardiac development (Bruneau et al., 1999; Krause et 1., 2004), it may be that the TBX 5 protein is itself quite stable, and able to be maintained in the right ventricle long after the Tbx 5 gene has ceased making transcript. It is thus possible that the apparent discordance 
between our work and that of Bimber is illusionary. Transcription off the Tbx 5 gene in the right ventricle could indeed be fully repressed at later stages of development (when we probe for it), but the earlier expression could give rise to a stable protein that is still detectable via immunohistochemistry.

Whole mount in situ hybridization is a complex technique exhibiting its own constellation of irksome (and sometimes unique) problems like sensitivity to degradation by RNases. The sequence of interest in any particular tissue, for example, might be present but in very low abundance, or might remain bound up with protein making hybridization with a complementary probe extremely improbable (if not, for all practical purposes, impossible). Tissue permeability, and thus target accessibility, represents another technically difficult problem to overcome. It is extremely important to increase the permeability of the tissue without destroying the morphological integrity of the tissue. Detergents or proteases can both be used, but both can literally disintegrate the embryo if used at too high a concentration for too long. The size of the probe is also an important parameter to consider. Choice of type of probe, its labeling conditions, stringency of the washes and determining the temperature of washes with or without shaking while maintaining the structural integrity of the extremely fragile embryo present a challenge in the successful functioning of the technique.

One of the most common problems encountered with in situ hybridization studies is the unwanted background staining. It is very difficult to diagnose the exact cause of background staining. Probe and/or alkaline phosphates antibody conjugate can also be trapped by the internal cavities of the tissue like the brain, heart and eyes. During the 
course of this study we were able to significantly reduce the background staining by opening the brain cavity by punching a hole in one or more regions of the forebrain, midbrain or the telecephalic hemisphere.

It is essential to be very careful during the process of embryo harvest, as the embryo is extremely delicate and tightly bound by protective membranes. Careful and complete removal of these adherent membranes is crucial to in situ hybridization studies as these membranes inhibit the penetration of fixative, dehydrating solutions and the probe.

After the harvest the embryos are supposed to be fixed immediately. Fixation is the first and a very crucial step for any hybridization protocol. It not only keeps the tissue/ cell intact but also prevents degradation of intracellular nucleic acid. $4 \%$ PFA (paraformaldehyde) is the most common and widely used fixative agent for any in situ hybridization protocol. In order to fix the embryos, we initially used $4 \%$ PFA which was prepared and chilled a day in advance of the harvest. Our experience during the course of this study yielded much better results with 4\% PFA prepared and chilled an hour before starting the harvest. It is essential to be very careful to prepare all the reagents in RNase free water.

We performed 8 sets of whole mount in situ hybridization experiments where we tried to optimize our protocols in order to significantly reduce the background signal observed in the initial results. We studied, for example, the effects of storing the embryos up to a month in methanol after fixation as compared to just moving to the next step of rehydrating the embryos. We concluded that using the freshly fixed embryos 
which were dehydrated and then rehydrated in one step yielded better results than storing them in $100 \%$ methanol as we observed hardening of the tissue in embryos which were stored in methanol (Fig. 33). Hardening of the tissue means that the proteins coagulate which further makes tissue permeability more difficult. This observation might be because methanol is used as a fixative and acts as a protein denaturizing agent.

Optimization studies were performed on the duration of proteinase $\mathrm{K}$ digestion. Duration of proteinase $\mathrm{K}$ digestion is a critical step as insufficient digestion would lead to low hybridization signal and over-digestion might destroy the tissue morphology. We compared the effect of performing proteinase $\mathrm{K}$ digestion for 15 minutes with respect to digestion for 30 minutes (data not shown). Better hybridization signal with 30 minutes digestion was observed. Secondary fixation consisting of $4 \%$ paraformaldehyde and $0.2 \%$ gluteraldehyde for 15 minutes yielded better results as compared to no secondary fixation.

We also optimized the stringency wash by decreasing salt concentration to wash off the non-specifically bound probe. During the course of this study we experimented with a number of hybridization temperatures such as $55^{\circ} \mathrm{C}, 60^{\circ} \mathrm{C}, 62^{\circ} \mathrm{C}$ and $65^{\circ} \mathrm{C}$. We concluded that the higher hybridization temperature of $65^{\circ} \mathrm{C}$ yielded the best results without destroying or altering the structural integrity of the tissue.

Many Tbx 5 hybridization studies have been conducted over the past decade, but almost none of these studies have published any significant information regarding their probe sequence, let alone the specific conditions used in their hybridization protocol. 
Wilson et al. (2002) states, "Specific residues within the T-box are 100\% conserved in all members of the family."

Also the expression domain of various $T b x$ family members in the heart remains controversial. According to Yamada et al. (2000), the transcripts of $T b x$ 2, Tbx 3 and $T b x$ 5 were expressed in an overlapping fashion in early crescent formation, indicating a high degree of sequence conservation amongst the Tbx family. This leads to serious doubts regarding the specificity of the probe. Whether the probe hybridizes to $T b x 5$ specifically or cross hybridizes to $T b x$ family members due to sequence conservation still needs to be determined. Bioinformatics tools like BLAST and Multiple Sequence Alignment (Fig. 10 and 11) were employed in this study to find an area of $T b x 5$ with minimum sequence conservation with other $T b x$ family members to ensure the specificity of the probe to $T b x$ 5.

During the course of the 199 base pair probe construction, we performed the Blue/ White screening using LA/AMP/IPTG/X-Gal plates to check for ligation. Along with white and blue colonies we also found some light blue colonies which after a week of incubation slowly turned dark blue. Along with the white colonies, we also sent out these light blue colonies for DNA sequencing. It was interesting to note that the light blue colonies contained the insert. It might be possible that the insert doesn't contain a STOP codon in frame with the lac $\mathrm{Z}$ gene, thus leading to a fusion protein which is functional as the alpha peptide of Lac Z (Murray et al., 1993). Probe length of less than 500 bp (199 bp in our case) might be maintained in lac Z's reading frame, leading to the formation of light blue colonies. 
We had to troubleshoot the in vitro transcription reaction to work efficiently.

Our initial attempts at in vitro transcription produced a low yield, which might be because our sequence of interest (Tbx 5) was somehow forming a secondary structure in the context of the plasmid which prevents efficient transcription. To circumvent this transcriptional inefficiency we designed new primers with the $\mathrm{T} 7$ promoter on the reverse primer followed by the desired region of the $T b x 5$ gene for the creation of the antisense probe (Fig. 37) and performed the PCR reaction. After cleaning up the PCR product we performed the in vitro transcription and got the desired results.

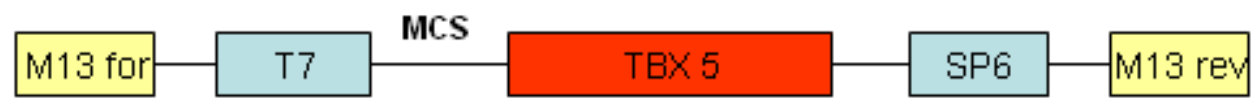

(A). Structure of linear template of the plasmid containing the TBX 5 insert.

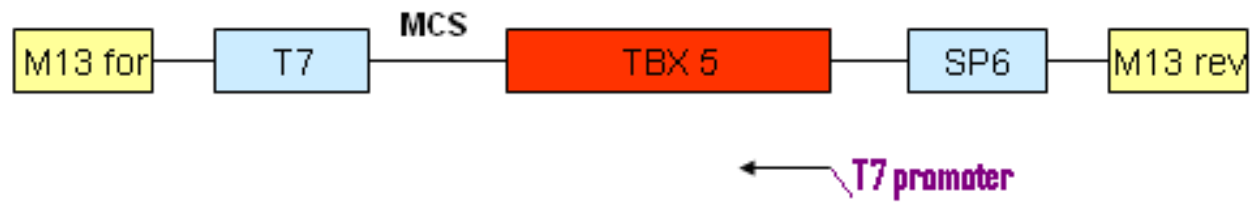

(B). Structure of the PCR amplified region for the creation of antisense RNA probe.

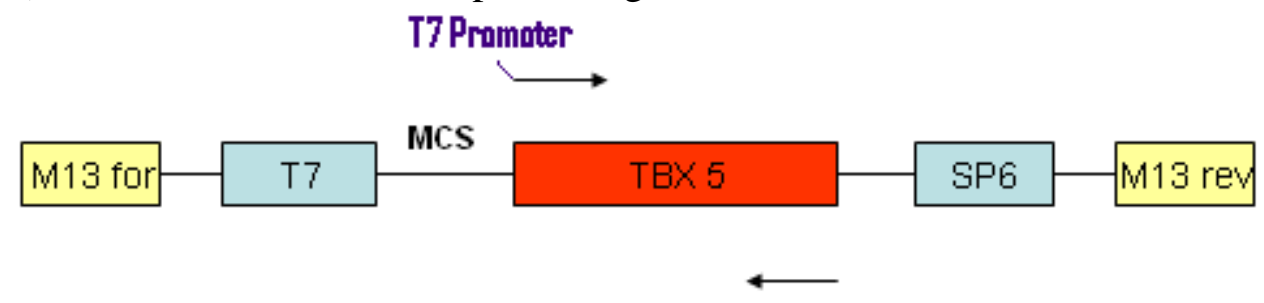

(C). Structure of the PCR amplified region for the creation of sense RNA probe.

Fig. 37. Depiction of primer design having T7 promoter at the end of the amplified region, for the successful creation of antisense by in vitro transcription. The arrows indicate the forward and the reverse primer used. 
One important aspect of this project was to compare the efficiency of the DNA probe vs. the RNA probe. For the riboprobe, in theory the bonding between the RNA probe and the mRNA present in the tissue should be more thermostable than a DNA: RNA hybrid, potentially giving rise to a stronger signal by minimizing disassociation of target:probe duplexes. Certainly a RNA: RNA hybrid would be more resistant to digestion by many common cellular RNases than either a free transcript or RNA probe, but this would also be true for a DNA: RNA duplex as well. During hybridization there is no competition between the sense and antisense, as only antisense is available for the riboprobe to hybridize with the target mRNA so the RNA probe should be more efficient. Unexpectedly, we did not find much difference between the specificity or the signal intensity between the RNA and the DNA probe. Our findings were in agreement with the findings of Forghani et al. (1999). In our experience the DNA probes are much more stable and are also more cost and time efficient thus proving to be a viable alternative to RNA probes.

We also compared probing the tissue with three different concentrations of 200 $\mathrm{ng} / \mathrm{ml}, 750 \mathrm{ng} / \mathrm{ml}$ and $1000 \mathrm{ng} / \mathrm{ml}$ for both the DNA probe and the RNA probe and did not find any significant difference in the results. So in principle it is a good idea to back off to lowest concentration, i.e., a concentration of $200 \mathrm{ng} / \mathrm{ml}$ in order to minimize background staining, non specific binding and be cost efficient.

Probe length is an important parameter to consider during in situ hybridization. A probe length of 200-1000 bp is considered optimum. Previous work done in Dr. White's laboratory using a 1000 bp probe yielded background signal, so we decide to use two 
different probes of $199 \mathrm{bp}$ and $665 \mathrm{bp}$ length. Consider a 665 bp probe, its molecular weight would be $665 * 660 / 2$ daltons $=219450$ daltons, which in itself is a huge molecule to penetrate the tissue. We compared two different probes of length $199 \mathrm{bp}$ and $665 \mathrm{bp}$. Shorter probe length allows easier probe penetration but carries less of chemical label (digoxygenin in our case) whereas larger probe length carries more digoxygenin so should lead to stronger signal strength with potentially less able to penetrate the tissue and/ or more likely to be trapped. Relative to the small number of experimental results that we have, we found the signal in the heart to be a little lighter in case of the $665 \mathrm{bp}$ probe.

In situ hybridization is very technique dependent where altering conditions like fixation, proteinase $\mathrm{K}$ digestion, stringency washes, and hybridization temperature has resulting effects which may have tremendous consequences on the results. In situ hybridization targets the mRNA present in the tissue. The mRNA molecule is only made when the gene for that particular protein is turned on and expressed, so in situ hybridization is dependent on the developmental stage of the embryo. Tbx 5 is known to be up/ down regulated in different parts of the chick embryo at various stages of development.

One future direction for the laboratory might be to perform microarray experiments on RNA isolated from different regions of the heart at different stages of development, but is limited by the lack of chick arrays containing large number of genes. Another alternative might be to perform microsurgery in conjunction with RT-PCR 
experiments under different growth conditions to reveal when and to what extent a specific gene is switched on.

With respect to in situ hybridization, we would highly suggest that more experiments be conducted to examine the effect of probe length on the signal strength. In spite of the amount of work done in this project, more work needs to be done to create a much more detailed developmental atlas for a better understanding of $T b x 5$ expression in chick organogenesis. 


\section{REFERENCES}

Alsan, B.H., and Schultheiss, T.M. "Regulation of Avian Cardiogenesis by Fgf8 Signaling." Development 129 (2004):1935-1943.

Armstrong, E.J.and Bischoff, J. "Heart Valve Development Endothelial Cell Signaling and Differentiation." Circulation Research 95 (2004): 459-70.

Baldini, A. "Digeorge Syndrome: An Update." Current Opinion in Cardiology 19 (2004): 201-204.

Basson, C. T., T. Huang, R. C. Lin, D. R. Bachinski, S. Weremowicz, A. Vaglio, R. Bruzzone, R. Quadrelli, M. Lerone, G. Romeo, M. Silengo, A. Pereira, J. Krieger, S. F. Mesquita, M. Kamisago, C. C. Morton, M. E.M Pierpont, C. W. Muller, J. G. Seidman, and C. E. Seidman. "Different TBX5 Interactions in Heart and Limb Defined by Holt-Oram Syndrome Mutations." PNAS 96 (1999): 2919-924.

Berg G.V.D., Moorman AFM. "Concepts of Cardiac Development in Retrospect." Pediatric Cardiology 30 (2009): 580-87.

Bimber, B., R. W. Dettman, and H. G. Simon. "Differential Regulation of Tbx 5 Protein Expression and Sub-cellular Localization during Heart Development." Developmental Biology 302.1 (2007): 230-42.

Black, B. and Olson, E. “Transcriptional Control of Muscle Development by Myocyte Enhancer Factor-2 (MEF2) Proteins." Annual Review of Cell and Developmental Biology 14 (1998): 167-96.

Bollag, R.J., Siegfried, Z., Cebra-Thomas, J.A., Garvey, N., Davinson, E.M. and Silver, L.M. "An ancient family of embryonically expressed mouse genes sharing a conserved protein motif with the T Locus.” Nature Genetics 7 (1994): 383-89.

Bour, B.A., O’Brien, M.A., Lockwood, W.L., Goldstein, E.S., Bodmer, R., Taghert. P.H., Abmayr, S.M. and Nguyen, H.T. "Drosophila MEF2, A Transcription Factor is Essential for Myogenesis." Genes and Development 9 (1995): 730-41.

Brown, J. G., Sergei I. Agulunik, Lee M. Silver, and Virginia E. Papaioannou. "Expression of T-box Genes TBX 2-TBX 5 during Chick Organogenesis." Mechanisms of Development 74 (1998): 165-69.

Bruneau, B. G., M. Logan, N. Davis, T. Levi, C. J. Tabin, J. G. Seidman, and C. E. Seidman. "Chamber-specific Cardiac Expression of TBX 5 and Heart Defects in Holt-Oram Syndrome." Developmental Biology 211 (1999): 100-08. 
Buckingham, M., Meilhac, S. and Zaffran, S. "Building the Mammalian Heart from Two Sources of Myocardial ells." Nature Review Genetics 6 (2005): 826-37.

Casey, E.S., O’Reilly, A.M., Conlon, F.L. and Smith, J.C. “The T-box Transcription Factor Bracahyury Regulates Expression of eFGF through Binding to Non Palindromic Response Element." Development 125 (1998): 3887-94.

Dobrovolskia-Zavadskia N. "Sou La Mortification Spontanee de la Queue Che la Souris Nouveaunee et Sur l'Existenced'un Caractere (facteur) Hereditaire Nonviable." Comptes Rendus des Seances de la Societe de Biologie et de ses Filiales 97 (1927): 114-116.

Drenckhahan, J. D. "Growth Plasticity of the Embryonic and Fetal Heart." Bioassays 31.12 (2009): 1288-98.

Fan, C., Liu M, Wang Q. "Functional Analysis of TBX 5 Missense Mutations Associated with Holt Oram Syndrome.” The Journal of Biological Chemisty 278 (2003): 8780-785.

Fishman M.C., Chien, R.C. "Fashioning the Vertebrate Heart.” Development 124 (1997): 2099-117.

Forghani B., Yu, G.J. and Hurst, J. W. "Comparison of Biotnylated DNA and RNA Probes for Rapid Detection of Varicella- Zoster Virus Genome by In Situ Hybridization." Journal of Clinical Microbiology (1991): 583-91.

Garg, V., Kathiriya, I.S., Barnes, R., Schluterman, M.K., King I.N., Butler, C.A., Rothrock, C.R., Eapen, R.S., Hirayama-Yamada K, J. K., Matsuoka, R., Cohen, J.C. and Srivastava, D. "GATA4 Mutations Cause Human Congenital Heart Defects and Reveal an Interaction with TBX 5." Nature 424 (2003): 443-47.

Ghosh, T.K., Song, F.F, Packham E.A., Buxton, S., Robinson, T.E., Ronksley, J., Self, T., Bonser, A.J., and Brook, D. "Physical Interaction between TBX5 and MEF2C is Required for Early Heart Development." Molecular and Cellular Biology 29 (2009): 2205-218.

Gilbert, S. F. Developmental Biology Sunderland, MA: Sinauer Associates, 2006.

Haenig, Benedicte, and Andreas Kispert. "Analysis of TBX18 Expression in Chick Embryos." Development Genes Evololution (2004): 407-11. 
Harris, B.S., O'Brien, T.X., and Gourdie, R.G. "Coronary Arteriogenesis and Differentiation of Periarterial Purkinje Fibers in the Chick Heart: Is There a Link?" Texas Heart Institute Journal 29 (2002): 262-70.

Hatcher, C.J. and Basson, C.T. "Specification of the Cardiac Conduction System by Transcription Factors." Circulation Research_105 (2009): 620-30.

Harvey, R.P. "Patterning the Vertebrate Heart." Nature 3 (2002): 544-56.

Hiroi, Y., Kudoh, S., Monzen, K., Ikeda, Y., Yazaki, Y., Nagai, R. and Komuro, I. “ Tbx 5 Associates with Nkx 2-5 and Synergistically Promotes Cardiomyocyte Differentiation." Nature Genetics 29 (2001): 276-80.

Hoffman, J.I.E. and Kaplan, S. "Tne Incidence of Congenital Heart Disease." Journal of the American College of Caradiology 39 (2002): 1890-90.

Iio, A., M. Koide, K. Hidaka, and T. Morisaki. "Expression Pattern of Novel Chick T-box Gene, TBX20." Development Genes Evolution 211 (2001): 559-62.

King, M., Arnold, J.S., Shanske, A. and Morrow, B.E. "T-gene and Limb Bud Development." American Journal of Medical Genetics Part A 140.13 (2006): $1407-13$.

Kispert, A. and Herrmann, B.G. "The Brachyury Gene Encodes a Novel DNA Binding Protein.” The EMBO Journal 12.8 (1993): 3211-3220.

Korzh, V. and Grunwald, D. "Nadine Dobrovolskaia and the Dawn of Developmental Genetics." Bio Essays 23 (2001): 365-71.

Koshiba,T.K., Takeuchi, J.K., Matsumoto, K., Momose,T., Uno,K., Hoepker,V.,Ogura,K.,Takahashi,N., Nakamura, H., Yasuda,K. and Ogura,T. "TBX 5 and the Retinotectum Projection.” Science 287 (2000): 134-37.

Krause, A., Zacharias , W., Camarata , T., Linkhart , B., Law, E., Lischke, A., Miljan, E., Simon, HG. "TBX 5 and TBX 4 Transcription Factors Interact with a New Chicken PDZ-LIM Protein in Limb and Heart Development." Developmental Biology 273 (2004): 106-20.

Larsen, William J. "Development of the Heart." Human Embryology Third ed. Churchill Livingstone, 2001. 157-94.

Lu J.H., Lu J.K., Choo S.L, Li Y.C, Yeh H.W,Shiue J.F and Yeh V.C. "Cascade Effects of Cardiac Myogenesis Gene Expression during Cardiac Looping in TBX 5 
Knockdown Zebrafish Embryos.” Journal of Biomedical Science 15 (2008): 77987.

Manner, J. "Cardiac Looping In The Chick Embryo: A Morphological Review with Special Reference to Terminological and Biochemical Aspects of the Looping Process." The Anatomical Record 259 (2000): 248-62.

Manner, J. "The Anaomy of Cardiac Looping: A Step towards the Understanding of the Morphogenesis of Several Forms of Congenital Cardiac Malformations." Clinical Anatomy_22 (2009): 21-35.

Minguillon, C., Logan, M. "The Comparative Genomics of T-Box Genes.” Briefings in functional genomics and Proteomics 2.3 (2003): 224-33.

Moorman A., Webb S., Brown N.A., Lamers W. and Anderson R.H. "Development of the Heart: (1) Formation of the Cardiac Chambers and Arterial Trunks." Heart 89.7 (2003): 806-14.

Munoz-Chapuli, R., Gonzalez-Iriarte, M., Carmona, R., Atencia, G., Macias, D. and Perez-Pomares, J. M. "Cellular Precursors of the Coronary Arteries.” Texas Heart Institute Journal 29.4 (2002):243-9.

Murray, E., K. Singer, K. Cash, and R. Williams. "Cloning-Qualified Blunt End Restriction Enzyme: Causes and Cures for Light Blue Colonies." Promega Notes Magazine (1993): 01-08.

Naiche, L.A., Harrelson, Z., Kelly, R.G. and Papaioannou,V.E. "T-box Genes in Vertebrate Development." Annual Review of Genetics 39 (2005): 219-39.

Newbury-Ecob, R.A., Leanage, R., Raeburn, J.A. and Young, I.D. "Holt-Oram Syndrome: A Clinical Genetic Study." Journal of Medical Genetics 33 (1996): 300-307.

. Plageman, T.F.and Yutzey, K.E. "Microarray Analysis of TBX 5 Induced Genes Expressed in the Developing Heart." Developmental Dynamics 235 (2006): 286880.

Ramsdell, A.F. "Left-Right Asymmetry and Congenital Cardiac Defects: Getting to the Heart of Matter in Vertebrate Left-Right Axis Determination." Developmental Biology (2005): 1-20. 
Saber, A.S., Shoghy, K.M, Erasha, A.M. and Nada, M.M. "Cardiac Looping and Formation of the Heart Regions in Japanese Quail Embryo (Coturnix coturnix) ." Journal of Veterinary Anatomy 1 (2008): 3-13.

Schoenwolf, G. C., and W. J. Larsen. Larsen's Human Embryology Philadelphia: Churchill Livingstone/Elsevier, 2009.

Searcy, R. D., E. B. Vincent, C. M. Liberatore, and K. E. Yutzey. "A GATA- Dependent NKX-2.5 Regulatory Element Activates Early Cardiac Gene Expression in Transgenic Mice." Development 125 (1998): 4461-470.

Stennard, F.A. and Harvey, R.P. "T-box Transcription Factors and Their Roles in Regulatory Hierercheriesin the Developing Heart.” Development 132 (2005): 4897-910.

Stern, C.D. "The Chick Embryo- Past, Present and Future as a Model System in Developmental Biology." Mechanisms of Development 121 (2004): 1011-013.

Tada, M. and Smith, J.C. "T-targets: Clues to Understanding the Functions of T-box Proteins." Development, Growth and Differentiation 43 (2001): 1-11.

Takeuchi, J.K., Ohgi, M., Takeuchi, K.K., Shiratori, H., Sakaki, I., Ogura,K., Saijoh, Y. and Ogura, T. "TBX 5 Specifies the Left/Right Ventricles and Ventricular Septum Position during Cardiogenesis.” Development 130 (2003): 5923-964.

Voronov, D.A., Alford, P.W., Xu, G. and Taber, L.A. "The Role of Mechanical Forces in Dextral Rotation during Cardiac Looping in the Chick Embryo." Developmental Biology 272 (2004): 470-80.

Waldo, K., Tomita, S.M., Kumiski, D. and Kirby, M.L. "Cardiac Neural Crest Cells Provide New Insight into Septation of the Cardiac Outflow Tract: Aortic Sac to Ventricular Septal Closure.” Developmental Biology 196 (1998): 129-144.

Wilson, V. and Conlon F.L. "The T-Box family." Genome Biology 3.6 (2002): Reviews 3008 .

Yamada, Miho, Jean Pierre Revelli, Matt Barron, Gregor Eichele, and Robert J.

Schwartz. "Expression of Chick TBX-2, TBX-3, and TBX-5 Genes during Early Heart Development: Evidence for BMP2 Induction of TBX- 2." Developmental Biology 228 (2000): 95-105. 
Zaragoza, M.V., Lewis LE, Sun G, Wang E, Li L, Salman IS, Feucht L. and Huang T. "Identification of the TBX 5 Transactivating Domain and the Nuclear Localization Signal." Gene (2004): 3309-18. 


\section{Appendix A}

\section{Protocol for Step Down RT-PCR}

Step Down RT-PCR was performed using Qiagen's One Step RT-PCR kit. The $25 \mu \mathrm{L}$ reaction was assembled on ice as follows

RNase free water

$16.84 \mu \mathrm{L}$

5XQiagen One Step RT-PCR buffer

$5 \mu \mathrm{L}$

dNTP mix

$1 \mu \mathrm{L}$

Tbx 5199 base pair forward primer $(0.6 \mu \mathrm{M})$

$1.5 \mu \mathrm{L}$

Tbx 5199 base pair reverse primer $(0.6 \mu \mathrm{M})$

$1.5 \mu \mathrm{L}$

Qiagen One Step RT-PCR enzyme mix

$1 \mu \mathrm{L}$

RNA at $3137.2 \mathrm{ng} / \mu \mathrm{L}$

$0.16 \mu \mathrm{L}$

$25 \mu \mathrm{L}$ 


\section{Appendix B}

\section{Protocol for Promega's pGEM- T Easy Vector System}

The transformation reaction was performed using Promega's pGEM- T Easy Vector

System. 3:1 insert: vector molar ratio was used (10 ng of insert DNA). The reaction was assembled as per follows:

- $\quad$ pGEM-T Easy vector tube was briefly centrifuged.

- Vortex the $2 \mathrm{X}$ ligation reaction and set the reaction as follows

\section{Ligation Reaction:}

\begin{tabular}{|c|c|c|c|}
\hline $\begin{array}{c}\text { 2X Rapid Ligation } \\
\text { Buffer }\end{array}$ & Standard Reaction & Positive Control & Background \\
\hline $\begin{array}{c}\text { pGEM-T Easy } \\
\text { Vector }\end{array}$ & $5 \mu \mathrm{L}$ & $5 \mu \mathrm{L}$ & $5 \mu \mathrm{L}$ \\
\hline PCR Product & $1 \mu \mathrm{L}$ & $1 \mu \mathrm{L}$ & $1 \mu \mathrm{L}$ \\
\hline Control Insert DNA & $\mathrm{X}$ & $\mathrm{X}$ & $\mathrm{X}$ \\
\hline T4 DNA Ligase & $1 \mu \mathrm{L}$ & $1 \mu \mathrm{L}$ & $1 \mu \mathrm{L}$ \\
\hline Deionized Water & $2 \mu \mathrm{L}$ & $1 \mu \mathrm{L}$ & $3 \mu \mathrm{L}$ \\
\hline Total Reaction & $10 \mu \mathrm{L}$ & $10 \mu \mathrm{L}$ & $10 \mu \mathrm{L}$ \\
Volume & & & \\
\hline
\end{tabular}

- Mix the reaction by pipetting and incubate the reaction at room temperature for 1 hour.

\section{Transformation Reaction}

Transformation was performed using highly competent JM 109 cells. 2 LA/AMP/IPTG/XGal plates were used for each ligation reaction. 
- $2 \mu \mathrm{L}$ of ligation reaction was placed in a sterile tube on ice. $50 \mu \mathrm{L}$ of JM109 competent cells were added to the tube. The tube was gently flicked and placed on ice for 20 minutes.

- The tubes were heat shocked for 45 seconds in a water bath at $42^{\circ} \mathrm{C}$.

- Tubes were immediately placed on ice for 2 minutes.

- $950 \mu \mathrm{L}$ of SOC medium was added to the tube.

- Reaction was incubated for 1.5 hours at $37^{\circ} \mathrm{C}$ with shaking.

- $150 \mu \mathrm{L}$ of reaction was plated using aseptic techniques on LA/AMP/IPTG/XGal plate.

- The plates were placed in the incubator at $37^{\circ} \mathrm{C}$ for overnight.

Vector map of Promega's pGEM-T Easy Vector from http://www.promega.com/figures/popup.asp?fn=1473va

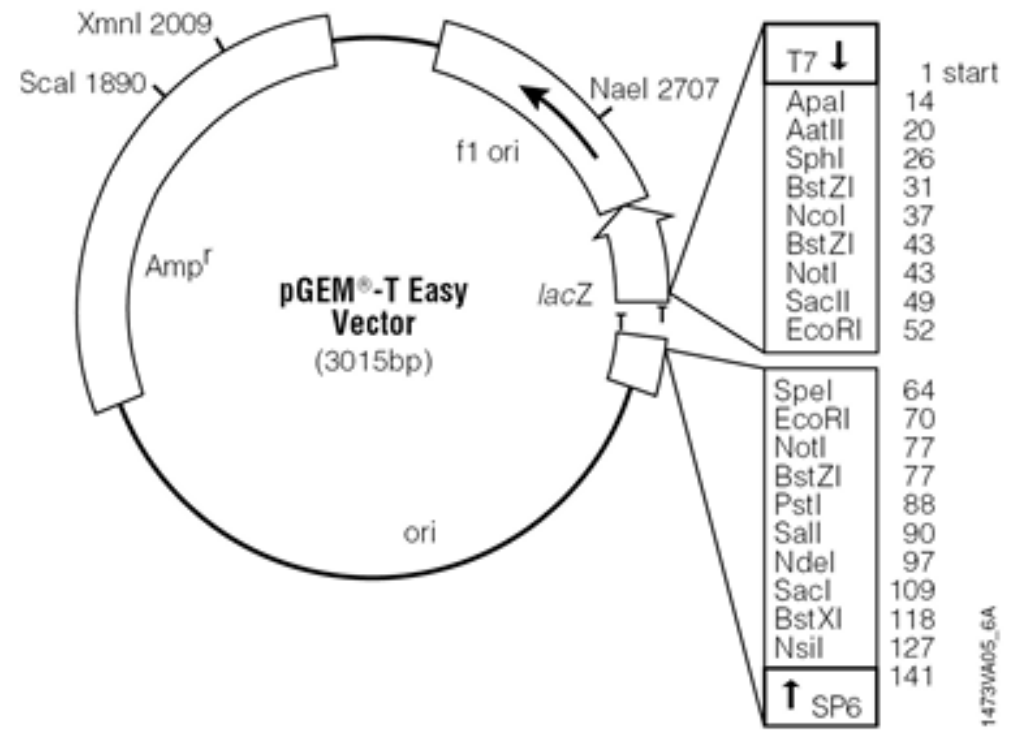




\section{Appendix C}

\section{Protocols for Zyppy MiniPrep Kit}

- Add $600 \mu \mathrm{l}$ of bacterial culture grown in LB media in a sterile $1.5 \mathrm{ml}$ centrifuge tube and centrifuge at max speed for 30 seconds. Discard the supernatant and repeat the steps if necessary for a maximum of $3 \mathrm{ml}$ of liquid culture. Dissolve the bacterial pellet completely in $600 \mu \mathrm{l}$ of TE or water.

- Add $100 \mu 1$ of $7 \mathrm{X}$ lysis blue to the centrifuge tube and mix by inverting 46 times. Change of color from opaque to clear blue indicates complete lysis. Care should be taken to proceed to the next step within 2 minutes.

- Add $350 \mu \mathrm{l}$ of cold neutralization buffer and mix thoroughly by inverting the tube. On completion of neutralization the solution turns yellow and yellow precipitate is formed.

- Centrifuge at $11,000-16,000 *$ g for 2-4 minutes.

- Transfer the supernatant to the Zymo Spin IIN column provided without disturbing the pellet.

- Place the column into Collection Tube and centrifuge for 15 seconds.

- Discard the flow through and place the column in the same Collection Tube.

- Add $200 \mu \mathrm{l}$ of Endo Wash Buffer to the column and centrifuge for 15 seconds. Discard the flow through.

- Add $400 \mu \mathrm{l}$ of Zyppy Wash Buffer to the column and centrifuge for 30 seconds.

- Transfer the column to a sterile $1.5 \mathrm{ml}$ micro centrifuge tube and add $60 \mu 1$ of Zyppy Elution Buffer to the center of the column matrix and let stand for 1 minute at room temperature.

- Centrifuge at max speed for 15 seconds to elute the plasmid DNA. 
Appendix D

\section{$\underline{\text { Protocol for Double Restriction Digest }}$}

\begin{tabular}{|c|c|c|c|c|}
\hline & uncut & $\begin{array}{c}\text { Single Cut } \\
(\text { NotI })\end{array}$ & $\begin{array}{c}\text { Single Cut } \\
(\text { EcoRI })\end{array}$ & $\begin{array}{c}\text { Double Cut } \\
(\text { NotI, EcoRI })\end{array}$ \\
\hline $\begin{array}{c}\text { 10 X RE Digest } \\
\text { Buffer H }\end{array}$ & $2 \mu \mathrm{l}$ & $2 \mu \mathrm{l}$ & $2 \mu \mathrm{l}$ & $2 \mu \mathrm{l}$ \\
\hline TBX 5 Plasmid & $1 \mu \mathrm{l}$ & $1 \mu \mathrm{l}$ & $1 \mu \mathrm{l}$ & $1 \mu \mathrm{l}$ \\
\hline $\begin{array}{c}\text { NotI }(10 \mathrm{U} / \mu \mathrm{l}) \\
\text { EcoRI }(10 \mathrm{U} /\end{array}$ & $\mathrm{X}$ & $1 \mu \mathrm{l}$ & $1 \mu \mathrm{X}$ & $1 \mu \mathrm{l}$ \\
\hline $\begin{array}{c}\text { Deionized } \\
\text { Water }\end{array}$ & $16.8 \mu \mathrm{X}$ & $15.8 \mu \mathrm{l}$ & $15.8 \mu \mathrm{l}$ & $14.8 \mu \mathrm{l}$ \\
\hline $\begin{array}{c}\text { Acetylated } \\
\text { BSA }\end{array}$ & $0.2 \mu \mathrm{l}$ & $0.2 \mu \mathrm{l}$ & $0.2 \mu \mathrm{l}$ & $0.2 \mu \mathrm{l}$ \\
\hline
\end{tabular}

Both NotI and EcoRI enzymes were from Promega. The reaction was assembled on ice. Reaction was incubated at $37^{\circ} \mathrm{C}$ overnight in water bath for complete digest. 
Appendix E

\section{Protocol for Qiagen's Taq DNA Polymerase PCR}

- Thaw 10X PCR buffer, dNTP mix, primer solutions, DNA and keep it on ice.

- Prepare a master mix as follows except the template DNA

\begin{tabular}{|c|c|}
\hline Reagents & Volume \\
\hline Deionized water & $38.75 \mu \mathrm{l}$ \\
\hline dNTP mix & $1 \mu \mathrm{l}$ \\
\hline Forward Primer & $2.5 \mu \mathrm{l}$ \\
\hline Reverse Primer & $2.5 \mu \mathrm{l}$ \\
\hline Template at 19.3 ng/ $\mu \mathrm{l}$ & $1 \mu \mathrm{l}$ \\
\hline Taq DNA polymerase & $0.25 \mu \mathrm{l}$ \\
\hline 10 X PCR Buffer & $5 \mu \mathrm{l}$ \\
\hline Total Reaction Volume & $50 \mu \mathrm{l}$ \\
\hline
\end{tabular}

- Dispense in PCR tubes. Reaction should be assembled on ice.

- Add template DNA.

- Place in thermal cycler as follows

\begin{tabular}{|c|c|c|}
\hline Reaction & Time & Temperature \\
\hline Initial Denaturation & 3 minutes & $94^{\circ} \mathrm{C}$ \\
\hline $\begin{array}{c}3 \text { step cycling } \\
\text { Denaturation }\end{array}$ & 30 seconds & $94^{\circ} \mathrm{C}$ \\
\hline Annealing & 30 seconds & $55^{\circ} \mathrm{C}$ \\
\hline Extension & 1 minute & $72^{\circ} \mathrm{C}$ \\
\hline Number of cycles & 40 & $72^{\circ} \mathrm{C}$ \\
\hline Final Extension & 5 minutes & \\
\hline
\end{tabular}


Appendix F

\section{Protocol for Promega's Wizard SV gel and PCR Clean-Up System}

- Transfer the PCR product to SV Minicolumn assembly and incubate at room temperature for 1 minute.

- Centrifuge the assembly in a microcentrifuge at $16,000 * \mathrm{~g}(14,000 \mathrm{rpm})$ for 1 minute. Discard the flow through and reassemble the SV Minicolumn and collection tube.

- Wash the column with $700 \mu$ l of Membrane Wash Solution and centrifuge for 1 minute at $16,000 * \mathrm{~g}$. Empty the wash through and repeat the wash with $500 \mu 1$ of Membrane Wash Solution and centrifuge the assembly for 5 minutes at 16,000* g.

- Empty the collection tube and reassemble the column assembly. Recentrifuge for 1 minute with microcentrifuge lid open to evaporate any residual liquid.

- Transfer the SV Minicolumn to a sterile $1.5 \mathrm{ml}$ microcentrifuge tube and add 50 $\mu 1$ of nuclease free water. Incubate at room temperature for 1 minute. Centrifuge at $16,000 * \mathrm{~g}$ for 1 minute.

- Discard the SV Minicolumn and store the eluted DNA at $4{ }^{\circ} \mathrm{C}$ or $-20{ }^{\circ} \mathrm{C}$. 
Appendix G

\section{Protocol for Roche's In Vitro Transcription}

- Reaction was set up on ice as follows:

\begin{tabular}{|c|c|c|c|}
\hline & Experimental & Positive Control & Negative Control \\
\hline In Vitro & TBX 5 DNA & Ambion's pTRI- & No DNA \\
Transcription & template $(1 \mu \mathrm{g})$ & Actin Mouse at0.5 & \\
Template & at274.4 ng/ $\mu \mathrm{l}$ & $\mu \mathrm{g} / \mu \mathrm{l})$ & $0 \mu \mathrm{l}$ \\
\hline DEPC Treated DI & $3.6 \mu \mathrm{l}$ & $2 \mu \mathrm{l}$ & $10 \mu \mathrm{l}$ \\
Water & $6.4 \mu \mathrm{l}$ & $8 \mu \mathrm{l}$ & $4 \mu \mathrm{l}$ \\
\hline 5X Labeling Mix & $4 \mu \mathrm{l}$ & $4 \mu \mathrm{l}$ & $4 \mu \mathrm{l}$ \\
( Vial 1a) & & & \\
\hline 5X Transcription & $4 \mu \mathrm{l}$ & & $2 \mu \mathrm{l}$ \\
Buffer (Vial 1b) & & $2 \mu \mathrm{l}$ & \\
\hline T7 RNA & $2 \mu \mathrm{l}$ & & $20 \mu \mathrm{l}$ \\
Polymerase & & & \\
\hline Total reaction & $20 \mu \mathrm{l}$ & & \\
Volume & & & \\
\hline
\end{tabular}

- Centrifuge briefly and incubate at $30^{\circ} \mathrm{C}$ for 15 minutes.

- Analyze on agarose gel to verify for the transcription product. 


\section{Appendix $\mathrm{H}$}

\section{Protocol for using Novagen's Red Pellet Paint}

- Bring Pellet Paint Co-Precipitant and $3 \mathrm{M} \mathrm{Na}$ Acetate to room temperature.

Invert Pellet Paint stock several times until uniform suspension is formed.

- Add $2 \mu 1$ Pellet Paint to RNA followed by 0.1 volumes of 3M Na Acetate. Mix the sample.

- Add 2 volume ethanol and vortex briefly. Incubate the sample at room temperature for 10 minutes.

- Spin the sample at $14,000-16,000 * \mathrm{~g}$ in a microcentrifuge for 15 minutes. A pink pellet would be observed the bottom of the tube.

- Remove supernatant with a pipet tip.

- Rinse pellet with $0.5 \mathrm{ml}$ of $70 \%$ ethanol and spin again t $14,000-16,000 * \mathrm{~g}$ for 10 minutes.

- Remove supernatant and rinse the pellet again with $0.5 \mathrm{ml}$ of $100 \%$ ethanol. Spin at $14,000-16,000 * \mathrm{~g}$ for 10 minutes.

- Remove the residual alcohol by vacuum drying.

- Resuspend the pink pellet in $50 \mu \mathrm{l}$ of DI water. 


\section{Appendix I}

\section{Protocol for Mirus's Label IT Nucleic Acid Labeling Kit:}

- Bring the Label IT vial to room temperature before use. Add the Reconstitution buffer to the pellet in the vial.

- Assemble the reaction as follows:

\begin{tabular}{|c|c|}
\hline Reagent & Volume \\
\hline Molecular Biology Grade water & $11.78 \mu \mathrm{l}$ \\
\hline 10X Labeling Buffer A & $5 \mu \mathrm{l}$ \\
\hline Nucleic Acid Sample at 274.4 ng/ $\mu \mathrm{l}$ & $18.22 \mu \mathrm{l}$ \\
\hline Label It Reagent & $5 \mu \mathrm{l}$ \\
\hline Total Reaction Volume & $40 \mu \mathrm{l}$ \\
\hline
\end{tabular}

- Incubate the reaction at $37^{\circ} \mathrm{C}$ for 1 hour. Spin the reaction after 30 minutes of incubation.

- Purify the reaction by microspin column purification. 
Appendix $\mathbf{J}$

\section{Protocol for Dot Blot Assay to check for the Labeling Efficiency (Roche)}

- 10 fold serial dilution series of Dig labeled DNA by Mirus Label IT was prepared starting from $1 / 10$ diluted DNA till $1 / 10^{\wedge} 7$.

- $1 \mu 1$ of the prepared diluents were applied to positively charged nylon membrane.

- DNA was cross linked to the nylon membrane by baking for 1 hour at $80^{\circ} \mathrm{C}$.

- Membrane was transferred to plastic container containing $20 \mathrm{ml}$ washing buffer and incubated for 2 minutes at $20^{\circ} \mathrm{C}$.

- Membrane was incubated in $10 \mathrm{ml}$ of blocking solution for 30 minutes.

- Next membrane was incubated in $10 \mathrm{ml}$ of antibody solution for 30 minutes.

- Membrane was washed twice in $20 \mathrm{ml}$ of washing buffer for 15 minutes each.

- Membrane was placed in $10 \mathrm{ml}$ of detection buffer for 5 minutes.

- Membrane with the DNA side up was placed on a developing folder and 1:10,000 diluted anti Dig AP were applied. Care was taken to immediately cover the membrane with another membrane for even distribution of the substrate while avoiding air bubbles.

- Membrane was incubated overnight at $4^{\circ} \mathrm{C}$.

- NBT/BCIP was used for color development. Membrane was incubated in dark and carefully monitored for color development. 